\title{
Distributional patterns and possible origin of leafhoppers (Homoptera, Cicadellidae)
}

\author{
Mervin W. Nielson ${ }^{1}$ \\ William J. Knight ${ }^{2}$
}

\begin{abstract}
The zoogeographical distribution of 42 cicadellid subfamilies and their assigned tribes and genera is compiled with distributional maps and proposed dispersal pathways of genera that are shared interzoogeographically. Possible origin of the subfamilies and tribes is proposed in an ancestral context from which the more modern extant groups evolved whereas origin of genera is in a more modern context. Notwithstanding their complex biogeography, the distributional data of the higher groups indicate that all of the cosmopolitan and near cosmopolitan subfamilies arose during early Cretaceous or possibly the late Jurassic period (140-116 m.y.a.) when continental drift was in its early stages. Nearly all of the New World and some Old World subfamilies are considered of more recent origin (late Cretaceous-Tertiary).

Ninety percent of the known genera $(2,126)$ are endemic to their respective zoogeographical region and subregion, thus indicating relatively high host specificity and low rate of dispersal. The majority ( $76 \%$ ) of known extant genera are pantropical in origin, suggesting early or possible Gondwanaland origin of their ancestors. Dispersal pathways of genera shared by more than one zoogeographical region were generally south to north (Neotropical/Nearctic, Oriental/Palaearctic) or west to east (Palaearctic/Nearctic, Oriental/Australian), from regions of high diversity to regions of low diversity and from warmer climates to cooler climates.

The most diverse and richest leafhopper fauna are present in the Neotropical and Ethiopian regions although taxal affinities between them are poorest. The most depauperate fauna are in the Nearctic region and in Australia, reflecting the impact of isolating and ecological factors on distribution and radiation. Ecological barriers were more evident between the Ethiopian and Oriental fauna than between any other zoogeographical combination. Taxal affinities appeared to be correlated with close continental proximities. Vicariance (physical) was the principal event that appeared to explain the distribution of many subfamilies and tribes whereas dispersal accounted for distribution of the majority of interzoogeographical genera.

KEY WORDS. Leafhoppers, Cicadellidae, distribution, dispersal, vicariance, origin, classificaton, habitats
\end{abstract}

Leafhoppers are excellent biological indicators of zoogeographical regions, thus they are prime models for biogeographical studies (METCALF 1949; LINNAVUORI 1959b; EVANS 1982). A number of groups are ecological, altitudinal, latitudinal and insular indicators as well, particularly within geographical arenas that feature hot, dry to cool, moist habitats. Many species are also excellent botanical indicators by way of their preferred hosts and ovipositional plant substrates. Their phytodependency, relatively high host plant specificity, and low vagility have contributed to a significant endemic zoogeographical profile. The dependency upon host plants

1) Monte L. Bean Museum, Brigham Young University, Provo, UT 8460, USA.

2) The Natural History Museum, London, UK, SW7 5BD. 
for food, protection and perpetuation of the species has been and still is one of the major mechanism governing the distribution of cicadellids, from isolated relicts to broad cosmopolitan occupations. WHITCOMB \& HiCKS (1988) in their excellent treatise of the genus Flexamia DeLong, 1926 provided detailed evidence of the role of host plants in leafhopper evolution in the Nearctic region. Other intrinsic factors, including genetic traits for survival efficacy, behavioural adaptations and favourable mutations, also have played a significant role in successful colonization of new habitats and geographical radiation.

The effect of vicariance is believed to have had a major impact in fashioning incipient phylogenetic development and subsequent radiation of many extant groups in the Auchenorrhyncha. BOER \& DUFFELS (1996a) attributed the present-day distribution of cicadas in Wallacea, New Guinea and West Pacific to the complex geotectonic history of the area. Correlation between geotectonics and origin/endemism of the Indo-Pacific cicadas was demonstrated by BOER \& DUFFELS (1996b). Jump dispersal is considered to have played a minor role but range expansion (dispersal) within a geographical area is likely to be common among many groups within the constraints of ecological and geological barriers. Long range cyclic expansion in North America is well documented for Circulifer tenellus (Baker, 1896) and Macrosteles fascifrons (Stål, 1858) (OMAN et al. 1990). GHAURI (1983) described an unprecedented case of long distance transoceanic dispersal by Balclutha pauxilla Lindberg, 1954 swarms of which descended on Ascension Island in the mid-Atlantic from sources in West Africa some 2500 miles away. A number of adventitive occupations of land masses by various species have occurred among leafhopper subfamilies that currently have multigeographical occupations. ARZONE et al. (1987) reported that only 3 leafhopper species were introduced from the Nearctic region into Europe. However, considerably more adventitious species have been reported in the Nearctic region from their origin in Europe and eastern Asia.

In this paper, we have presented data on endemic genera that may provide substantive clues to the ancestral and zoogeographical origin of 42 subfamilies and their attendant tribes. We view the ancestral origin of the subfamilies in the context of geological history whereas zoogeographical origin is given in a more modern context based on extant endemic genera. A discussion of taxa shared by more than one zoogeographical region is also given, showing origin and dispersal pathway for a number of genera. These data may provide a historical pathway leading up to their present zoogeographical occupations and important inferences for origin. The origin of genera shared by more than one zoogeographical region, in certain cases, is problematical. In instances where the number of species was dominant in one region, we reasoned that the group originated in that region and dispersed from areas of highest density/diversity to areas of least density/diversity, similar to patterns followed by population dispersal of species. However, we recognize the possibility that the reverse may be true and that more data, particularly phylogenetic analysis of such groups, will be helpful in assessing their origin and dispersal pathway.

A brief review of taxonomy, habitats and host plants is presented. No phylogenetic analyses are presented here although inferences are given from the literature. 
The current distribution of some endemic genera may have been the result of relicts left behind during the extinction processes of its siblings. These survivors also may be far removed from the actual center of their geographical origin. In such cases, it could lead to false conclusions on their true zoogeographical origin and/or the processes that led to the development of the group. The relationship between biogeographical distribution and phylogenetic position (ancestral/derived), and to what extent it exists among leafhoppers, is a veritable challenge for taxonomists and biogeographers.

The data presented herein are based on zoogeographical records and analyses of known genera that were treated by OMAN et al. (1990) and YOUNG (1986). Additional subsequent records (after 1985) also were gleaned (ABDUL-NoUR 1988; BLOCKER 1991, 1992; BLOCKER \& JOHNSON 1988; CWIKLA 1988; DIETRICH 1990; DieTrich \& Vega 1995; Dlabola 1987; FreytaG 1987, 1989, 1990; Godoy \& WEBB 1994; Li 1986; KNIGHT \& WEBB 1988, 1993; NIELSON 1986a,b, 1988b, 1989a, 1992a,d; RAMCHANDRA RAO 1989; THAPA 1989; THERON 1986, 1988; WEBB 1987; ZHANG 1990, 1994).

Fossil records of Cicadellidae also were considered (BECKER-MIGDISOVA 1949, 1962; EvanS 1948, 1956, 1958c, 1961b,c, 1966, 1971d, 1972c, 1988; DieTrich \& VEGA 1995; HAMILTON 1971a, 1987, 1990, 1995; OMAN 1937a; SHCHERBAKOV 1982, 1984, 1986, 1988, 1990, 1991, 1992, 1993).

SHCHERBAKOV (1992) erected the family Karajassidae from fossils found in Jurassic formations and considered the group ancestral to leafhoppers. The oldest leafhoppers (Cicadellinae, Myerslopiinae, Ledrinae) have thus far been identified from lower Cretaceous (116 m.y.a.) (DiETRICH \& VEGA 1995; HAMILTON 1990, 1992; SHCHERBAKOV 1992). EVANS (1949) attributed the origins of Ulopinae and Macropsinae to the southern continent (Gondwanaland) without stating any fossil evidence. Later (1956) he placed the Hylicinae in the Triassic from fossil records found in Australia. These accounts, however, are thus far too few to give significant clues to the overall zoogeographical origin of many of our modern subfamilies. Insufficient fossil evidence, lack of more definitive subfamily phylogeny, incomplete knowledge of many tropical faunas as well as inadequate understanding of the taxonomy of many taxa allow us to make only broad assumptions as to their place of origin and distribution pathway of the higher categories.

\section{Biogeographical and phylogenetic considerations}

Cosmopolitan subfamilies of leafhoppers, chiefly the Deltocephalinae and Typhlocybinae, have long been classified as terminal groups (OMAN 1949; RIBAUT 1952). However, we view that their ancestral origin probably took place early about the time continental drift began, otherwise there appears to be no plausible explanation for their current, widespread distribution. Even a low rate of dispersal which may have resulted in a uniform distributional profile clearly is not demonstrated among the major taxal units. An implied correlation between terminal taxa (Deltocephalinae, Typhlocybinae) and late geographical origin also does not appear to be logical. Rather, it appears to be related to a higher and more successful rate of radiation among these subfamilies. However, their taxal relationship to geographi- 
cally isolated groups, viz., Gyponinae, Bythoniinae, Koebeliinae, raises some important questions on the geographical origin of these and other groups in the cicadellid lineage. There are other cosmopolitan or near cosmopolitan groups, viz., Cicadellinae, Coelidiinae, Idiocerinae, that are taxally and phenetically separate entities whose origin likewise may be early. It is clear, therefore, that there was a movement of many leafhopper groups by and during continental drift, and each radiated according to its own inherent capacity to take advantage of ecological opportunities and speciate for range expansion.

Insular endemism is not uncommon among leafhopper groups. Island endemism was demonstrated by KNIGHT \& WEBB (1988) and by WEBB (1987) in the tribe Macrostelini (Deltocephalinae) in the Hawaiian Islands in the Pacific and St. Helena Island in the Atlantic, respectively. The Hawaiian macrosteline fauna consists of 10 endemic species which are believed to be derived from a single, widespread, Indo-Pacific founder species. The St. Helena fauna consists of 8 macrosteline endemics, the origin of which is unclear because broad generic difference exists among the four genera. Endemics are also evident in New Zealand (KNIGHT 1975) and the numerous endemic species of Tharra Kirkaldy, 1906 (Coelidiinae) are well known among the vast island habitats in the South Pacific (NIELSON 1975).

The evolutionary development of the Cicadellidae, one of the largest families of insects, from possibly late Jurassic or early Cretaceous periods to our present day has given rise to over 40 recognized extant subfamilies, each consisting of variable generic composition and with varying degrees of taxonomic gaps within and among the groups. The taxonomic hiatus between many subfamilies is so pervasive that it has thus far defied a satisfactory explanation of their interrelationships. The depth and degree of the relationship among these groups require much more study. Application of DNA analyses and principles of phylogenetic systematics, which are beyond the scope of the present paper, are sorely needed.

BRUNDIN (1967) cited the rule of geographical vicariations of sister groups as an important part of the system to resolve phylogenetic relationships, emphasizing the importance of derived characters and the rule of deviation or differences among groups. In particular, he cited examples of the relationship of species groups found in South America and Australasia and their transantarctic connections. HENNIG (1965) indicated that, although somewhat restrictive, the importance of geographical distribution of organisms is not to be underestimated for phylogenetic systematics.

ESKOV \& GoLOVATCH's (1986) paleontological treatise on the origin of trans-pacific disjunctions strongly suggest that vicariance ("mobilistic biogeography") and land bridges had little to do with the dispersal of the world land fauna. They cited many examples of disjunct distributions that cannot be explained by vicariance. They also emphasized that extinction played just as an important part of phylogenesis as did speciation. Furthermore, the paleontological evidence indicates that the world land mass during pangaeaic times was flooded with fauna and much of the extant fauna of today are remnants that survived the extinction processes. 
SHCHERBAKOV (1993) presented a geological history of the Auchenorrhyncha based on fossil evidence indicating that the group arose about mid-Permian (260 m.y.a.) and that the ancestors of leafhoppers came into existence during the beginning of Jurassic (210 m.y.a.). In connection with morphological features of early leafhoppers, SHCHERBAKOV (1992) discussed the discal position of ocelli found on Palaearctic fossil adult specimens from the late Jurassic period. He considered the discal position of ocelli as ancestral to the facial position. EVANS (1975b) in his study of Thymbrini, although finding remnants of ocelli on the discal region of nymphs and fully developed ocelli on the face of adults of the same species, nevertheless, postulated ocellar drift from the face to the crown as the phylogenetic pathway from ancestral to derived. There are a number of so-called primitive groups which do not possess ocelli (Ulopinae, Myerslopiini), or if present, are facial (Idiocerinae, Tartessinae, Eurymelinae, Agalliinae, Macropsinae, etc.). However, we believe that single traits, while very important in certain applications, should not be relied upon entirely for drawing phylogenetic relationships.

Nymphal morphology has important considerations in phylogenetic relationships of various groups that should not be underestimated. VILBASTE's (1972, 1975,1982 ) comparative studies of the morphology of nymphs and adults of several subfamilies offer some promising insights to taxonomic, phylogenetic and biological relationships.

That the development of sucking mouth parts (leafhoppers) was underway prior to the advent of dicotyledons plants (angiosperms) is fairly well accepted. The origin of angiosperms (the major host of modern leafhoppers) has not been correlated to a definite geological period but the latest data points to early Cretaceous or about 120 m.y.a., considerably later than the estimated period (140 m.y.a.) when the major land masses began to separate (WEIJERMARS 1989).

We have interpreted, in some instances, that the zoogeographical origin of subfamilies and/or tribes postulated by our colleagues referred to herein, are based on extant groups rather than their ancestors that were present long before the extant groups rose in historical time.

\section{Zoogeography and historical geology}

We have followed the designations of six zoogeographical regions and several subregions of each region for this study, as proposed by WALLACE (1876) and elaborated by DARLINGTON (1957). Some applications of phytogeography proposed by GooD (1974) have also been employed.

Only a brief account of the historical biogeography is given here, much of it following BROWN \& GIBSON (1983) and BRIGGS (1989). Details, as they apply to the distribution of the various leafhopper taxa, are discussed below under their respective subfamilies. The current position of the major land masses (Zoogeographical Regions) of the world was the result of continental movements via plate tectonics from an original single land mass (Pangaea), the separation of which was initiated and controlled by underlying geological forces. The present day distribution patterns of many groups of insects reflect the complex geotectonic history of the many areas as will be discussed below. WEGNER (1924) proposed the theory of 
continental drift, which was widely refuted shortly thereafter by geologists, but which has since received universal acceptance among systematists, biogeographers and geophysicists.

The breakup of Pangaea was initiated by the opening of the North Atlantic during the Lower to Upper Triassic about 200-180 m.y.a. Most of eastern North America was opposite Africa. There was a broad and continuous land connection from U.K. to Greenland and Canada during lower Cretaceous. North America drifted away from Europe, and the eastern coast, from New York to Yucatan, was a sedimentary basin and under water from the Upper Jurassic to Eocene. Alaska collided with Siberia in the Eocene forming a land bridge known as the Bering strait.

Subsequent separation of the continents began during early Jurassic times about 180 m.y.a. when the southern land masses (Gondwanaland) separated from the northern land mass (Laurasia). Both land masses were about equal in size and tropical throughout. Laurasia developed a separation between North America and Eurasia about 135 m.y.a. These two continents were still in contact with Greenland about 65 m.y.a. at the end of the Cretaceous period. The shifting of the continents eventually left about $2 / 3$ of the land masses in the Northern Hemisphere and $1 / 3$ in the Southern Hemisphere.

Gondwanaland, consisting of South America, Africa, Antarctica, Arabia, India, Madagascar, Tasmania, New Guinea, New Zealand, New Caledonia, and Australia eventually divided and its component parts drifted to their present positions over the following 140 million years. There is evidence that Australia was somewhat more isolated from the other continents of Gondwanaland than heretofore believed (BRIGGS 1989). Africa and South America were broadly attached along their centers. They were equatorial in the Jurassic and are equatorial today. Active spreading of Africa and South America began during lower Cretaceous about 127 m.y.a., the connection at the equator acting as a pivot as the southern portions spread apart 115 m.y.a. By the end of the Cretaceous, the distance between Brazil and West Africa was about $800 \mathrm{~km}$. The break was complete by the Eocene. A mid-Atlantic bridge (oceanic islands) was present but no solid land connection was present between the continents subsequent to their separation.

Antarctica was situated about latitude 50 degrees south during Jurassic times and is now at the south pole. All of the land masses surrounded Antarctica, although some were separated by water. The southern tip of South America and Antarctica were very close during the Cretaceous. New Zealand, originally attached to Antarctica, broke away and drifted northward about 80 m.y.a. New Zealand was not connected to Australia, either before or after this event, but continued to have connection indirectly with Antarctica. Australia, New Guinea and Tasmania were all one land mass. Southeastern Australia lost connection to Antarctica during the Mesozoic (150 m.y.a.) but Southwest Australia was fused to Antarctic during the Tertiary. About 53 m.y.a., Australia moved northward and Antarctica moved southward. The possible connection of New Caledonia to New Guinea or to New Zealand is problematical.

Madagascar and India broke away about 148 m.y.a. India separated from Madagascar about 80-90 m.y.a. and collided with southern Asia during early Eocene 
about 50 m.y.a. Sri Lanka is part of the Indian plate. Several islands in the Indian ocean are continental in origin and may have been attached to Gondwanaland. The Mascarenes and Seychelles may have been part of India.

According to Ross (1956) connections between North America and South America occurred once during the mid-Cretaceous and again between the Eocene and the present, with two successful partial bridges in late Oligocene and lower Miocene followed by long periods of separation. BROWN \& GIBSON (1983) in their history of Central America and West Indies indicated that the land bridge between Mexico and South America was severed in the early Cretaceous. A series of islands (part of Central America) formed in the Cretaceous and moved eastward via the Caribbean plate which became the Greater Antilles. The Panama-Choco island arc collided with the northwestern margin of South America and formed the land bridge between the Americas during the Miocene about 6 m.y.a. (KELLOGG \& VEGA 1995).

Evidence from fossil records suggest that the terrestrial biota were once broadly distributed over the entire Pangaean supercontinent (BRIGGS 1989). It is probable that leafhoppers (and all other insects as well) were similarly distributed. SMILEY (1979) proposed that the flora during the Permian period was more or less segregated into four distinct regions, one of which was Gondwanaland (southern Africa, southern South America, Australia and India). This area is of considerable importance on the origin of many subfamilies of leafhoppers. The relationship of the southern South America biota (17 diverse insect taxa) is closer to those of Australia, Tasmania, New Guinea, New Caledonia and New Zealand than it is to biota of northern South America whereas the relationship of northern South America biota is more closely related to those of North America (CRISCI et al. 1991).

Australia has a number of endemic primitive insect groups, viz., Mastotermes Froggatt, 1896 in the Isoptera, Colletidae in the Hymenoptera, zygopteran Odonata and some Neuroptera and Lepidoptera (BROwN \& GIBSON 1983). Also, the most primitive groups of leafhoppers are found in Australia. This is additional evidence that suggests Australia had a large insect fauna while it was part of Gondwanaland.

\section{Historical classification of the Cicadellidae}

The hierarchical classification of the leafhopper family began in 1825 when LE PELETIER \& SERVILle proposed Ulopidae (Ulopides) and Tettigonidae (Tettigonides) (= Cicadellinae) for a group of European leafhopppers. Over the next 175 years, the development of classification led to the proposed naming and/or usage of no less than 3 superfamily names (OLMI 1975), 16 family-group names (OLMI 1975), reduction to 10 subfamily-group names (HAMILTON 1983), elevation to 50 subfamily-group names (KNIGHT \& NIELSON 1986) and reduction to 40 subfamily-group names, including 17 synonyms and 159 tribal-group names which include 40 nominotypical names, 31 synonyms and numerous subtribal-group names (OMAN et al. 1990). Over 25-year increments from 1825 to 1996, 3 hierarchical names were proposed during the period 1825-1850, 11 during 1851-1875, 3 during 1876-1900, 33 during 1901-1925, 43 during 1926-1950, 41 during 1951-1975 and 20 during 1976-1996. 
Major classification schemes or provisional listings have been proposed by the following: Le Peletier \& Serville (1825); Amyot \& Serville (1843); DOHRN (1859); SAHLBERG (1871); BERG (1879); VAN DUZEE (1892, 1917); EDWARDS (1896); OSHANIN (1908); DISTANT (1908-1916); HAUPT (1929); RIBAUT (1952); OMAN (1933b, 1938b,c, 1942a, 1949); MEDLER (1942); DELONG (1948); EVANS (1947, 1966, 1977); WAGNER (1951); ROSS (1957); LINNAVUORI (1959b, 1960a, 1972a,b, 1975a, 1978a,d, 1979a,b); LINNAVUORI \& QUARTAU (1975); EMELJANOV (1962, 1964); METCALF $(1962,1968)$; WEIDNER \& WAGNER (1968); NAST (1972, 1976); OLMI (1975); ANUFRIEV (1978); HAMILTON (1983); OMAN et al. (1990).

The usage of family-group names proposed by METCALF (1962-1968) and superfamily-group names by OLMI (1975) have not been accepted because of dissimilar taxonomic gaps between them and established families in the Fulgoroidea. Moreover, a proper perspective would not be maintained by elevating subfamilies until and unless a coordinated study of the entire world fauna justifies it (OMAN 1949, 1971; Young 1968).

It is clear that the higher classification of leafhoppers is unsatisfactory. For example, WAGNER (1951) proposed three major groupings, the Typhlocybides (one subfamily), Iassides (five subfamilies) and Cicadellides (seven subfamilies), which was followed closely by LINNAVUORI (1959b), but has not received general usage. HAMILTON (1983) proposed 10 subfamilies, combining several unnatural and loosely conceptualized groups and a key to subfamilies, part of which is flawed; viz., the majority of Coelidiinae are left standing without the type-genus, Coelidia Germar, 1821.

DIETRICH (1993) presented an overall view of the complexities involved in developing a phylogeny and offered several proposals that may lead to a satisfactory classification of the hierarchical groups. The long historical development of the classification system was a necessary exercise and the complexity and diversity of the classification was most asssuredly an expected byproduct. Furthermore, there are a number of peculiar cicadellid specimens in museums that are yet unclassified and await assignment to new subfamilies or to existing ones. It is safe to say, in light of the discovery of a recent new subfamily, Tinterominae, by GODOY \& WEBB (1994), that additional new subfamilies may exist in the tropical regions of the world. All of these potentially new taxa may require substantial conceptual changes for a newly proposed classification scheme, the finality of which may not be reached for many years to come. Finally, it is presumptuous to say that there are too many higher categories in our present system (who is to say how many there should be?) and to reduce the number for the sake of simplicity without applying the merits of sound phylogenetic systematics is premature.

\section{Zoogeographical distribution and origin of the Cicadellidae}

There are 2,336 documented genera of leafhoppers in the world (pre-1993). We have determined that $90 \%$ are endemic to their respective zoogeographical region, $7 \%$ are bigeographical and $3 \%$ are multigeographical. The zoogeographical segregation of known endemic genera $(2,126)$ among 42 major subfamilies of 
Cicadellidae is shown in table I. The data also include 206 genera shared by two or more interzoogeographical regions (IGZ). These are shown in the summation of the last two columns.

Table I. Richness and diversity of endemic genera of $\mathbf{4 2}$ major subfamilies of Cicadellidae in six zoogeographical regions.

\begin{tabular}{|c|c|c|c|c|c|c|c|c|c|}
\hline \multirow{2}{*}{ Subfamily } & \multicolumn{7}{|c|}{ Zoogeographical Region (1) } & \multicolumn{2}{|c|}{ Shared (2) } \\
\hline & AUS & ETH & NEA & NEO & ORI & PAL & Total & ॥ & $\|+$ \\
\hline Deltocephalinae & 34 & 80 & 104 & 169 & 46 & 229 & 662 & 70 & 9 \\
\hline Typhlocybinae & 7 & 82 & 11 & 41 & 165 & 56 & 362 & 37 & 10 \\
\hline Cicadellinae & 25 & 31 & 13 & 203 & 50 & 16 & 338 & 12 & 2 \\
\hline Coelidiinae & 3 & 15 & 1 & 77 & 6 & $0^{*}$ & 102 & 4 & 0 \\
\hline Idiocerinae & 22 & 14 & $0^{*}$ & 16 & 22 & 15 & 89 & 3 & 1 \\
\hline Gyponinae & 0 & 0 & 7 & 74 & 0 & 0 & 81 & 6 & 0 \\
\hline Ledrinae & 27 & 11 & $0^{*}$ & 9 & 14 & $0^{*}$ & 61 & 6 & 1 \\
\hline lassinae & 4 & 9 & $0^{*}$ & 25 & 6 & 2 & 46 & 3 & 3 \\
\hline Penthimiinae & 8 & 12 & $0^{*}$ & 1 & 22 & $0^{*}$ & 43 & 0 & 3 \\
\hline Nirvaninae & 8 & 7 & 0 & 11 & 13 & $0^{*}$ & 39 & 2 & 1 \\
\hline Selenocephalinae & 1 & 17 & 0 & 0 & 12 & 4 & 34 & 4 & 1 \\
\hline Tartessinae & 37 & 0 & 0 & 0 & 1 & 0 & 38 & 4 & 0 \\
\hline Eurymelinae & 34 & 0 & 0 & 0 & 0 & 0 & 34 & 0 & 0 \\
\hline Agalliinae & $0^{*}$ & 5 & 4 & 14 & 3 & 5 & 29 & 1 & 3 \\
\hline Ulopinae & 3 & 8 & 0 & $0^{*}$ & 6 & 1 & 29 & 3 & 1 \\
\hline Macropsinae & 5 & 4 & 3 & 2 & 2 & 1 & 17 & 6 & 5 \\
\hline Neocoelidiinae & 0 & 0 & 1 & 12 & 0 & 0 & 13 & 2 & 0 \\
\hline Hylicinae & 0 & 2 & 0 & 0 & 12 & 0 & 14 & 0 & 0 \\
\hline Adelungiinae & 0 & 0 & 0 & 0 & 0 & 13 & 13 & 0 & 0 \\
\hline Eupelicinae & 1 & 4 & 3 & $0^{*}$ & $0^{*}$ & 3 & 11 & 0 & 1 \\
\hline Neobalinae & 0 & 0 & $0^{*}$ & 12 & 0 & 0 & 12 & 1 & 0 \\
\hline Paraboloponinae & 1 & 2 & 0 & 0 & 3 & 1 & 7 & 1 & 1 \\
\hline Aphrodinae & 0 & 2 & $0^{*}$ & $0^{*}$ & 2 & 1 & 5 & 3 & 1 \\
\hline Acostemminae & 1 & 6 & 0 & 0 & $0^{*}$ & 0 & 7 & 0 & 0 \\
\hline Megophthalminae & 0 & 3 & 2 & 0 & 0 & 2 & 7 & 0 & 0 \\
\hline Xestocephalinae & 1 & 1 & $0^{*}$ & 2 & 2 & $0^{*}$ & 6 & 0 & 1 \\
\hline Mileewinae & $0^{*}$ & 1 & 0 & 2 & 2 & $0^{*}$ & 5 & 0 & 1 \\
\hline Mukariinae & 0 & 2 & 0 & 0 & 1 & $0^{*}$ & 3 & 0 & 0 \\
\hline Nioniinae & 0 & 2 & $0^{*}$ & 1 & $0^{*}$ & 0 & 3 & 2 & 0 \\
\hline Phereurhininae & 0 & 0 & 0 & 3 & 0 & 0 & 3 & 0 & 0 \\
\hline Stegelytrinae & 0 & $0^{*}$ & 0 & 0 & 0 & 3 & 3 & 1 & 0 \\
\hline Makilingiinae & $0^{*}$ & 0 & 0 & 0 & 1 & 0 & 1 & 0 & 0 \\
\hline Phlogisinae & 0 & 1 & 0 & 0 & $0 *$ & $0^{* *}$ & 1 & 0 & 0 \\
\hline Arrugadinae & 0 & 0 & 0 & 1 & 0 & 0 & 1 & 0 & 0 \\
\hline Austroagalloidinae & 1 & 0 & 0 & 0 & 0 & 0 & 1 & 0 & 0 \\
\hline Bythoniinae & 0 & 0 & 0 & 1 & 0 & 0 & 1 & 0 & 0 \\
\hline Drakensbergeninae & 0 & 1 & 0 & 0 & 0 & 0 & 1 & 0 & 0 \\
\hline Euacanthellinae & 1 & 0 & 0 & 0 & 0 & 0 & 1 & 0 & 0 \\
\hline Evansoliinae & 0 & 0 & 0 & 1 & 0 & 0 & 1 & 0 & 0 \\
\hline Koebeliinae & 0 & 0 & 1 & 0 & 0 & 0 & 1 & 0 & 0 \\
\hline Signoretinae & 0 & $1(3)$ & 0 & 0 & $1(3)$ & 0 & 1 & $1(3)$ & 0 \\
\hline Tinterominae & 0 & 0 & 0 & 1 & 0 & 0 & 1 & 0 & 0 \\
\hline Total Subfamilies & 20 & 26 & 11 & 24 & 22 & 15 & 42 & 22 & 18 \\
\hline Total Genera & 234 & 320 & 150 & 678 & 392 & 353 & 2126 & 162 & 44 \\
\hline
\end{tabular}

(1) Numbers (zeros) with single asterisks signify absence of endemic genera but occupation by species through vicariance, dispersal or adventitious means; double asterisks indicate taxonomy pending; (2) number of genera shared by two (II) and by more than two (II+) zoogeographical regions, respectively; (3) only one genus is known and it is shared by both regions. 
Our concept of endemism is based on the best available evidence of the known zoogeographical distribution of the taxa and does not necessarily preclude the possibility that subsequent fossil evidence may come to light that might prove to be contrary to our judgements. It is also possible that many of the extant genera are relicts (allochthonous/autochthonous) that survived extinction from a former vast faunal pangaeaic population. However, we wish to propose here that areas of highest endemicity and/or highest taxal diversity are possible centers of origin for respective groups within a given zoogeographical area. This does not imply that such origins are the historical centers because many groups are recently derived (within the last 1-10 million years) and many of them likely had their ancestral centers elsewhere. In other words, secondary or even tertiary radiation may have taken place in areas marked by high species diversity. In cases where genera are shared by more than one zoogeographical region, we make no assumption that they arose earlier than endemic genera, although it is possible that this may have occurred in some groups. The pathway of dispersal for most groups (intercontinental) appears to have occurred from regions of highest diversity to regions of lowest diversity. This proposal, while admittedly contestable, is based on high endemicity of the genera, low vagility and high host specifity characteristics, all of which promote diversity in situ. Furthermore, populations usually must become sufficiently established (colonized) in a given geographical area before dispersal takes place. During this phase, a base of diversity is produced from which elements may disperse to newly occupied regions.

We also propose that rates of radiation varied greatly among taxa. Those having the broadest distribution with the greatest diversity (tribes and genera) had higher rates than those having restricted geographical occupations with limited diversity. Species diversity among genera also varied considerably, some exceedingly more successful than others, even among those represented by higher taxa of low diversity.

In table I, the largest number of subfamilies is represented in the Ethiopian (26) and Neotropical (24) regions whereas the fewest are portrayed in the Palaearctic (15) and Nearctic (11) regions. The remaining two regions have about the same number of subfamilies (20-22). The fewer number of subfamilies present in the northern hemisphere appears to have ecological and topological barrier implications. Of particular interest and of considerable phylogenetic importance are the greater representation of generally considered "primitive" or ancestral subfamily endemics in the Australian region (Australia only) than in any other region (EvaNs 1966). Portrayal of endemism of the so called derived groups (Deltocephalinae, Typhlocybinae) is contrastingly poor on this continent.

Eleven subfamilies (Deltocephalinae, Typhlocybinae, Cicadellinae, Coelidiinae, Idiocerinae, Ledrinae, Iassinae, Penthimiinae, Agalliinae, Macropsinae, Xestocephalinae), a distinct minority, but with the majority of genera, have cosmopolitan distribution. The distribution is based chiefly on endemic genera and by some species of a very few genera that have subsequently occupied adjoining regions by dispersal through land bridges or by adventitious means. Fourteen subfamilies, or $35.7 \%$, are currently monogeographical (Eurymelinae [Australia 
only], Adelungiinae [Palaearctic], Phereurhininae [Neotropical], Stegelytrinae [Palaearctic], Makilingiinae [Philippine Islands only], Phlogisinae [Ethiopian], Arrugadinae [Neotropical], Austroagalloidinae [Australia only], Bythoniinae [Neotropical], Drakensbergeninae [Ethiopian], Euacanthellinae [Australia only], Evansolinae [Neotropical], Koebeliinae [Nearctic] and Tinterominae [Neotropical]. Many, if not all, of these zoogeographically isolated assemblages may be remnants of relict groups that survived extinction. Six of them (33\%) are represented in the Neotropical region. Two subfamilies, the Gyponinae and Neocoelidiinae, have representative endemic genera in the Neotropical $(74,12)$ and Nearctic $(7,1)$ regions, respectively, but all of those in the Nearctic realm are believed to have originated from the neotropics. Thus, based on the current subfamily classification, the Neotropical region appears to be the origin of the richest faunal diversity of endemic leafhoppers.

Endemic genera are richest in the Neotropical region (678, 31.9\%), suggesting a highly viable, radiational environment followed by a somewhat more subdued genesis in the Oriental region $(392,19.1 \%)$. The most depauperate expression of taxal origin and radiation occurred in the Nearctic realm $(150,7.0 \%)$. The dearth of endemism here may be related to intermittant periods of isolation of the northern land mass, the effects of glaciation and discontinuous access of fauna from the southern land mass by the periodical opening and closing of the Isthmus of Panama. The Australian (Australia only) fauna is also particularly paucious, indicating that continental isolation was the limiting factor for dispersal and radiation of biota (BRIGGS 1989).

About $10 \%$ of the total number of known genera have bigeographical or multigeographical distribution. These data are summarized in table II, showing the number of shared subfamilies and shared genera among 23 interzoogeographical (IZG) regions. Taxal affinities among several IZG regions are evident. These affinities are discussed more fully below under the treatment of the respective subfamilies. In general shared taxa were greater in the Nearctic/Neotropical regions than in the Palaearctic/Nearctic regions, suggesting closer geographical affiliation between the former two regions than in the latter two during periods of radiation. However, it is important to consider the biological and ecological advantages for radiation that were presumably present in the Neotropical region where it is known that the derived flora now dominate the landscape (SMLEY 1979). Shared taxa in the Palaearctic/Oriental regions were about equal to the number of shared taxa in Palaearctic/Nearctic regions, but significantly higher than shared taxa in the Palaearctic/Ethiopian regions. The barriers (ecological, topological) were more evident between the Palaearctic and Ethiopian regions than between the Palaearctic and Oriental regions. Taxal affiliations between the Oriental and Ethiopian fauna were more evident than between the Oriental and Australian regions, adding support to continental and island topography as principal isolating mechanism for taxal discontinuity. Although taxal relationships between the Oriental and Ethiopian regions are closer than either one is to its nearest zoogeographical neighbor, there was an apparent ecological barrier that allowed radiation to proceed along separate lines within each region. Poor taxal affinity between the Ethiopian and Neotropical regions, and similar pairs, also suggests that their respective faunas arose after separation of continents which gives us a possible time of origin for these taxa. 
There are eight IZG combinations in which only one genus within a subfamily is shared by more than one zoogeographical region (Tab. II). The origin of these genera, in most cases, is difficult to evaluate, except for Biadorus Nielson, 1979 (Coelidiinae: Terulini) which is adventive in the Ethiopian region (see below).

Table II. Diversity of shared subfamilies and shared genera among 23 combinations of IZG regions.

\begin{tabular}{lcc}
\hline \multicolumn{1}{c}{ Interzoogeographical region } & Number of subfamilies (1) & Number of genera \\
\hline Cosmopolitan & 4 & 8 \\
Old World Only & 3 & 4 \\
Holarctic & 5 & 39 \\
Holarctic/Neotropical & 2 & 5 \\
Holarcti/Neotropical/Ethiopian & 2 & 2 \\
Holarctic/Ethiopian & 1 & 1 \\
Holarctic/Ethiopian/Oriental & 1 & 1 \\
Holarctic/Oriental & 3 & 3 \\
Holarctic/Ethiopian/Australian & 1 & 1 \\
Holarctic/Australian & 1 & 1 \\
Palaearctic/Ethiopian & 4 & 10 \\
Palaearctic/Ethiopian/Oriental & 5 & 9 \\
Palaearctic/Ethiopian/Australian & 3 & 3 \\
Palaearctic/Oriental & 8 & 37 \\
Palaeactic/Oriental/Australian & 1 & 2 \\
Palaearctic/Australian & 1 & 1 \\
Nearctic/Neotropical & 10 & 69 \\
Ethiopian/Oriental & 12 & 21 \\
Ethiopian/Oriental/Australian & 5 & 5 \\
Ethiopian/Australian & 1 & 1 \\
Ethiopian/Neotropical & 1 & 1 \\
Ethiopian/Oriental/Neotropical & 1 & 1 \\
Oriental/Australian & 8 & 15 \\
\hline
\end{tabular}

(1) Data based on endemic genera.

\section{Treatment of subfamilies}

\section{Deltocephalinae Dallas, 1870}

Taxonomy. This large, highly complex, cosmopolitan group is comprised of 23 tribes (OMAN et al. 1990). The Balcluthini has been suppressed recently as a junior synonym of Macrostelini (KNIGHT \& WEBB 1986) and we have followed this work. Numerous tribal synonyms testify of the degree of difficulty and range of disagreement over tribal classification (OMAN et al. 1990). LINNAVUORI (1959b) considered placing Neocoelidiinae as a tribe of this group showing shared affinities to justify it but that action was not proposed. One tribe, Hecalini, for many years was previously accorded subfamily status by nearly all leafhopper taxonomists until LINNAVUORI (1959b) proposed a tribal status in the Deltocephalinae.

OMAN (1949) assembled the genera of the Nearctic fauna into four groups based on connective configuration and its fusion/articulation to the aedeagus. Two of these groups have tribal significance, the Deltocephalini and Athysanini. This scheme applies well to the Neotropical fauna (LINNAVUORI 1959b; BLOCKER et al. 1995; FANG et al. 1995) but whether or not it has valid application to the Old World fauna remains to be determined. Moreover, the phylogenetic relationship between the New World and the Old World tribes remains a very important but unresolved issue. 
Habitat and Host Plants. Species of the group inhabit grasses, shrubs and trees in a wide range of ecological situations. They all feed in the phloem tissue, as far as is presently known. Many species are host specific, especially on grasses and certain shrubs. A number are generalists and opportunists which allows for a large number of vector species to transmit phytopathogenic organisms to many species of plants (NIELSON 1968b, 1979c, 1985). Among eight known vector subfamilies, the Deltocephalinae are most important and are known for having the greatest number of vector species. This capability may be considered a derived trait in pathogen/vector relationships.

Distribution and Zoogeographical Origin. This subfamily is widely distributed in all zoogeographical regions and has the largest number of endemic genera (Tab. I). For these reasons, no maps of distribution are given. A few species are adventitious in some regions or have dispersed intercontinentally. The Palaearctic region exhibits the greatest number (229) of endemic genera, which appears to be a reflection of a very high rate of radiation and may be an indication of the center of origin of the group. The relatively high number (169) of endemic genera in the Neotropial region also supports an effective radiational profile. The fewer endemic (104) genera exhibited in the Nearctic region than in the Palaearctic and Neotropical regions is believed to be related to a period of isolation by geological and/or ecological forces that separated it for a time from the Neotropical and Palaearctic regions. Without the contribution of the Deltocephalinae from the Palaearctic and Neotropical regions, the Nearctic leafhopper fauna would be relatively depauperate. The richness (169) of endemic genera in the Neotropical region may be related largely to floral diversity of the area (THORNE 1973). The Ethiopian fauna is moderately rich (80) whereas the Oriental (46) and Australian (34) fauna are poorest. KNIGHT (1983a) recorded 83 genera and 275 species in Southeast Asia and the Pacific Island area. Very little of this fauna are true endemics in Australia according to Evans (1966).

Eight tribes (Chiasmusini, Coryphaelini, Goniagnathini, Grypotini, Paralimnini, Platymetopiini, Stenometopiini, Tetartostylini) are confined to the Old World and likely originated there. Four tribes (Cochlorhinini, Acinopterini, CeriIlini, Luherini) are restricted to the New World, the former is endemic in the Nearctic region and the latter three originated in the Neotropical region. Among three Holarctic tribes (Cicadulini, Doraturini, Fieberiellini), the origin of the former two is problematical and the latter is Palaearctic, having in the Nearctic region a single, widespread, introduced species, Fieberiella florii (Stål, 1864). The origin of the cosmopolitants Athysanini, Deltocephalini, Hecalini, Macrostelini, Opsiini, Scaphoideini and Scaphytopiini is somewhat more problematical.

Studies of 24 genera in the tribe Deltocephalini by BLOCKER et al. (1995) and FANG et al. (1995) showed that most (15) of the genera are of Nearctic origin, five are Neotropical, three are Neogeic and one is Palaearctic. It is possible that the ancestors of the other tribes were ancestrally widespread prior to continental drift. This is especially true for the two largest tribes, Athysanini and Deltocephalini. Opsiini has become cosmopolitan by introduction of Opsius stactogalus Fieber, 1866 by means of world wide exportation of its Tamarix host. Circulifer tenellus, 
another representative of the tribe, also has become widespread by introductions into the New World and the Australian region (see below).

Seventy-nine genera in the Deltocephalinae are shared by more than one zoogeographical region, which comprise about $10 \%$ of the total known genera (Tab. I). Genera shared by more than one IZG region are given in table III followed by a discussion of their possible origin and dispersal/vicariant pathways.

Table III. Shared genera of the subfamily Deltocephalinae in 13 interzoogeographical regions.

\begin{tabular}{ll}
\hline \multicolumn{1}{c}{ Interzoogeographical Region } & \multicolumn{1}{c}{ Genus } \\
\hline Cosmopolitan & Balclutha, Exitianus, Hecalus, Scaphoideus \\
Holarctic & Boreotettix, Cazenus, Cicadula, Cosmotettix Ribaut, 1942, Coulinus Beirne, \\
& T954, Deltocephalus, Diplocolenus, Elymana, Errastunus Ribaut, 1946, \\
& Euscelis, Fieberiella, Hardya, Idiodonus, Limotettix, Macustus, Mocuellus \\
& Ribaut, 1946, Paluda DeLong, 1937, Pinumius Ribaut, 1946, Psammotettix, \\
Scleroracus, Thamnotettix, Verdanus, Zelenius (?) \\
Holarctic/Neotropical & Athysanella, Osbornellus, Colladonus \\
Holarctic/Neotropical/Ethiopian & Circulifer, Macrosteles \\
Holarctic/Australian & Rosenus \\
Palaearctic/Ethiopian & Jubrinia, Neolimnus, Sotanus, Tetartostylus \\
Palaearctic/Ethiopian/Oriental & Recilia, Stymphalus, Glossocratus, Neoaliturus, Paralimnus \\
Palaearctic/Ethiopian/Oriental/Australian & Chiasmus, Nephotettix, Orosius \\
Palaearctic/Ethiopian/Australian & Nesoclutha Evans, 1947 \\
Palaearctic/Oriental & Doratulina, Mimotettix, Paralaevicephalus, Paramesodes, Takagiella, \\
& Yamatotettix \\
Nearctic/Neotropical & Acinopterus, Amblysellus Sleesman, 1929, Ascius, Atanus, Chlorotettix, \\
& Cloanthanus, Convelinus, Daltonia, Doleranus, Graminella, Haldorus, \\
& Laevicephalus, Menosoma, Ollarianus, Paraphlepsius, Planicephalus, \\
& Polyamia, Reventazonia, Sanctanus, Scaphytopius, Spangbergiella, \\
& Stirellus, Texananus, Tropicanus, Zabrosa \\
Ethiopian/Oriental & Litura \\
Ethiopian/Oriental/Australian & Hodoedocus \\
\hline &
\end{tabular}

The Holarctic and Nearctic/Neotropical IZG regions shared the largest number of genera ( 23 and 25 , respectively). Taxal affinities were closer within each combined region than between them, indicating a taxonomic exclusiveness and an inimically, closer phylogenetic relationship of genera that was apparently influenced by a contiguous continental affiliation during part of the historical development of the continents.

Only four genera (Balclutha Kirkaldy, 1900, Exitianus Ball, 1929, Hecalus Stål, 1864, Scaphoideus Uhler, 1889) in the subfamily are considered cosmopolitan and each one represents a separate tribe. Of particular interest is the genus Scaphoideus, which is very rich in the Nearctic (46) and Oriental (26) regions but is poorly or doubtfully represented in the other four regions. The disjunct species richness between the Oriental and Nearctic regions suggest that the taxonomy of the genus in the Oriental region needs careful restudy. Furthermore, one species in South Africa has been transferred to a new genus by THERON (1974b) after it was proposed provisionally first by LINNAVUORI (1961). The other seven species have been allocated to Scaphoidophyes Kirkaldy, 1906, a subgenus of Scaphoideus (BARNETT 1980; BARNETT \& FREYTAG 1976), thus the genus may not be represented at all in the Ethiopian region, particularly if the subgenus merits generic rank. The group is marginally represented (one species) in the Neotropical region (Guatemala) and the single record in Australia may be adventitious. 
Of the 23 Holarctic genera, ten (Boreotettix Lindberg, 1952, Euscelis Brullé, 1832, Fieberiella Signoret, 1880, Thamnotettix Zetterstedt, 1838, Macustus Ribaut, 1942, Deltocephalus Burmeister, 1838, Diplocolenus Ribaut, 1946, Hardya Edwards, 1922, Verdanus Oman, 1949, Cicadula Zetterstedt, 1840) appear to have originated in the Palaearctic region based on the dominant number of species in that region. The first six genera each have a shared species, all of which are believed to be adventitious or were introduced into the Nearctic region by commerce. The genus Deltocephalus (sensu stricto) appears to be Palaearctic in origin. This large genus has numerous representatives in the Palaearctic region. Only one species, $D$. pulicaris (Fallén, 1806), is Holarctic and it is believed to have been introduced into North America. The taxonomic relationship between Palaearctic Deltocephalus and the New World Deltocephalus-like genera (sensu BLOCKER et al. 1995) is unclear but if closely related it is possible that the latter group may be a vicariant coupled with explosive radiation in the Nearctic region. Four genera (Cazenus Oman, 1949, Scleroracus Van Duzee, 1894, Elymana DeLong, 1936, Idiodonus Ball, 1936) are of Nearctic origin, this region having a preponderance of species. Two of these genera have a shared species that dispersed from the Nearctic to the Palaearctic region via the Bering strait. The origin of the remaining nine genera is problematical because each region has about an equal number of species for each respective genus. Both regions share 2 species of Limotettix Sahlberg, 1871 and 4 species of Psammotettix Haupt, 1929, all of which apparently dispersed via the Bering strait. Zelenius Emeljanov, 1966 appears to be restricted to the Nearctic region although there is an unconfirmed record in the Palaearctic region.

VILBASTE (1980a) cited a number of leafhopper species (30-53), mostly Deltocephalinae, shared by Kamchatka and several major geographical areas, including Alaska, Nearctic region, Kuril Islands, Primorye Territory, Central Siberia, Central Asia and Europe. The highest number of shared fauna was found in Central Siberia (76.1\%) and Europe $(69.7 \%)$ whereas the lowest number of shared fauna was in the Kurile Islands (35.5\%) and Alaska (39.5\%). About $42 \%$ shared the Nearctic region. A large number of genera (25) are shared by the Holarctic region.

The Holarctic/Neotropical group shares three genera, Athysanella Baker, 1898, Colladonus Ball, 1836, and Osbornellus Ball, 1932. The origin of the former two genera appears to be the Nearctic region whereas the latter is most likely Neotropical. All of the genera are marginal, or have minor representation, in the Palaearctic region. There is no evidence to indicate that these marginal occupations were adventitious. Colladonus is richly represented in the Nearctic region. Several species have been described recently from Costa Rica which has extended the range much farther into the Neotropical region than had been previously known (NIELSON \& GoDOY 1992, 1995). Only a single, widespread species occurs in the Palaearctic region. This genus is an interesting case because radiation has been largely restricted to the western Nearctic region whereas none has occurred with its single palaearctic species, C. torneelus (Zetterstedt, 1828) (NIELSON 1957). The latter is most closely related to C. youngi Nielson, 1957 in Alaska and Canada and it is probable that its ancestral origin is the Nearctic region from which it dispersed transcontinentally via the Bering strait after the last ice age. Athysanella is widespread in the Nearctic 
region and is known by a single species in Mongolia and several species in Mexico (BLOCKER 1985). Osbornellus is well represented in the Nearctic and Neotropical regions, the latter as far south as Argentina. It has been reported in Europe as the nominate form for the subgenus Mavromoustaca Dlabola, 1967 (DLABola 1967e, 1979c). However, the taxonomy of the European group needs careful review to determine its true relationship to the New World Osbornellus.

The near cosmopolitan occupations by Circulifer Zachvatkin, 1935 and Macrosteles Fieber, 1866 were largely by dispersion and/or by adventitious events. The genus Circulifer originated in the Mediterranean basin (OMAN 1948b). All occupations, primarily by C. tenellus, in the Nearctic/Neotropical/Ethiopian/Australian (Hawaiian Islands) regions were entirely adventitious (OMAN 1970; LINNAVUORI 1959b), a rare phenomenon among leafhopper distributional histories. The origin of Macrosteles is problematical and its widespread presence was by dispersal and/or vicariation. However, the Ethiopian record is believed to be adventitious and the recent finding of specimens in Costa Rica by the senior author suggests dispersion from its Nearctic neighbor.

Four Palaearctic/Ethiopian genera (Jubrinia Linnavuori, 1962, Neolimnus Linnavuori, 1953, Sotanus Ribaut, 1942, Tetartostylus Wagner, 1951) have marginal occupations but they dominate one or the other of the two regions. Tetartostylus is dominant in South Africa where the genus likely originated. Neolimnus is more prevalent in the Palaearctic region and may have originated there. The origin of the other two genera is problematical.

Rosenus Oman, 1949 occurs in the Holarctic and Australian (Australia) regions, the latter by way of introduction. It is represented in the Palaearctic/Nearctic region by a nearly equal number of species between regions; its origin, therefore, is difficult to determine.

The origin of the Palaearctic/Ethiopian/Oriental genera (Recilia Edwards, 1922, Stymphalus Stål, 1866, Glossocratus Fieber, 1866, Neoaliturus Distant, 1918, Paralimnus Matsumura, 1902) is more problematical. Recilia and Stymphalus are widespread in the Palaearctic and Ethiopian regions with a marginal or doubtful occurrence in the Oriental region. LINNAVUORI (1975) reported one species of Recilia in Fiji (Australian region) but it appears that this group may have originated in the Ethiopian region where the majority of species presently occur. Glossocratus is dominant in the Ethiopian region and may have originated there, whereas species of Paralimnus are equally distributed between the Oriental and Palaearctic regions. Neoaliturus is rather marginal in most of its range although several species are widespread in the Palaearctic region. The type locality of the type-species of the genus is in the Laccadive Islands in the Oriental region which is quite far removed from Asia and Africa. This is not to imply that it is the center of the origin of the group. The origin of the group is, therefore, problematical.

The broadly distributed genera, Chiasmus Mulsant \& Rey, 1855, Nephotettix Matsumura, 1902, and Orosius Distant, 1918, are each shared in the Old World by at least one species in two or more regions. Chiasmus has about the same number of species, including one shared species, in the Palaearctic and Oriental regions. The genus likely originated in the Oriental region. Nephotettix clearly originated in the

Revta bras. Zool. 17 (1): 81 - 156, 2000 
Oriental region where most of the species are known. Orosius is dominant in the Australian region where it is believed to have originated. One species is shared by three regions.

The origin of the Palaearctic/Oriental genera, Doratulina Melichar, 1903, Mimotettix Matsumura, 1914, Paralaevicephalus Ishihara, 1953, Paramesodes Ishihara, 1953, Takagiella Vilbaste, 1969 and Yamatotettix Matsumura, 1914 is more problematical, except for Takagiella and Yamatotettix, which appear to be Palaearctic. The other genera largely occur marginally in both regions along their adjacent zoogeographical borders.

There are 25 genera that are shared by the Neogeic region. Fifteen genera (Acinopterus Van Duzee, 1892, Ascius DeLong, 1943, Atanus Oman, 1938, Chlorotettix Van Duzee, 1892, Doleranus Ball, 1936, Haldorus Oman, 1938, Menosoma Ball, 1931, Ollarianus Ball, 1936, Planicephalus Linnavuori, 1954, Reventazonia Linnavuori, 1959, Sanctanus Ball, 1932, Spangbergiella Signoret, 1879, Tropicanus DeLong, 1944, Unerus DeLong, 1936, Zabrosa Oman, 1949) originated in the Neotropical region where their species are more abundant. Several of these genera have identical number of species that are shared by both regions, indicating dispersal from the Neotropical to the Nearctic region. Four genera (Convelinus Ball, 1931, Laevicephalus DeLong, 1926, Paraphlepsius Baker, 1897, Polyamia DeLong, 1926 ) originated in the Nearctic region. Both regions share at least two species in the latter two genera. The origin of six genera (Cloanthanus Ball, 1931, Scaphytopius, Ball, 1931, Daltonia Oman, 1949, Graminella DeLong, 1936, Stirellus Osborn \& Ball, 1902, Texananus Ball, 1918) is problematical. Each region shares about the same number of species. Overall, it appears that most of the Neogeic genera have Neotropical origin with dispersals mostly directed northward.

The Ethiopian/Oriental genus, Litura Knight, 1970, had its origin in the Oriental region where most of the known species occur. The broadly distributed genus Hodoedocus Jacobi, 1910 that occurs in the Ethiopian/Oriental/Australian needs further study. The record in the Australian region is based on a female and a record in the Neotropical region is questionable. Most of the species occur in the Ethiopian region.

The absence of shared genera between the Ethiopian and Neotropical region appears to be related to isolation of the two continents or to the extinction of those ancestral deltocephaline lineages that gave rise to the ancestors of the modern extant genera. Furthermore, the long period of isolation following continental drift effectively closed off gene flow that was available among the fauna on other intercontinental land masses where shared genera are more evident.

The Himalayan range was possibly an effective barrier between the Palaearctic and Oriental regions for this group. The subsaharan-northern Ethiopian arid arc also provided an ecological barrier between the Palaearctic/Ethiopian regions, and possibly between the Ethiopian/Oriental regions. EvANS (1966) considered the majority of deltocephaline fauna of Australia as of recent adventitious origin. This has considerable significance for the biogeographical history of the subfamily because it implies that Australia received little or no faunal input of this group from adjacent land masses during Gondwanaland times. THULBORN (1986) showed that 
many labyrinthodont amphibians were common in Australia but that it had few reptiles during the Triassic, suggesting that the continent was isolated earlier and for longer periods than previously thought.

The Australian fauna apparently received some contribution from the Oriental region and vice versa, particularly between Australia proper and the Indo-Malayan land masses. It is plausible that each group of genera endemic to its respective zoogeographical region may have developed a special ecological bondness to its region which prevented them from dispersing to adjoining land masses of different or similar, but unacceptable habitat zones.

We propose that the geohistorical origin of this cosmopolitan subfamily was very early (late Jurassic/early Cretaceous) before or during Gondwanaland fragmentation because at the present time there appears to be no known alternative evidence to explain its current cosmopolitan distribution. This is not to imply that the group is an ancestral one. On the contrary, it is a group that appears to be highly efficacious for speciation and radiation, the rates of which were apparently much higher than in most of the other extant subfamilies. The center of origin of the subfamily may be revealed when phylogenetic analyses of the tribes are done.

Phylogenic Inference. The subfamily may be a highly derived assemblage of forms of unprecedented complexity even though we proposed that it arose early in the geobiogeographical history of the world. The degree of its relationship to other subfamilies, however, is problematical.

\section{Typhlocybinae Kirschbaum, 1868}

Taxonomy. This large, distinctive subfamily is a highly complex, cosmopolitan group that is especially rich in the Oriental region. No distributional maps for this group are given here. Eight tribes are currently recognized, Alebrini, Dikraneurini, Empoascini, Erythroneurini, Helionini, Jorumini, Typhlocybini and Zyginellini (OMAN et al. 1990). The subfamily had previously been called Zyginae, Eupteryginae and Cicadellinae, the former two subsequently declared junior synonyms. The usage of the family-group name, Cicadellinae, for the typhlocybines was brief as the name replaced the family-group name, Tettigellinae, after the genus Tettigella China \& Fennah, 1945 was declared invalid by the Commission of Zoological Nomenclature. The genus Typhlocyba Germar, 1833 was the next available name and declared the valid nominal usage for this subfamily by the Commission.

YouNG (1952) classified the New World elements of the group which comprise six of the eight known tribes, including the Erythroneurini which he established. In a later study, YouNG (1957) treated the tribe Alebrini, the only tribe that has an appendix on the forewing, elucidating 25 genera from the New World. Numerous taxa have been elucidated by Irena Dworakowska (see OMAN et al. 1990), but the subfamily is in serious need of keys to assist in identification.

Habitat and Host Plants. These small leafhoppers occupy diverse ecological niches and feed on a wide variety of trees, shrubs, herbaceous plants and grasses. Many species are parenchyma cell feeders which is rare or nonexistant among other subfamilies of leafhoppers. The genus Erythroneura Fitch, 1851 is especially well 
known for its partitioning of specific feeding sites on the same host species to avoid competition between leafhopper species (HEPNER 1966a,b,c,d).

Distribution and Zoogeographical Origin. The Typhlocybinae are widely distributed in all zoogeographical regions and has next to the highest number of endemic genera (Tab. I). Nearly half of the total number of known endemic genera occur in the Oriental region although the high figure may be due, in part, to more numerous taxonomic studies of the group in that part of the world, chiefly by Dworakowska (see OMAN et al. 1990). The Ethiopian and Palaearctic fauna are also rich in endemic forms. Representation in the Nearctic and Australian regions is poor.

KNIGHT (1983a) recorded 62 genera and 239 species in Southeast Asia and the Pacific region, which represent about $17 \%$ of the world genera. The senior author's collections of the subfamily in Costa Rica ranked them in the lower 10 percentile for species richness, which appear to confirm the comparatively poor faunal representation in the Neotropical region.

Five tribes (Empoascini, Erythroneurini, Alebrini, Dikraneurini, Typhlocybini) are cosmopolitan and are probably vicariants having representative endemic genera in all regions except Australia proper. Two tribes (Helionini, Zyginellini) are Old World and likely originated in the Oriental region. Jorumini is New World and appeared to have originated in the Neotropical region. In the Alebrini, all of the genera of the New World originated in the Neotropical and southern Nearctic regions except Alebra Fieber, 1872 which is Holarctic. The origin of this genus is problematical although YouNG (1952) found constant differences between North American and European specimens of the type species, Cicada albostriella Fallén, 1826 suggesting that it was introduced into North America.

Genera of Typhlocybinae shared by 12 IZG regions are shown in table IV. The greatest number of genera are shared by the Palaearctic/Oriental regions, followed by the Ethiopian/Oriental, the Nearctic/Neotropical and the Holarctic regions.

Table IV. Shared genera of the subfamily Typhlocybinae in 11 interzoogeographical regions.

\begin{tabular}{ll}
\hline \multicolumn{1}{c}{ Interzoogeographical Region } & \multicolumn{1}{c}{ Genus } \\
\hline Cosmopolitan & Empoasca, Erythroneura \\
Holarctic & Dikraneura, Forcipata, Notus, Ossiannilssonola, Ribautiana, Typhlocyba \\
Holarctic/Oriental/Australian & Zygina, Alebra \\
Holarctic/Ethiopian/Oriental & Eupteryx \\
Holarctic/Australian & Kybos \\
Palaearctic/Ethiopian & Imbecilla, Lichtrea, Lublinia \\
Palaearctic/Ethiopian/Oriental/Australian & Austroasca, Empoascanara, Dialecticopteryx \\
Palaearctic/Ethiopian/Oriental & Diomma, Helionidia, Zyginella \\
Palaearctic/Oriental/Australian & Alebroides \\
Palaearctic/Oriental & Agnesiella, Aguriahana, Alebroides, Anufrievia, Apheliona, Arboridia, Erythria, \\
& Frutioidia, Hauptidia Dworakowska, 1970, Heliona, Helionides, Limassolla, \\
& Platytetticis, Singapora, Tautoneura, Ziczacella, Zyginidia \\
Nearctic/Neotropical & Alconeura, Diceratalebra, Dikrella, Joruma, Kunzeana, Kunzella, Protalebrella, \\
& Solanasca \\
Ethiopian/Oriental & Accacidia, Acia, Coganoa, Empoascanara, Gambialoa, Omiya, Sundara \\
\hline
\end{tabular}

The widespread distribution of Empoasca Walsh, 1862 and Erythroneura leaves open the origin of these genera. Their high host specificity refutes distribution by adventitious means. Moreover, partitioning (vicariance) produced taxonomic 
differences within presently constituted genera where radiation was obvious in each of their respective continental occupations. These genera are candidates for renewed taxonomic studies to verify their present cosmopolitan/bigeographical occupations, respectively. YounG's (1952) key to the New World Empoasca does not appear to work for the Old World (European) fauna, which suggests different but closely related taxonomic elements that may require generic separation or a revised concept of the genus.

Among six genera (Dikraneura Hardy, 1850, Forcipata DeLong \& Caldwell, 1942, Notus Fieber, 1866, Ossiannilssonola Christian, 1953, Ribautiana Zachvatkin, 1947, Typhlocyba) shared by the Holarctic region, Dikraneura and Ossiannilssonola are believed to have originated in the Nearctic region where they are clearly dominant. Notus is dominant in the Palaearctic region and likely originated there. The origin of the remaining genera is problematical as each is shared about equally by both regions. Dispersal was evident via the Bering strait in some genera where shared species have been recorded, and in Dikraneura a few species are marginal in the Neotropical region via dispersal southward.

The two Holarctic/Oriental/Australian genera, Zygina Fieber, 1866 and Alebra, have recent links by introductions or adventitious means into the Oriental region. The mostly endemic forms of Zygina in the Australian region are thought to represent other genera (DWORAKOWSKA, personal communication). A single, introduced species of Alebra occurs in New Zealand. The origin of the Holarctic fauna of these genera is problematical although most of the species of Zygina occur in the Nearctic region where the genus may have originated. Members of both genera dispersed either from one or the other region via the Bering strait into their respective counterpart region and radiated after the closing of the strait or they were vicariated during late Jurassic or early Cretacaeous times.

Kybos Fieber, 1866 is primarily an Holarctic genus with 2 introduced species in the Australian region (New Zealand). The origin of the group is problematical but its origin may have followed a similar pathway described for the two preceding genera.

Eupteryx Curtis, 1829 [1831] is widespread in the Holarctic, Ethiopian and Oriental regions with adventitious species in the Nearctic region. The origin of the group is problematical.

The genera Imbecilla Dworakowska, 1970, Lichtrea Dworakowska, 1976, and Lublinia Dworakowska, 1970 appear to have originated in the Ethiopian region where most of the known species occur. One or two species of each genus in the southern Palaearctic region apparently dispersed northward from the Ethiopian region.

Three genera, Diomma de Motschulsky, 1863, Helionidia Zachvatkin, 1946, and Zyginella Loew, 1855 are widely distributed in the Palaearctic/Ethiopian/Oriental regions. Diomma has representatives in the Australian region. The origin of these groups is problematical although the Diomma forms in the Pacific region appear to have originated in the Oriental region and dispersed eastwardly.

The genus Alebroides Matsumura, 1931 is so widespread in the Australian, Oriental and Palaearctic regions that it is difficult to assess its origin. 
Among 17 Palaearctic/Oriental genera, five (Anufrievia Dworakowska, 1970, Apheliona Kirkaldy, 1907, Arboridia Zachvatkin, 1846, Singapora Mahmood, 1967, Tautoneura Anufriev, 1969) are believed to have originated in the Oriental region where the species are dominant. Agnesiella Dworakowska, 1970 is clearly Palaearctic and shares one species in the Nearctic region. Draberiella Dworakowska, 1971, a subgenus of Agnesiella, is exclusively Oriental and this region may be the center of origin for the nominate form. Four genera, Erythria Fieber, 1866, Heliona Melichar, 1903, Ziczacella Anufriev, 1970, and Zyginidia Haupt, 1929, are believed to have originated in the Palaearctic region where most of the species occur. The large genus Aguriahana Distant, 1918 occurs along the mountainous regions bordering the Palaearctic and Oriental zone where its apparent confinement may be the place of origin. DWORAKOWSKA (1972a) postulated that this genus arose no earlier than the Pliocene. The origin of Frutioidia Zachvatkin, 1946, Helionides Matsumura, 1931, Limassolla Dlabola, 1965, and Platytetticis Strand, 1942 is problematical.

The widespread Old World genera Austroasca Lower, 1952 and Dialecticopteryx Kirkaldy, 1907 have numerous species in the Pacific which suggest an Oriental origin for those species. The center of origin within its broad range is difficult to postulate, similar to the problem with several widely distributed genera in the Old World. Empoascanara Distant, 1918 is also widespread but clearly of Oriental origin where nearly all of the known species occur.

The eight Neotropical/Nearctic genera (Alconeura Ball \& DeLong, 1925, Diceratalebra Young, 1952, Dikrella Oman, 1949, Joruma McAtee, 1924, Kunzeana Oman, 1949, Kunzella Young, 1952, Protalebrella Young, 1952, Solanasca Ghauri, 1974) appear to have originated in the Neotropical region. Their presence in the Nearctic region (Sonoran) is marginal by only a few species.

The Ethiopian/Oriental group (Accacidia Dworakowska, 1971, Acia McAtee, 1934, Coganoa Dworakowska, 1976, Gambialoa Dworakowska, 1972, Omiya Dworakowska, 1981, Sundara Ramakrishnan \& Menon, 1972) have mixed origins. Accacidia is most abundant in the southern Palaearctic region from North Africa to northern India and may have originated there. Acia and Omiya are clearly dominant in the Ethiopian region. Gambialoa appears to have its origin in the Oriental region where most of the species occur. The origin of Coganoa and Sundara is problematical.

The subfamily may have originated during late Jurassic/early Cretaceous times in Gondwanaland prior to completion of continental drift to account for its cosmopolitan distribution. They are weak flyers and dispersal between the Neotropical and Ethiopian by this means is highly unlikely. The data in table I support the Old World origin of most of the typhlocybine genera, the center appearing to be in the Oriental region where the major pool of modern genera occur.

Phylogenic Inference. The subfamily is generally believed to be a derived group although Evans (1947) suggested that they lie close to the "jassid" (cicadellid) stem and are neither derivatives of, nor ancestral to, any other group. He considered the small size, structure of the head and occasional pitted appearance to be primitive features. The reduction of venation in the forewings was evidence of early specialization. The loss of ocelli among many forms also suggest specialization. 
YouNG (1952) presented a conventional tree for two tribes, Dikraneurini and Erythroneurini, for the Western Hemisphere Typhlocybinae, emphasizing that it was impractical to develop a phylogeny of the entire group until after the Palaearctic fauna are understood. We agree and add that the relationship of all of the major tribal elements of the subfamily should be reassessed. With reference to the Alebrini, YounG (1957) believed that it is not closely related to any of the other typhlocybine tribes. Even interrelationships among the genera in the tribe are not clear.

\section{Cicadellinae Van Duzee, 1916}

Taxonomy. This large, unique, cosmopolitan subfamily is presently comprised of seven tribes, the Anoterostemmini, Cicadellini, Errhomenini, Evacanthini, Mileewanini [sic], Pagaroniini, and Proconiini, all attributed to various authors (OMAN et al. 1990). For the purpose of this paper we are treating all of the above listed tribes in the Cicadellinae except the Mileewini which is treated as a subfamily below. Some of these assemblages were recommended to subfamily status (Evacanthinae, Errhomeninae) or be transferred to the Typhlocybinae, viz., Mileewini by Young (1968). The subfamily was formerly called Tettigonides, Tettigoniellinae, Amblycephalinae and Tettigellinae during its taxonomic history. The genus Amblycephalus Curtis, 1833 was declared a synonym of Cicadella Latreille, 1817 and a junior homonym of Amblycephalus Kirschbaum, 1858, and the other three nominotypical generic names were invalidated by the Commission of Zoological Nomenclature, including the usage of the genus Cicadella prior to that of Latreille 1817. This action fixed the name for the family and the subfamily as well (OMAN et al. 1990).

YOUNG $(1968,1977,1986)$ basically divided the subfamily into two tribes, the Proconiini and the Cicadellini. The Old World Cicadellini, except for the Cicadella genus group, are not closely related to the New World Cicadellini (YounG 1986). The Errhomenini, based on Errhomenus Fieber, 1866, is a reinstated valid name for the proposed replacement name of Errhomenellus Puton, 1886 (OMAN et al. 1990), even though Young $(1968,1977)$ proposed the latter name as the basis for subfamily status. The genus Tettigoniella Jacobi, 1904 used by YouNG (1986), is an isogenotypic synonym of Cicadella Latreille. The species treated under that name require assignment to a new, yet undescribed genus. YouNG's (1993) treatment (published posthumously) of the New Guinea genus Archeguina Young, 1993 in the tribe Mileewini requires restudy as this group does not appear to be allied taxonomically to members typical of the Mileewinae which Young believed should be allied to the Typhlocybinae.

This subfamily is a complex of forms universally reknown for its inflated clypeus and attendant mnusculature required for probing and ingesting sap from the xylem. They are also known colloquially as "Sharpshooters" because of the continuous flicking of copious excretions of fluids by the anal appendage following the process of ingestion from the xylem. A large number of species are vector specific of a bacterial agent-causing plant disease (NIELSON 1968b, 1979c, 1985). 
Habitat and Host Plants. The tropical regions are very rich in species although they are common in warm temperate regions below the 50 parallel in the northern hemisphere. The group is typically known as xylem feeders and this is probably true for all species in the subfamily. Many groups feed on a wide range of plants; some are exclusively grass and sedge feeders whereas others are specialists on shrubs and trees. A large number of species are generalists, laying eggs on herbaceous plant species and feeding on a broad range of herbs, shrubs and trees. High populations congregate on individual plants, especially in the Fall in temperate and subtropical regions. They appear to be attracted to plants that are in the senescent stage.

Distribution and Zoogeographical Origin. This subfamily is cosmopolitan. Numerous endemic genera are present in most of the zoogeographical regions (Tab. I). By far the largest number of endemic genera occur in the Neotropical region which represents $60 \%$ of the world's cicadelline endemic fauna. In contrast, the huge Holarctic region has only a small fauna, comparable to that in each of the remaining smaller zoogeographical regions.

The Australian region has a fair number of endemic genera although only 1 genus is believed to be endemic to Australia itself (YoUNG 1986). KNIGHT (1983a) compiled 21 genera and 157 species (mixture of endemic and nonendemic forms) from Southeast Asia and Pacific Island region. The Nearctic and Palaearctic regions have the poorest endemic fauna and it is likely that all of them originated from their southern adjacent land masses.

The large tribe Cicadellini is virtually cosmopolitan. With the exception of the strictly Palaearctic genus Cicadella, all other Old World genera, as a group, are closely related to but distinct from its counterpart group in the New World (YOUNG 1986). This has vicariant implications suggesting radiation along separate lines between the New and Old World fauna of Cicadellini after separation of the continents.

Another possible case of vicariance involves seven genera (Bubacua Young, 1977, Cubrasa Young, 1977, Caribovia Young, 1977, Camaija Young, 1977, Hadria Metcalf \& Bruner, 1936, Cibra Young, 1977, Ehagua Melichar, 1926) of the tribe, all of which are restricted to the Caribbean Islands. During the Cretaceous (Turonian), a series of islands that formed in Central America was pushed northeastward by the Caribbean plate to become the Greater Antilles (BROWN \& GIBSON 1983). A fossil cicadelline related to Graphocephala Van Duzee, 1916 was identified in Dominican amber by DIETRICH \& VEGA (1995) which supports origin of these genera. We suggest that the ancestors of the cicadelline genera (and others in the subfamilies Coelidiinae and Agalliinae, see below) were carried to this location where they radiated to present day genera with over 30 known species.

The tribe Proconiini is considered New World only and most likely originated in the Neotropical region. However, there are two genera, Namsangia Distant, 1908 (India and China) and Jilijapa Melichar, 1925, that may belong to the Proconiini pending completion of studies by MEJDALANI (personal communication, 5 December 1997). Several genera, Acrogonia Stål, 1869, Diestostemma Amyot \& Serville, 1843, Deselvana Young, 1968, Tretogonia Melichar, 1924, Yunga Melichar, 1924, Cyrtodisca Stål, 1869, Pseudophera Melichar, 1925, Acrobelus Stål, 
1869, Egidemia China, 1927 and Abana Distant, 1908, have crossed the Isthmus and occupied Central America but they have not reached the Nearctic region. All of these genera appear to have Neotropical origin. Other genera, Depanana Young, 1968, Quichira Young, 1968, Catorthorrhinus Fowler, 1898, Amblydisca Stål, 1869, Dictyodisca Schmidt, 1928, and Procama Young, 1968 are restricted to Central America and none has dispersed north to Mexico nor south into mainland South America. The genera Cuerna Melichar, 1925 and Paraulacizes Young, 1968 have also dispersed northward from Central American origin, the former has radiated in the Nearctic region and extended as far north as Alaska. All of the genera that originated north of the Panamanian Isthmus appear to have become isolated from Neotropical ancestral stock and radiated during the period before the final closing of the Isthmus of Panama during the Miocene.

The Anoterostemmini are Palaearctic only and probably originated there where little or no radiation occurred. The Evacanthini, Errhomenini and Pagaroniini are Holarctic. These tribes present an interesting study of Pacific arc dispersal where elements of all tribes presently occupy each region. The Evacanthini are believed to have originated in the Palaearctic region and its representatives entered the Nearctic region by adventitious means. The richness of Pagaroniini along the eastern Palaearctic zone suggest that the direction of dispersal was eastward into the western Nearctic zone via the Bering strait well before the beginning of the epochal ice periods. Many new species of Pagaronia Ball, 1902 were recently described by HAYASHI \& ARAI (1990) and HAYASHI \& YOSHIDA (1995) from Japan. The fauna far outnumber the few species in the Nearctic region, lending additional support for eastern Asiatic origin of the tribe.

A similar dispersal pathway may have occurred in the tribe Errhomenini but it is possible that it took place in the opposite direction inasmuch as radiation was limited to but more profuse in the Nearctic than in the Palaearctic region. The fossil genus Mesojassoides Oman, 1937 of Cretaceous origin is a member of the tribe Errhomenini by virtue of its similar, errhomenid wing venation (OMAN \& MUSGRAVE 1975). The phylogenetic relationship of this group to the modern genera is uncertain but it may represent the ancestral stock of Errhomenini. The northern hemisphere apparently did not have the flora and ecology that are conducive for cicadelline radiation.

The biogeographical regions that share genera of the Cicadellinae are shown in table V. In connection with the distribution of shared genera, a proposed pathway from region to region is shown in figure 1 . Similar maps are given in the discussion of shared genera of several subfamilies that follow. Most pathways are by dispersal, others are by vicariance or adventitious means. The number of endemic genera are indicated in the open circle for each zoogeographical region. The names of shared genera are enclosed in a box with a small arrow pointing to the arrow of direction of probable pathway. A double-headed arrow with solid circles indicates that the direction of pathway and origin of those genera is uncertain.

Most of the genera of Cicadellinae are shared by the Neotropical/Nearctic (Neogeic) regions where it is likely that most if not all are of Neotropical origin. In the majority of these genera, most of their species occur in South America, and their 
respective attendant species that occur in the Nearctic region are of more recent origin, either by radiation or by dispersal from their southern origin, following the closing of the Panamanian Isthmus.

\section{CICADELLINAE}

Number of endemic genera

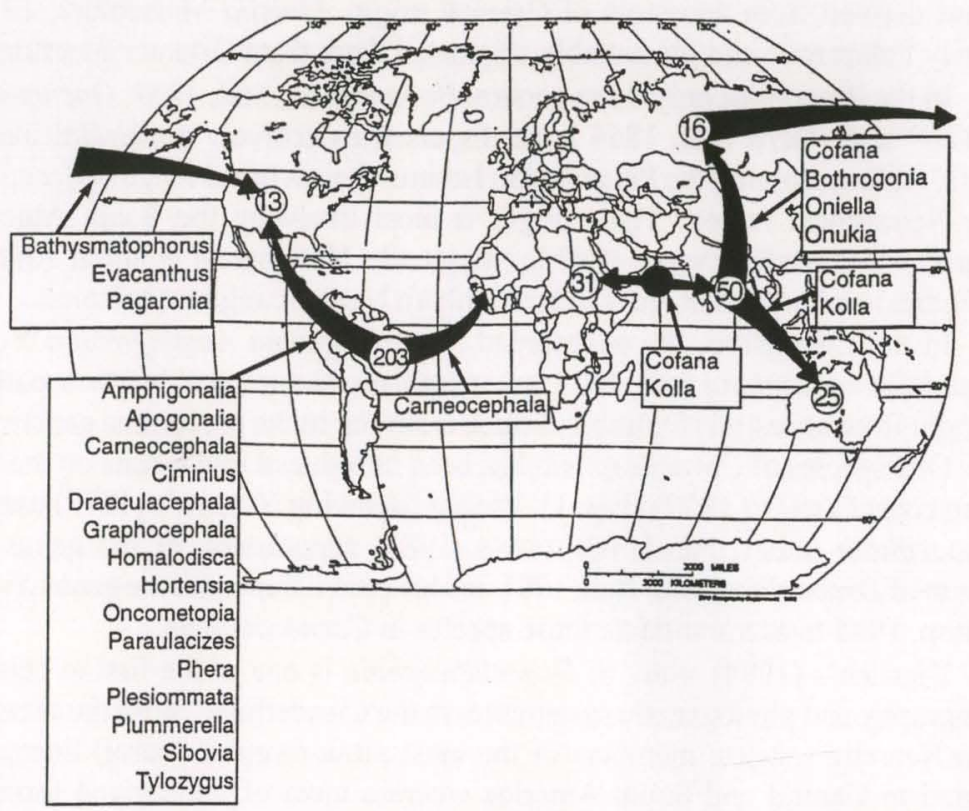

Fig. 1. Distribution of endemic genera of Cicadellinae and proposed pathway of dispersal of shared genera (Carneocephala Ball, 1927 adventitious in Africa).

Table V. Shared genera of the subfamily Cicadellinae in five interzoogeographical regions.

\begin{tabular}{ll}
\multicolumn{1}{c}{ Interzoogeographical Region } & \multicolumn{1}{c}{ Genus } \\
\hline Holarctic & Bathysmatophorus, Evacanthus Le Peletier \& Serville, 1825, Pagaronia \\
Palaearctic/Ethiopian/Oriental/Australian & Cofana \\
Palaearctic/Oriental & Bothrogonia, Oniella, Onukia \\
Nearctic/Neotropical & Amphigonalia, Apogonalia, Cameocephala, Ciminius, Draeculacephala, \\
& Graphocephala, Hortensia, Homalodisca, Oncometopia, Paraulacizes, \\
& Phera, Plesiommata, Sibovia, Tylozygus \\
Ethiopian/Oriental/Australian & Kolla \\
\hline
\end{tabular}

In the tribe Errhomenini, the genus Bathysmatophorus Sahlberg, 1871 has a continuous Holarctic distribution from Europe eastward to the west coast of North America with its attendant Nearctic subgenus Hylaius Oman \& Musgrave, 1975 (OMAN \& MUSGRAVE 1975). The origin of the group appears to be Palaearctic. The origin of Cofana Melichar, 1926 is problematical, having nearly equal number of species in the Ethiopian, Oriental and Australian regions. It is marginal in the 
Palaearctic region. A few species are shared by 2-3 of these regions. Kolla Distant, 1908 appears to have originated in the Oriental region where most (20) of the species occur. Two species are strictly Palaearctic and four species reside solely in the Ethiopian region.

Bothrogonia Melichar, 1926 and Onukia Matsumura, 1912 are equally represented in the Oriental and Palaearctic regions. Two species of Bothrogonia are shared by both regions. The origin of these genera is unclear but it is possible that they are derived from ancestors of Oriental origin. Oniella Matsumura, 1912 is primarily Palaearctic and presumably originated there from Oriental ancestors.

In the Proconiini only three genera, Homalodisca Stål, 1869, Oncometopia Stål, 1869 and Phera Stål, 1864 have dispersed extensively northward into the Nearctic region, crossing the Panamanian Isthmus from a broad range of occupation in the Neotropical region. Their origin is most likely on the South American continent. Apogonalia Evans, 1947 is marginally Neotropical (Central America, West Indies) and has extended into the southern Nearctic region (Arizona).

In the Cicadellini, the widespread Nearctic genera Amphigonalia Young, 1977 and Carneocephala Ball, 1927, are marginally Neotropical but their pathway and origin from ancestral Neotropical stock is similar to the proconiine genera cited above. One species of Carneocephala has been introduced into Ghana on the West African coast (YounG 1977) (Fig. 1). We are following YounG's (1977) usage of Carneocephala rather than HAMILTON's (1985) suppression of the genus as a synonym of Draeculacephala Ball, 1901 and his establishment of the genus Xyphon Hamilton, 1985 to accommodate those species in Carneocephala.

Dietrich's (1994) study of Draeculacephala is one of the first to correlate biogeography and phylogenetic systematics in the Cicadellidae. With the exception of two Nearctic species, members of the most plesiomorphic (basal) lineage are restricted to Central and South America whereas most of the derived forms are mostly Nearctic as indicated in his cladogram. However, he proposed that the genus either originated in Central America, Mexico or Southwestern United States.

We propose an alternative possibility for consideration. It is more likely that the group originated in South America and that the dispersal pathway and radiation of Draeculacephala from South America to North America took two major routes. One to the West Indies via movement of the Caribbean plate and the other through Mexico. The origin of the South American component is based on tracking the distribution of three species (youngi Dietrich, 1994, clypeata Osborn, 1926, soluta Gibson, 1919) whose ranges, in part, include South America, Central America, West Indies and Southeastern United States and two indigenous species that have dispersed little, tucumanensis Dietrich, 1994, which is restricted to northern Argentina and albipicta Dietrich, 1994, known only from Ecuador.

One species, clypeata occupies the northern half of South America, Central America and much of the West Indies, the latter occupation via the Caribbean plate during middle Cretaceous and a secondary intrusion into Central America after the continents rejoined during the Miocene. Another species, soluta, widely distributed in the northern half of South America and Central America, apparently occupied 
the latter region during the Miocene. A widespread species, youngi, occupies the northern half of South America. Two species, bradleyi Van Duzee, 1915 and producta (Walker, 1851), may have Neotropical origin from their base in the West Indies (Cuba) whose ranges also include southeastern U.S. and Florida, respectively. However, it is conceivable that dispersal of these forms could have occurred in the other direction. It is significant that none of the Nearctic or Mexican subregional species have reached Central America or South America.

We proposed that the West Indies lineage of the genus gave rise to Southeastern and Eastern forms in United States, and these gave rise to Midwestern United States and Canadian forms east of the Rocky Mountains. The Mexican lineage produced forms that dispersed into Southwestern United States and Western North America. It is also possible that a southern route from Mexico gave rise to forms along the southern border and midwestern area of United States.

The large genus Graphocephala Van Duzee, 1916 occurs from northern South America to southern Canada and its origin is very likely Neotropical. Radiation was especially evident in the Nearctic region. Ciminius Metcalf \& Bruner, 1936, Hortensia Metcalf \& Bruner, 1936, Plesiommata Provancher, 1889 and Sibovia China, 1927 are very widespread from northern Brazil to southern United States and most likely of Neotropical origin. Tylozygus Fieber, 1865 ranges from southern South America to southern United States.

The origin of the subfamily appears to have taken place during early Cretaceous/Jurassic period in Gondwanaland prior to separation of the continents. This view offers a feasible explanation of the cosmopolitan distribution of the subsequent endemic forms. Distinctive primitive features (swollen clypeus, discal ocelli) possessed by the subfamily and the extinct Jurassic family Karajassidae also support the early origin of the group. The center of origin may be the Neotropical region where most of the endemic genera occur and where explicit radiation took place after continental drift.

Phylogenic Inference. The relationship of Cicadellinae to other subfamilies is problematical. Evans (1947) believed that the group is allied to the Aphrodinae but this view is not held by current taxonomists. YouNG's $(1968,1977,1986)$ treatment of the group did not reveal clues to the origin of or relationship to other groups. However, he felt that the Proconiini exhibited more primitive features than do the Cicadellini. His proposed transfer of certain tribes to other subfamilies or designation of new subfamilies indicates the complexities inherent with the subfamily (sensu lato).

The phylogenetic significance of the "hind knees", reaching to or not reaching the proepimeron (lateral lobe of the pronotum) and which is the diagnostic character that separates the tribes Cicadellini and Proconiini, is problematical. The zoogeographical profile of these tribes suggests that the Proconiini is the derived group, since the latter apparently arose after separation of the African and South American continents, notwithstanding that it appears to have some primitive features. For the subfamily, the discal ocelli and the tumid clypeus with its close functional relationship to xylem feeding appear to be retentive, primitive features that are possessed also by the presumed, ancestral cercopoid group, Cercopoidea. 


\section{Coelidiinae Dohrn, 1859}

Taxonomy. This moderately large, pantropical subfamily currently consists of nine tribes (Gabritini, Hikangiini, Sandersellini, Teruliini, Thagriini, Tharrini, Tinobregmini, Youngolidiini, Equeefini) following a revision of the group by NiELSON $(1975,1977,1979 b, 1982 e, 1983 e)$ and studies by THERON (1984c). Several genera formerly assigned to the subfamily by METCALF (1964b) have been removed and some were provisionally assigned to other subfamilies while others await reassignment (NIELSON 1975). The tribe Equeefini was established by THERON (1984c) and relegated to Coelidiinae to accommodate some of these and several new genera. Preliminary cladistical studies segregated Equeefini as a distinct outgroup clade from the other tribal clades suggesting that the group does not belong in Coelidiinae and warrants subfamily status.

Habitat and Host Plants. This group prefers and is primarily restricted to warm, moist habitats even in temperate regions where occupations are marginal. Host records are poorly known but the group occurs chiefly on shrubs and trees. Members of the tribe Tinobregmini have been reported on mixed herbaceous/shrub habitats. In Costa Rica the senior author and associates have collected several genera on shrubs only. Members of the genus Jikradia Nielson, 1979 were frequently taken on Rubus Linnaeus, 1735 (Rosaceae). In Arizona, numerous specimens of Harasupia snowi Lawson, 1927 were taken on Arctostaphylos Adans, 1763 (Ericaceae) by the senior author. Grasses are not known to be hosts.

Distribution and Zoogeographical Origin. A more detailed discussion of the distribution of the subfamily is presented in published papers by the senior author. Only a brief account is given here. The subfamily occupies the tropical regions of the world and is only marginal in the temperate zones in both hemispheres. The majority (77) of the endemic genera occupy the Neotropical region whereas the remainder are in the Ethiopian (15), Oriental (6), Australian (3) and Nearctic (1) regions (Tab. I). There are no endemic genera in Australia.

The largest tribe, Coelidiini, is widely distributed across the tropical beltway. In this tribe, only two genera, Lodiana Nielson, 1982 and Calodia Nielson, 1982, share more than one zoogeographical region (Palaearctic, Oriental) and these are marginal occupations (Tab. VI). Mahellus Nielson, 1982 is marginal in both Oriental and Ethiopian (Malagasian) regions and of possible insular origin.

Table VI. Shared genera of the subfamily Coelidiinae in five interzoogeographical regions.

\begin{tabular}{ll}
\hline Interzoogeographical Region & \multicolumn{1}{c}{ Genus } \\
\hline Palaearctic/Oriental & Lodiana \\
Palaearctic/Oriental/Ethiopian & Calodia \\
Nearctic/Neotropical & Harasupia, Jikradia \\
Ethiopian/Oriental & Mahellus \\
Ethiopian/Neotropical & Biadorus \\
Oriental/Australian/Palaearctic & Thagria Melichar, 1903 \\
Oriental/Australian & Tharra \\
\hline
\end{tabular}

The Teruliini are restricted to the New World except for one adventitious species (Biadorus africanus (Spångberg, 1878)) in the central west coast of Africa 
(Tab. VI). Two genera (Harasupia Nielson, 1979, Jikradia) share the neogeic region (Tab. VI) and both are believed to have originated from Neotropical stock from which they radiated northward following the closure of the Panamanian Isthmus. Gabritini and Sandersellini are neotropically restricted, each with a narrow range; the former in Brazil and Guiana and the latter stretching from Panama to Peru. The gabritines are strictly Brazilian and appear to mimic a predatory stance with its raptorial-like forelegs, a specialized feature.

Tinobregmini are disjunctively widespread in the neotropics and in the southern perimeter of the Nearctic region. The group needs a taxonomic review. Hikangiini is a small tribe restricted to the Ethiopian region. The Youngolidiini occupy the Ethiopian and Neotropical regions but recent, preliminary cladistical analysis support separation of the group into two tribes which may remove the puzzling problem of disjunct distribution.

Two large tribes, Thagriini and Tharrini, are strictly Oriental and Australian in distribution, respectively, although the former group has reached the southern Palaearctic region and the latter group is also marginally Oriental. Only three species of Tharrini occur in Australia and these are restricted to the northeastern area.

The subfamily is considered to have originated during late Jurassic/early Cretaceous with its center in Gondwanaland. The tribe Coelidiini is of similar origin, having radiated profusely in the Neotropical region. There are no members of this tribe in the Nearctic region. The limited number of genera in the Ethiopian and Oriental regions suggest that although they are of early origin as well, radiation was restricted except at the species level in the Oriental region. The Teruliini arose after continental drift occurred and presumably from Coelidiini stock in the Neotropical region where radiation was very high. All genera of this tribe in the Nearctic region are of Neotropical origin. The Gabritini, Sandersellini and Tinobregmini also are of Neotropical origin. The Youngolidiini may be a vicariant group, one radiating in the Neotropical region and the other radiating in Africa after separation of the continents, or the group may be separate tribes. The Hikangiini are of Ethiopian origin of limited radiation. The tribes Thagriini and Tharrini originated in the Oriental and Australian regions, respectively.

Phylogenic Inference. A phylogenetic analysis of this subfamily is pending. The group appears to have no close alliances to any existing subfamily.

\section{Idiocerinae Kirschbaum, 1868}

Taxonomy. This subfamily is a fairly large, homogenous group that consists chiefly of two large, widespread genera, Idiocerus Lewis, 1834 and Idioscopus Baker, 1915, and a large number of small genera. No tribes, except its nominotypical name, have been established, which is unique for such a relatively large group (OMAN et al. 1990). The Nearctic elements were studied by FREYTAG (1964) in which he also designated several species groups and developed a phylogenetic tree for the species. Oriental and Neotropical fauna were partially elucidated by MALDONADO-CAPRILLES $(1951,1964,1965)$. Australian and Afrotropical faunas were studied by WEBB $(1983 \mathrm{a}, \mathrm{b})$. The generic classification of the group appears to be 
well established, although some taxonomic disagreements are evident among the Holarctic fauna of Idiocerus and its cogeners that were studied by FREYTAG (1964), Dlabola (1974b), Hamilton (1980a) and Ossiannilsson (1981). Many new genera in the Oriental region await description.

Unique endemic genera of the group have been described from Chile (FREYTAG \& MORRISON 1969), Australia (EVANS 1941, 1942, 1966; WEBB 1983b), Oriental region (MALDONADO-CAPRILLES 1972a,b, 1976, 1985a) and the Australian and Afrotropical region (WEBB 1983a,b).

Habitat and Host Plants. Idiocerines are widespread from sea level to 12,000 feet in mixed lowland and montane habitats. Populatons are very abundant and univoltine in the Holarctic region. Many species are attended by ants. This group feeds entirely on shrubs and trees as far as is known. Many species are host specific on Salix Linnaeus, 1735 (Salicaceae), Populus Linnaeus, 1735 (Salicaceae) and other plant species in the Holarctic region. In Australia they are specialists on Eucalyptus L'Hérit, 1788 (Myrtaceae) (Evans 1966).

Distribution and Zoogeographical Origin. The idiocerines are cosmopolitan, mostly by endemic forms and singularly by dispersion into the Nearctic region from its Palaearctic neighbor. The endemic genera are nearly equally (14-22) distributed among the zoogeographical regions, except for the Nearctic region in which there are none presently known (Tab. I).

Genera shared by more than one zoogeographical region are given in table VII. Idiocerus is broadly distributed in the Holarctic region. Records of Idiocerus in Australia and the Ethiopian region are referable to other genera (WEBB 1983a,b). LINNAVUORI's (1956a) record of the genus in the Neotropical region (Brazil) is doubtful. In the absence of endemic genera the Nearctic fauna of Idiocerus appears to have originated in the Palaearctic region by dispersal via the Bering strait possibly before the ice age began (Fig. 2). A few species are adventitious. Its reported occurrence in the Neotropical region (Chile) and Madagascar appears to be problematical (FREYTAG \& MORRISON 1969; FREYTAG \& KNIGHT 1966; OMAN et al. 1990; WeBB 1983b). Adventitious species from the Palaearctic region have been found in New Zealand (KNIGHT 1974b). Of interest is the possibility that the record of Macropsinae in Chile may in fact be members of Chileanoscopus Freytag \& Morrison, 1969 (Idiocerinae) described by FREYTAG \& MORRISON (1969) (see discussion under the subfamily Macropsinae).

Table VII. Shared genera of the subfamily Idiocerinae in four interzoogeographical regions.

\begin{tabular}{ll}
\hline Interzoogeographical Region & Genus \\
\hline Holarctic & Idiocerus \\
Ethiopian/Oriental/Australian & Chunra \\
Oriental/Palaearctic & Idioscopus \\
Oriental/Australian & Busoniomimus \\
\hline
\end{tabular}

Idioscopus occurs in the Oriental and Palaearctic regions. Members of the group formerly recorded in the Ethiopian region have been referred to other genera (WeBB 1983b). Its origin appears to be Oriental (Fig. 2). Chunra Distant, 1908 is 
present in the Ethiopian, Oriental (Indonesia) and Australian (NE Australia) regions. Its disjunct distribution between tropical Africa and Indonesia is puzzling although it may indicate that the genus was widespread in earlier times and later become ecologically isolated (Fig. 2). However, it is recommended that the Oriental and Australian elements be restudied. Busoniomimus Maldonado-Capriles, 1977 is widespread in the Oriental and Australian regions. Elements of the genus followed the Indo-Malayan pathway to Australia (Fig. 2). The origin appears to be Oriental.

\section{IDIOCERINAE}

Number of endemic genera

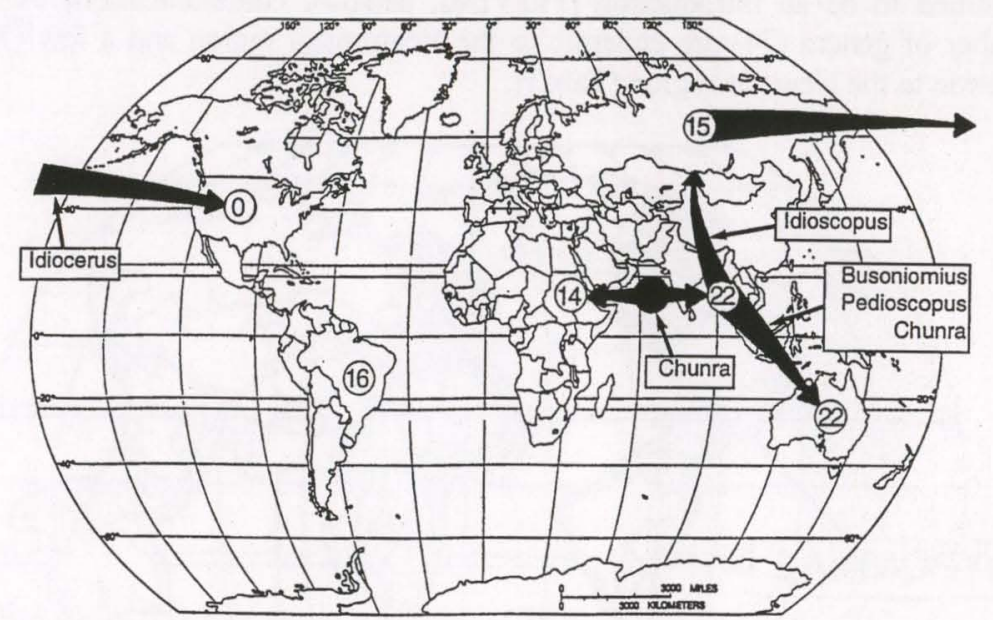

Fig. 2. Distribution of endemic genera of Idiocerinae and proposed pathway of dispersal of shared genera.

The subfamily may have late Jurassic/early Cretaceous origin in Gondwanaland and centered in the Old World tropics. During continental drift, elements were established in their respective zoogeographical regions except in the Nearctic region. Radiation was especially active in tropical regions, resulting in numerous endemic genera. In Australia, EvANS (1966) considered the group of Tertiary origin but we believe they rose much earlier given the more primitive characterization of the subfamily, relatively close relationship to the Agalliinae and geobiology of the continent.

Phylogenic Inference. The relationship of this subfamily is believed to be close to the Agalliinae with which it shares a number of primitive characters.

\section{Gyponinae Stål, 1870}

Taxonomy. The subfamily Gyponinae is a large, somewhat homogenous group that largely occupy the Neotropical region. Only the nominotypical tribe, Gyponini, is recognized at present (OMAN et al 1990). The subfamily name has held 
a long term usage over Scarinae, an older name which may be the valid name for the group until the International Commission of Zoological Nomeclature is requested to suspend the Rules in favour of Gyponinae. This rather unique group was cited as a tribe of the Ethiopian Iassinae by LINNAVUORI \& QUARTAU (1975).

Habitat and Host Plants. This subfamily ranges from tropical habitats to cold, temperate zones. Many species are arboreal, feeding on trees and shrubs, especially oaks in the temperate regions. Some species frequent herbaceous plants.

Distribution and Zoogeographical Origin. This group is confined to and widely distributed in the New World (Fig. 3) except for Curtara DeLong \& Freytag, 1972 which was recently reported from the west coast of Africa (Fig. 4) and is presumed to be an introduction (FREYTAG, personal communication). A large number of genera (74) are endemic to the Neotropical region and a few (7) are endemic to the Nearctic region (Tab. I).

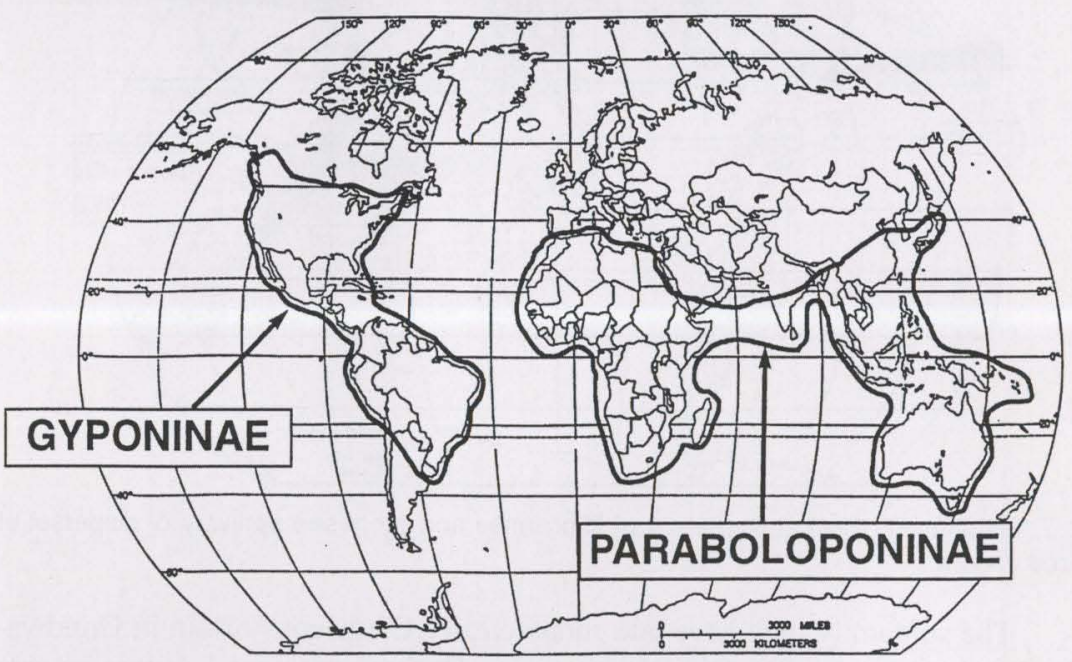

Fig. 3. Distribution of the subfamilies Gyponinae and Paraboloponinae.

Among the many known genera in the Neotropical region only nine (12\%) are neogeic (Tab. VIII) and most of these, if not all, are believed to have had their origin in the Neotropical realm (Fig. 4).

Table VIII. Shared genera of the subfamily Gyponinae in one interzoogeographical region.

\begin{tabular}{lc}
\hline \multicolumn{1}{c}{ Interzoogeographical Region } & Genus \\
\hline Nearctic/Neotropical & Acuera DeLong \& Freytag, 1972, Acusana DeLong, 1942, Gypona Germar, \\
& 1821, Gyponana Ball, 1920, Obtusana DeLong \& Freytag, 1964, Polana \\
& DeLong, 1942, Ponana Ball, 1920, Prairiana Ball, 1920, Rugosana DeLong, \\
& 1942
\end{tabular}

This subfamily is believed to have Cretaceous origin because of its apparent derived relationship to the Iassinae (LINNAVUORI \& QUARTAU 1975). Gyponines 
may have come from an ancestral "neotropical" iassine and subsequently radiated in the Neotropical region following the separation of the African and South American continents. Northward dispersal to the Nearctic region probably took place after joining of the Panamanian isthmus during the Eocene.

\section{GYPONINAE}

Number of endemic genera

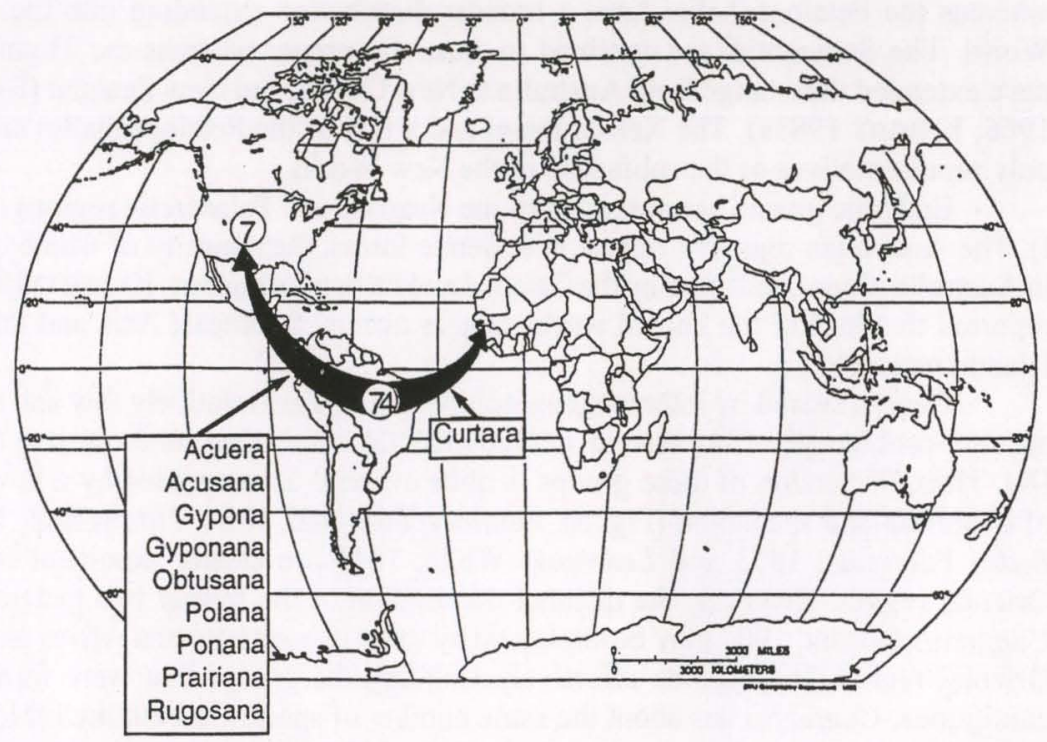

Fig. 4. Distribution of endemic genera of Gyponinae and proposed pathway of dispersal of shared genera (Curtara DeLong \& Freytag, 1972 adventitious in Africa).

Phylogenic Inference. EVANS (1947a) alluded to a relationship of this group to the Iassinae (Jassinae sic!). A relationship between the Ethiopian Iassinae and Gyponinae was also indicated by LINNAVUORI \& QUARTAU (1975a). The group has retained the discal ocelli, a primitive condition recently proposed as ancestral to marginal or facial position (SHCHERBAKOV 1992).

\section{Ledrinae Fairmaire, 1855}

Taxonomy. The Ledrinae are a small, primitive, cosmopolitan group that is dominant in the Ethiopian, Oriental and Australian regions. Five tribes are recognized, Ledrini, Petalocephalini, Stenocotini, Thymbrini and Xerophloeini (OMAN et al. 1990).

The Xerophloeini, which LINNAVUORI (1959b) considered worthy of a subfamily rank, has only two genera, Xerophloea Germar, 1839 and Xedreota Kramer, 1966. Three genera, Clinonana Osborn, 1938, Ohausia Schmidt, 1911 and 
Hespenedra Kramer, 1966 have not been given tribal assignments. KRAMER's (1966) placement of the first two genera in Ledrinae was a provisional one notwithstanding their having certain character associations with the Gyponinae.

Habitat and Host Plants. This group prefers tropical regions but has limited occupation in temperate regions. The New World ledrines are grass feeders whereas in Australia they feed primarily on Eucalyptus (Evans 1966).

Distribution and Zoogeographical Origin. This subfamily is cosmopolitan. The Ledrini are broadly distributed in the Ethiopian, Oriental and Australian regions whereas the Petalocephalini have a broader distribution extending into the New World. The Stenocotini are confined to Australia proper whereas the Thymbrini have extended their range from Australia to New Guinea and New Zealand (EvANS 1966; KNIGHT 1983a). The Xerophloeini and a few of the Petalocephalini are the only representatives of the subfamily in the New World.

Endemic genera are absent from the Nearctic and Palaearctic regions (Tab. I). The Australian region is richest in endemic forms, the majority of which occur in Australia proper, followed by the Oriental and Ethiopian regions. KNIGHT (1983a) reported that half of the known world species occupy Southeast Asia and Pacific Island areas.

Genera shared by interzoogeographical regions are relatively few and some are non-problematical because of intercontinental-connecting land masses. (Tab. IX). Thus, dispersion of these groups is quite evident, accompanied by a low rate of evolution and speciation (Fig. 5). Petalocephala Stål, 1854, Tituria Stål, 1865, Ledra Fabricius, 1803 and Ledropsis White, 1844 are clearly dominant in the Oriental region. However, the disjunct distribution of the former two genera and Confucius Distant, 1907 may be explained by the arid zone between Africa and the Oriental region (India), thus effectively isolating the groups that were formerly contiguous. Confucius has about the same number of species in both the Ethiopian and Oriental regions. Parapetalocephala Kato, 1931 is a very small group in the Oriental and Palaearctic regions. One species is shared by both regions and one is known only in the Palaearctic region, thus the origin of the group is problematical. The neogeic Xerophloea is believed to have originated in the Neotropical region where most of the species occur (NIELSON 1962b).

Table IX. Shared genera of the subfamily Ledrinae in five interzoogeographical regions.

\begin{tabular}{ll}
\hline \multicolumn{1}{c}{ Interzoogeographical Region } & \multicolumn{1}{c}{ Genus } \\
\hline Palaearctic/Ethiopian/Oriental/Austral & Petalocephala \\
Palaearctic/Oriental & Ledra, Parapetalocephala \\
Palaearctic/Ethiopian/Oriental & Confucius, Tituria \\
Palaearctic/Oriental/Australian & Ledropsis \\
Nearctic/Neotropical & Xerophloea \\
\hline
\end{tabular}

This primitive group may have late Jurassic/early Cretaceous origin in Gondwanaland. The center of origin appears to be Australia where most of the endemic genera presently occur. It appears that elements of the subfamily were part of the "Antarctic" fauna. Vicariate groups arose in the Neotropical region (Xerophloeini), Ethiopian and Oriental (Ledrini) and Australia proper (Thymbrini) in and 


\section{LEDRINAE}

\section{Number of endemic genera}

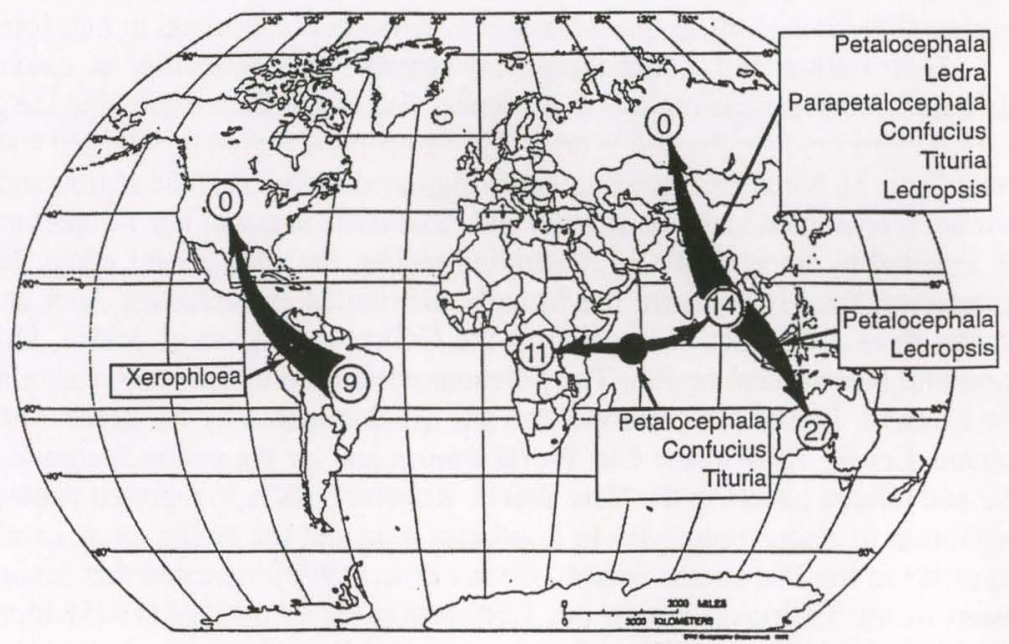

Fig. 5. Distribution of endemic genera of Ledrinae and proposed pathway of dispersal of shared genera.

from which they slowly radiated. Evans (1966) believed that only a few genera may be of pre-Tertiary origin. He presumed that some genera of the Ledrini gained access to Australia from the Indo-Malayan pathway during Tertiary isolation but it is more likely they were already present on the continent much earlier given their proposed Jurassic/Cretaceous origin. LINNAVUORI (1972) proposed that the group arose during the late Mesozoic. He believed most of the African genera, however, evolved during the Tertiary period. Some genera may be pre-Tertiary relicts.

Phylogenic Inference. Evans $(1959,1966,1969)$ suggested that the group was derived from the Ulopinae. LINNAVUORI (1972) postulated that the group is one of the most primitive subfamilies and was derived from the ulopine stem. KRAMER (1966) suggested that Clinonana may be the connecting link between the gyponines and ledrines.

\section{lassinae Walker, 1870}

Taxonomy. This moderately large, nearly cosmopolitan subfamily is comprised of seven tribes (Hyalojassini, Iassini, Krisnini, Platyjassini, Reuplemmelini, Selenomorphini, Trocnadini), all established by Evans (1947a, 1953a, 1966a, 1972a, 1974a) except the Iassini. For many years the group was called Jassinae (EVANS 1966, 1972b, 1974; HAMILTON 1983, and others), which is incorrect usage. Jassus Fallén, 1806 is an incorrect spelling of Iassus Fabricius, 1803 and was placed on the official index of rejected and invalid generic names by Commission of Zoological Nomenclature (OMAN et al. 1990). EvANS (1974) considered the tribe Selenomorphini as a subfamily. 
Habitat and Host Plants. This group is common in the tropical regions of the world, its presence decreasing in temperate regions. Many species are arboreal feeders on a broad range of trees, shrubs and herbaceous plants. The Trocnadini and Reuplemelini feed on eucalypts whereas the Krisnini are arboreal in rain forests.

Distribution and Zoogeographical Origin. This subfamily is commonly distributed in the tropical regions of the world. Except for the tribe Iassini, the group has limited presence in the Old World. The Neotropical region is richest in endemic genera (Tab. I). None are known to have originated in the Nearctic region and only a few are represented in the Australian and Palaearctic regions. The Reuplemmelini and Trocnadini are endemic in Australian region, the Platyjassini occur only in Madagascar, the Hyalojassini are broadly distributed in Southeast Asia and the Krisnini have a disjunct occupation in the Guinea subregion of Africa, Oriental region and Neotropical region. The Selenomorphini are endemic to Australia and New Zealand. Iassini are cosmopolitan and are dominated by the genus Batracomorphus Lewis, 1834 in the Old World tropics and by the genus Stragania Stål, 1862 and related genera in the New World. KNIGHT $(1983 a, b)$ reported widespread distribution of Batracomorphus in Southeast Asia and the Pacific area, extending East as far as the Marquesas Islands. OMAN et al. (1990) indicated that Iassus was present in the Ethiopian region but LINNAVUORI \& QUARTAU (1975) found no representatives of this genus in Africa.

Genera shared by more than one zoogeographical area are few (Tab. X). A proposed pathway of dispersal is shown in figure 6. Batracomorphus is widely distributed in the Old World. Numerous species (375) have been described thus far, particularly from the Afrotropical and Oriental regions. Eight species groups are being proposed by VIRAKTAMATH (personal communication) for the eastern Oriental and Australian regions, including the four species groups from the same regions previously proposed by KNIGHT (1983). Only three of eight groups are represented in the Ethiopian region. The most primitive species, angustatus (Osborn, 1934), is well represented in the Oriental and Pacific regions, but is absent in the Ethiopian region. The highest diversity of the genus is found in the Oriental and Australian regions, and the predominant Afrotropical group is represented by only 8 species in the Oriental region and by two species in the Pacific region. There are fewer related species between the Ethiopian and Oriental regions than between the Oriental and Australian regions. These data strongly suggest that the genus originated in the Oriental region. Radiation was apparent within and separately between the Oriental and Ethiopian regions.

According to LINNAVUORI \& QUARTAU (1975), Batracomorphus is of recent origin and apparently evolved from either Ethiopian or Oriental stock from which it radiated profusely in those regions. Recently, QUARTAU (personal communication) proposed an early origin (Jurassic) of Batracomorphus and that the Oriental region received elements from Africa via India when the subcontinent drifted to its present location. We propose that the genus radiated over a contiguous area from its origin in the Oriental region, later vicariated by development of an arid zone between tropical Africa and India, thus cutting off gene flow and isolating each population, then followed by secondary radiation within each respective zoogeographical region. 


\section{IASSINAE}

Number of endemic genera

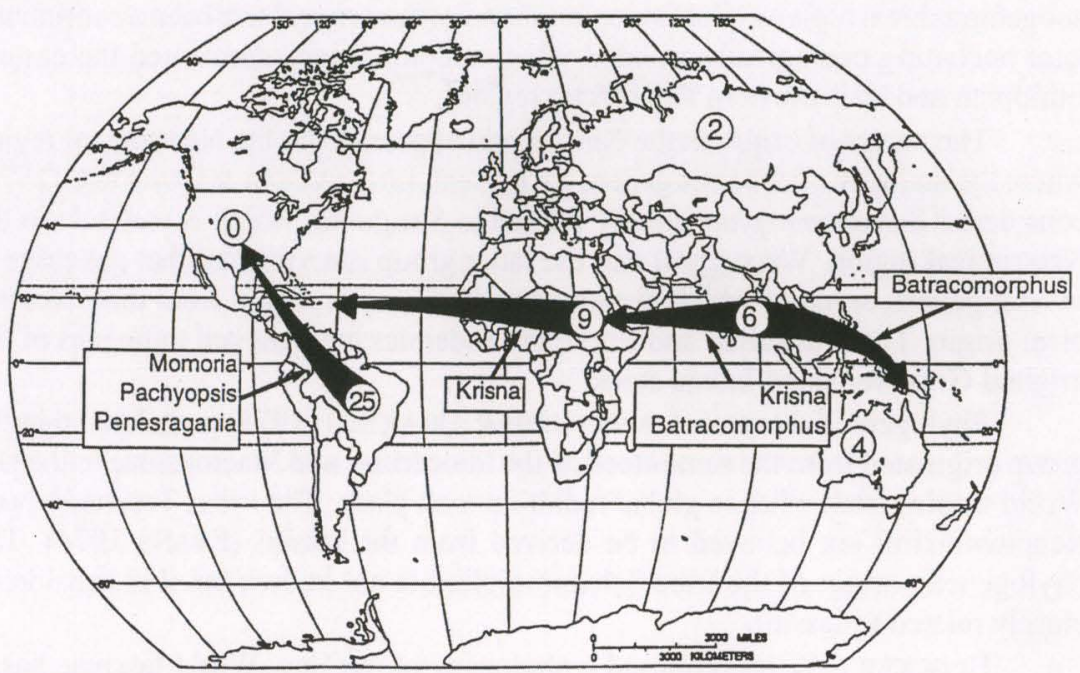

Fig. 6. Distribution of endemic genera of lassinae and proposed pathway of dispersal of shared genera.

Table X. Shared genera of the subfamily lassinae in four interzoogeographical regions.

\begin{tabular}{|c|c|}
\hline Interzoogeographical Region & Genus \\
\hline Cosmopolitan except New World & Batracomorphus \\
\hline Nearctic/Neotropical & Momoria, Pachyopsis, Penestragania \\
\hline Ethiopian/Oriental/Neotropical & Krisna \\
\hline
\end{tabular}

Krisna Kirkaldy, 1900 is broadly distributed in the Ethiopian and Oriental regions with a notable disjunct distribution in the Neotropical region. Radiation in the Old World followed a similar pattern given for Batracomorphus. The origin of the former group is believed to be Oriental where the majority of species now occur. Four species of Krisna described from the Neotropical region (Puerto Rico, Dominican Republic) are probable vicariants (Fig. 6). Recently, DIETRICH \& VEGA (1995) described a fossil specimen from Dominican amber placing its origin between 25-40 m.y.a.

Three genera (Momoria Blocker, 1979, Pachyopsis Uhler, 1877, Penestragania Beamer \& Lawson, 1945) related to Stragania are Neogeic and are believed to have their origin in the Neotropical region. Dispersal into the Nearctic region occurred after the continents were joined.

We believe the iassines arose during late Jurassic/early Cretaceous in Gondwanaland, much earlier than during Tertiary times (5-65 m.y.a.) as proposed by LINNAVUORI \& QUARTAU (1975). They postulated that global radiation took place from the center of origin in the Old World tropics, whether before or after the 
continents had acquired their present locations, is not clear. We propose that the groups vicariated, giving rise to elements that are now restricted within each of the zoogeographical regions. The Ethiopian/Oriental fauna may have been a continuum, later becoming ecologically isolated when arid conditions dominated the eastern Ethiopian and southwestern Palaearctic regions.

The center of origin in the New World appears to be the Neotropical region where the majority of endemic genera are present. LINNAVUORI \& QUARTAU (1975) considered Batracomorphus closely related to Stragania, which is endemic in the Neotropical region. We suggest that the latter group is a vicariant that gave rise to several genera, some of which dispersed to the Nearctic region from their Neotropical origin. The Australian and Ethiopian endemics are believed to be part of the original Gondwanaland faunal stock.

Phylogenic Inference. LINNAVUORI \& QUARTAU (1975) postulated that the group originated from the same stock as the Idiocerinae and Macropsinae in the Old World tropics from whence global radiation took place. The tribes Trocnadini and Reuplemmelini are believed to be derived from the Iassini (Evans 1974). The phylogenetic origin of the tribe Selenomorphini is not known but it is considered closely related to Iassini.

BLOCKER (1979c) proposed a phylogeny of the New World Iassinae based on weighted derived characters in inferred cladistic sequence. Four natural groups were devised but a number of cases of parallel evolution resulted which failed to produce a satisfactory tree. He recommended further studies by using additional taxa.

\section{Penthimiinae Kirschbaum, 1868}

Taxonomy. This small, cosmopolitan and somewhat enigmatic subfamily presently consists of one tribe, Penthimiini (OMAN et al. 1990), although LINNAvUORI (1977) believed tribal groupings may be necessary following a careful study of the Oriental fauna which has yet to be done. The subfamily has been associated as a tribe with the Iassinae (EvANS 1947) and Deltocephalinae (WAGNER 1951; LINNAVUORI 1959b), sharing with the latter many major affinities but differs from it by possession of several primitive features (LINNAVUORI 1977). EVANS (1972) placed considerable importance to major characters shared by it and the Iassinae.

Habitat and Host Plants. The group is arboreal on trees and shrubs in tropical regions. They are restricted in temperate zones. In Australia they are widespread, particularly in lower rainfall areas (EvANS 1966).

Distribution and Zoogeographical Origin. The Penthimiinae are cosmopolitan but endemic genera are unknown in the Northern Hemisphere. The group is very rich in the Oriental region where the majority (22) of endemic genera occur (Tab. I). The Ethiopian region is also quite rich. The group has limited distribution in the Southeast Asia and Pacific regions (KNIGHT 1983a). Of the three genera that were elucidated in the Neotropical region by LINNAVUORI (1959b), only Eovulturnops Evans, 1947 is considered endemic. One was provisionally placed in the tribe and the other is believed to have been introduced from Africa. 
Of the three genera that occupy more than one zoogeographical region, the genus Penthimia Germar, 1821 is widespread except for the Neotropical and Australian regions. Members of this genus in the Nearctic region are believed to be derived from Palaearctic stock. The other two genera, Haranga Distant, 1908 and Uzelina Melichar, 1903, are present in both the Oriental and Ethiopian regions but of unresolved origin. Their distribution may be explained by ecological isolation (vicariance) similar to the mode given for taxa described in the above subfamilies.

Penthimiines may be of early Cretaceous origin with the center of origin in the Oriental region. Penthimia is of recent origin in the Oriental region from which it dispersed to the Palaearctic region and to the Nearctic region by dispersal or adventitiously (LINNAVUORI 1977). The single known Neotropical endemic, Eovulturnops, may be a vicariant.

Phylogenic Inference. The relationship of penthimiines to other subfamilies is problematical, although Evans (1972) related it to the Iassinae. LINNAVUORI (1977a) presented some phylogenetic problems among tribal groups that he proposed, citing the origin of Musosa Linnavuori, 1977 as an early derivative of the Penthimia stock and some genera that are presumed relicts as forming their own evolutionary lines. Of interest is the suggestion that the Selenocephalinae evolved from the Citorus Stål, 1866 stock in one of the tribal groups of Penthiiminae.

\section{Nirvaninae Baker, 1923}

Taxonomy. The Nirvaninae are a relatively small, primarily pantropical, relict group of near cosmopolitan distribution. Four tribes are recognized, the Balbillini, Macroceratogoniini, Nirvanini, and Occinirvanini (OMAN et al. 1990).

Habitat and Host Plants. Nirvanines are tropical in all of the regions they occupy. Many species prefer cloud forest habitat and they feed on a wide range of plants from grasses to shrubs and trees. VIRAKTAMATH \& WESLEY (1988) recorded several host plant species of this group throughout its range.

Distribution and Zoogeographical Origin. The subfamily is nearly cosmopolitan but has no representatives in the Nearctic region (Fig. 7). Endemic genera are essentially pantropical and present in all zoogeographical regions except for the Palaearctic and Nearctic regions (Tab. I). The occupied regions contain about the same number of endemic genera. In the Palaearctic region, Sophonia Walker, 1870 [= Pseudonirvana Baker, 1923] is an extension from the Oriental elements (KUOH \& KUOH 1983b). The Balbillini occur in the Oriental region (Sri Lanka, Malaysia, Indonesia) and the Ethiopian region (Guinean subregion). The Occinirvanini are Oriental and Australian with one endemic genus in each region. Macroceratogoniini are confined to the Australian region whereas Nirvanini are pantropical from the Australian to Neotropical regions (EvANS 1966, 1973; KNIGHT 1983a; KRAMER 1964b; LiNNAVUORI 1959a, 1979b; NiELSON \& GODOY 1995d; VIRAKTAMATH \& WESLEY 1988).

Four genera (Balbillus Distant, 1908, Chudania Distant, 1908, Nirvana Kirkaldy, 1900, Sophonia) have interzoogeographical distribution. The former two share the Ethiopian and Oriental regions, Nirvana shares the Oriental and Australian regions, and the latter has made inroads into the tropical areas of the Palaearctic 


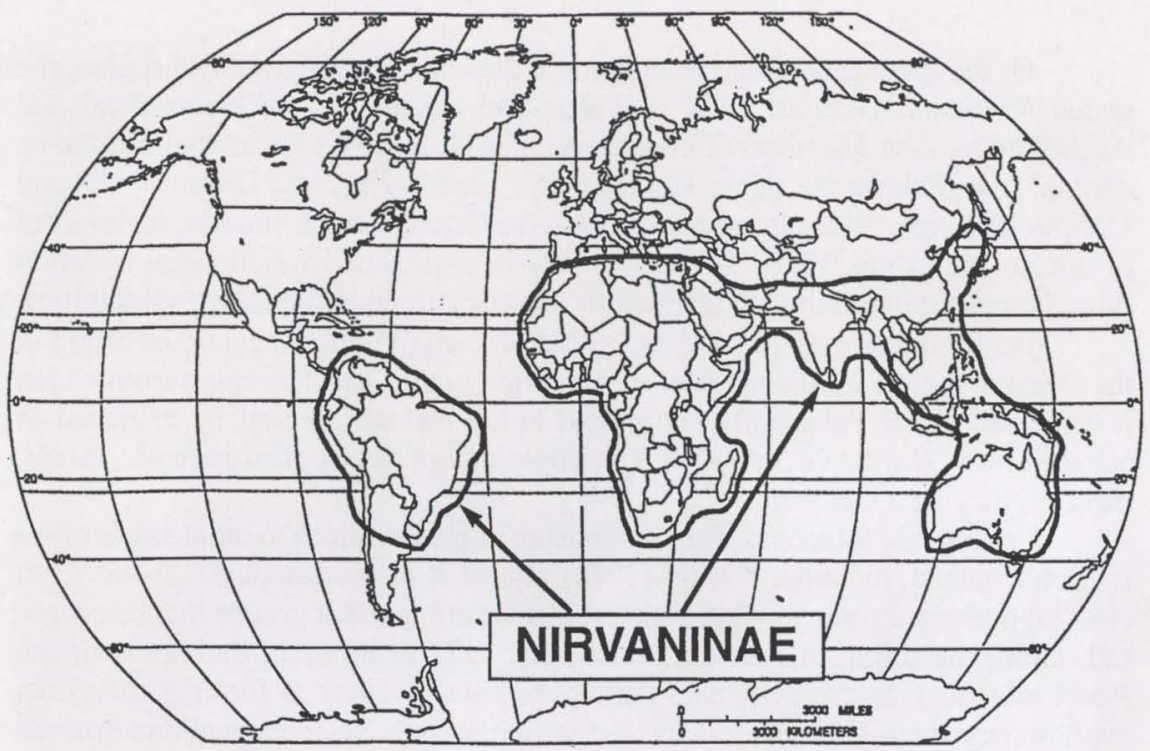

Fig. 7. Distribution of the subfamily Nirvaninae.

region from the Oriental region. VIRAKTAMATH \& WESLEY (1988) have indicated that species of Afrotropical Balbillus may belong to another genus, thus the group may be strictly Oriental. Chudania and Sophonia are marginal in the Palaearctic region and they likely originated in the Oriental region.

The origin of nirvanines is believed to be in late Jurassic/early Cretaceous with its center in the Oriental region where radiation took place into the Australian and Ethiopian regions. According to LINNAVUORI (1979b) the elements of the tribe Nirvanini that occur in the Neotropical region were adventitious events. This hypothesis does not appear to be correct in view of the many genera (14) now known in the Neotropical region. Moreover, DIETRICH \& VEGA's (1995) description of a fossil nirvanine, Krocarites Dietrich \& Vega, 1995, from Domincan amber was estimated to be 25-40 million years old. It appears more likely that the tribe was vicariated when South America separated from the African continent and carried with it elements which formed the present day fauna. A secondary vicaration occurred when Central America drifted northeastward to form the West Indies during the middle Cretaceous period.

Phylogenic Inference. LINNAVUORI (1979a) believed this group to be a derivative of the Aphrodinae-Cicadellinae stock. The most advanced tribe is Nirvanini and the most primitive are the Balbillini and Macroceratogoniini, which are of pre-tertiary origin.

\section{Selenocephalinae Fieber, 1872}

Taxonomy. The Selenocephalinae are a rather distinct, pantropical group with somewhat limited distribution in the Old World. Seven tribes are recognized, Adamini, Bhatiini, Drabescini, Dwightiini, Hypacostemmini, Ianeirini and Seleno- 
cephalini (LinNAVUORI \& AL-NE'AMY 1983; OMAN et al. 1990). The Drabescini were previously accorded family status by several authors (ISHIHARA 1950; LINNAVUORI 1960, 1978a; EVANS 1966; KNIGHT 1983a), but LINNAVUORI \& AL-NE'AMY (1983) relegated it to tribal status in their studies of the African fauna.

Habitat and Host Plants. The group ranges from rain forest to savanna habitats and are frequently arboreal. They feed primarily on shrubs and trees and often in understory areas in rain forests.

Distribution and Zoogeographical Origin. The subfamily is restricted to and broadly distributed in the Old World (Fig. 8). The Bhatiini are widely distributed in the Ethiopian, Oriental, Australian and marginally in the Palaearctic regions. Drabescini are broadly distributed in the Oriental and Australian regions. The remaining tribes are strictly Ethiopian.

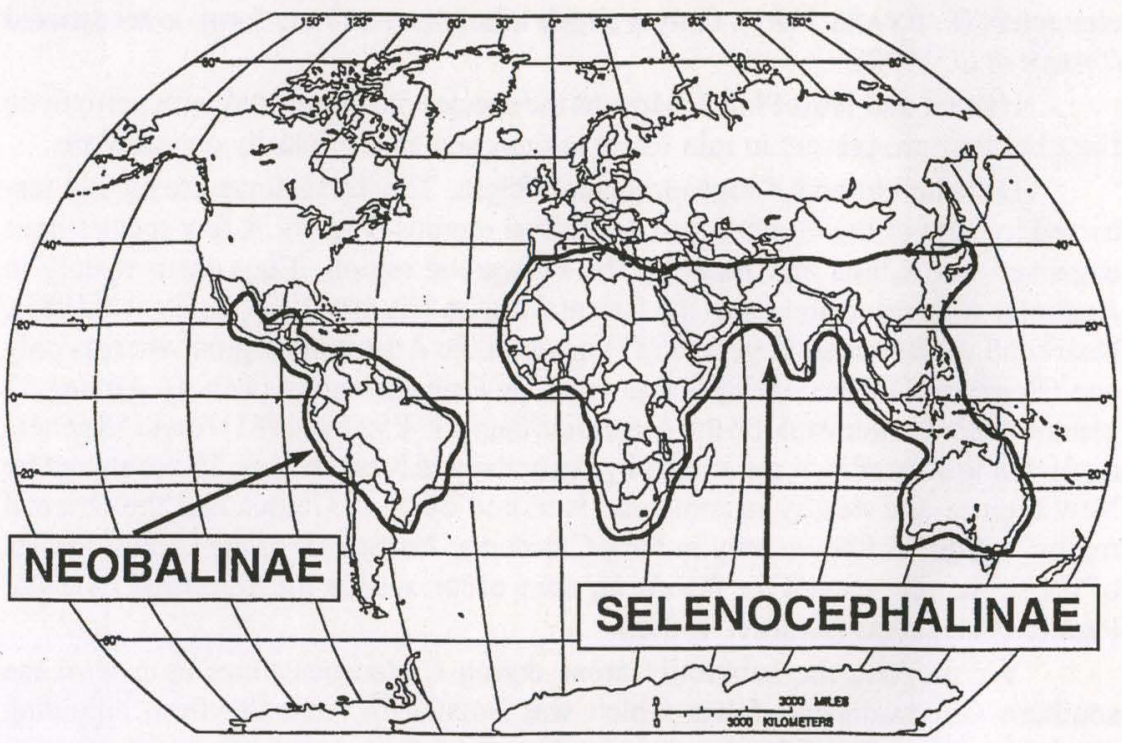

Fig. 8. Distribution of the subfamilies Neobalinae and Selenocephalinae.

Endemic genera dominate the Ethiopian and Oriental regions (Tab. I). There are no known representatives in the Neotropical or Nearctic regions except for a possible new, undescribed genus from Ecuador (ZHANG \& WEBB 1993). The placement of one endemic Australian genus in the tribe by EVANS (1966) was a provisional one. Only two genera share interzoogeographical regions, Kutara Distant, 1908 in the Palaearctic and Oriental regions and Drabescus Stål, 1870 in the Ethiopian and Oriental regions, both of which likely originated in the Oriental region. It is possible that Drabescus was widely distributed, becoming vicariated by ecological barriers between the two regions.

This group is believed to have originated during Cretaceous times in southern Asia after separation of the continents in view of their absence from the New World 
and Australia. Palaearctic elements probably came from the Oriental region by dispersal and the Australian fauna is likely of Indo-Malayan origin.

Phylogenic Inference. LINNAVUORI (1978) and LINNAVUORI \& AL-NE'AMY (1983) believe the group is derived from Penthimiinae stock and that their evolution paralleled the Deltocephalinae although they are not related to it. In view of the late origin of the group, we believe that if parallel evolution occurred it took place late during the phylogenetic development of Deltocephalinae.

\section{Tartessinae Distant, 1915}

Taxonomy. This primitive group is recognized only from the Australian and Oriental regions. Numerous genera have been described, primarily from Australia and New Guinea, but tribal designations were omitted owing to insufficient common characters (F. Evans 1981). Only a single tribe, the nominate form, is recognized (OMAN et al. 1990).

Habitat and Host Plants. Most of the species are associated with xerophytic flora but they are present in rain forest regions and feed primarily on eucalypts.

Distribution and Zoogeographical Origin. The Tartessinae are mostly restricted in parts of the Oriental and Australian regions (Fig. 9). A few species have dispersed into China and Japan in the Palaearctic region. They occur mainly in Australia with extensions into the Oriental region (EVANS 1966; F. EVANS 1981). Nearly all of the endemic genera (37) occur in the Australian region whereas only one (Borduria Distant, 1908) is known in the Oriental region (Tab. I). Among 37 genera studied in her work on the Australian fauna, F. EVANS (1981) found 18 genera restricted to Australia, 4 are shared by Australia and New Guinea, 13 are shared by New Guinea and nearby islands, one is shared by New Guinea and the Oriental region and one is known only in New Caledonia. Among all of the known species of the subfamily, except for Borduria, none occur outside the Southeast Asia and Pacific Island areas (KNIGHT 1983a).

We propose the subfamily arose during Cretaceous times as part of the southern Gondwanaland fauna which was isolated in Australia from adjoining continents. Elements of the group later radiated into the remaining Australian region and into the Oriental region via temporary land bridges. EVANS (1966) believed the subfamily originated during Tertiary times which is later than our proposed time of origin.

Phylogenic Inference. The group's relationship to other subfamilies is problematical.

\section{Eurymelinae Amyot \& Serville, 1843}

Taxonomy. The Eurymelinae are considerd one of the most primitive subfamilies of leafhoppers (EVANS 1946). The group has been considered a family rank since its inception (EvANS 1946, 1959b, 1965b, 1966, 1969b, 1973a, 1974) except when DAVIS (1975) relegated it to subfamily status. DAVIS (1975) also reduced the number of tribes from three to two because the character gradient in females was 


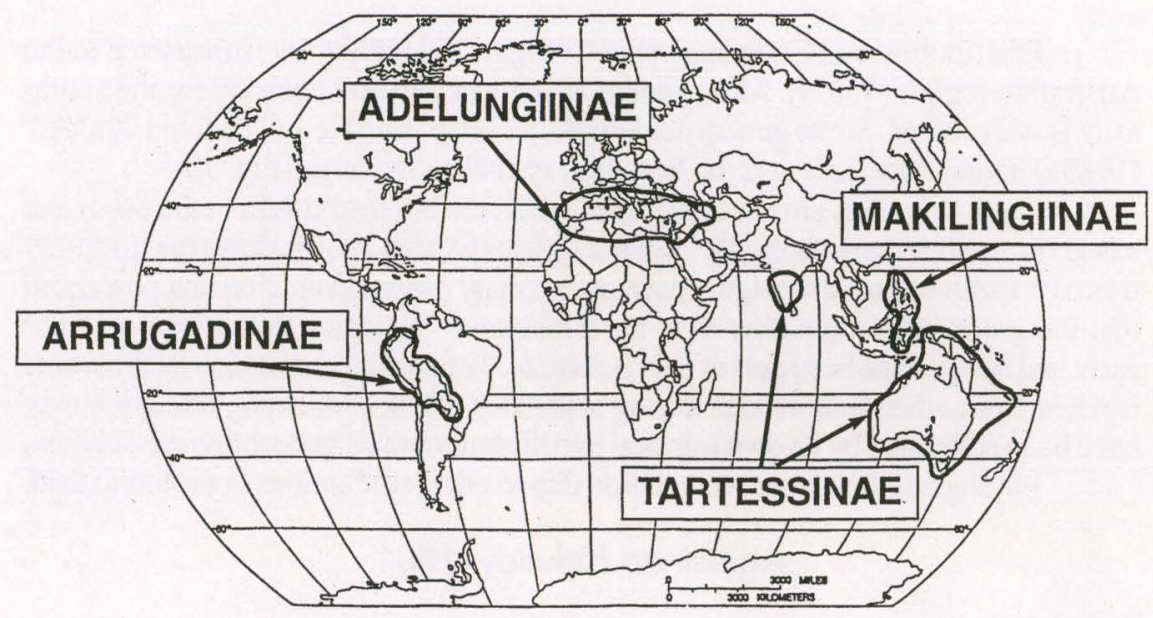

Fig. 9. Distribution of the subfamilies Arrugadinae, Adelungiinae, Tartesssinae and Makilingiinae.

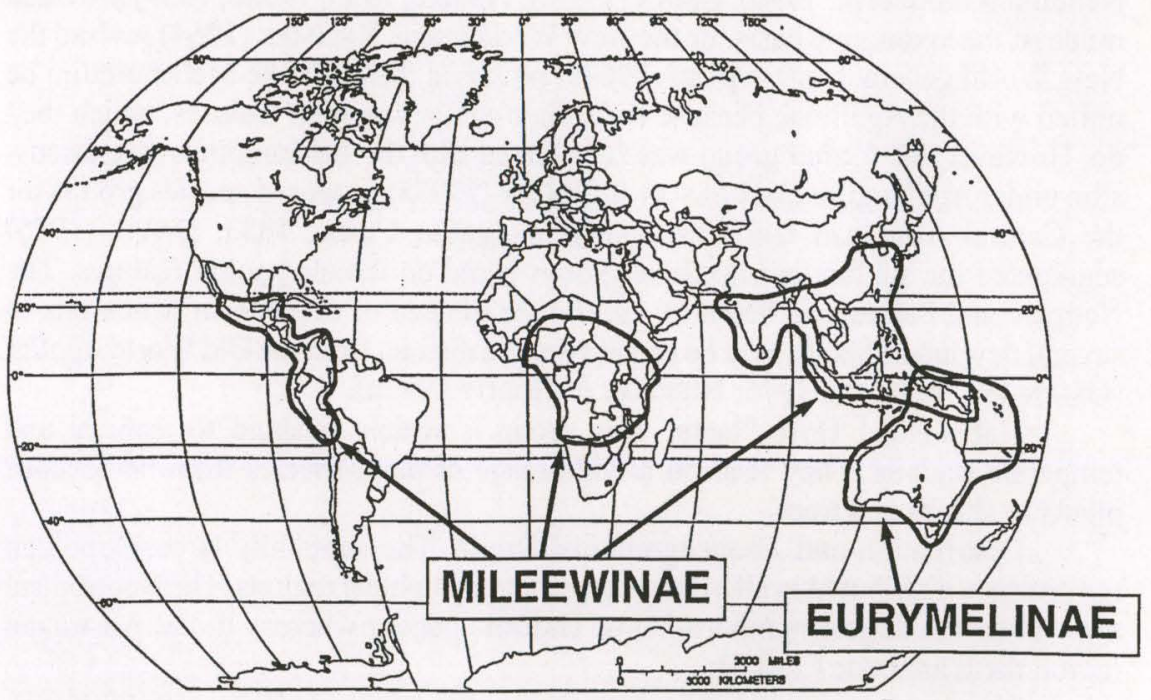

Fig. 10. Distribution of the subfamilies Mileewinae and Eurymelinae.

continuous between Eurymelini and Ipoini. EVANS (1977) rejected his proposal based on distinctive characters of wing venation and male genitalia but DAVIS (1975) found that the gap between eurymelids and other cicadellid groups was no greater than between cicadellid groups he studied. OMAN et al. (1990) recognized three tribes, Eurymelini, Ipoini, and Pogonoscopini in the subfamily.

Habitat and Host Plants. The subfamily's nearly restrictive feeding to members of the genus Eucalyptus and specialized feeding on roots and myrmecophilous association make them a unique group. 
Distribution and Zoogeographical Origin. The subfamily is restricted to the Australian region (Tab. I). Most genera are endemic to Australia where the subfamily is widespread. Some genera occur in New Guinea and New Caledonia. KNIGHT (1983a) added Tasmania and the Solomon Islands to its range (Fig. 10).

The eurymelids are not considered relicts having their origin in the Mesozoic based on fossil records from the Upper Triassic (Evans 1966). However, SHCHERBAKOV (1981) refutes the origin based on his study of wing venation and postulated that the group arose no earlier than the Cretaceous. We agree that the group arose early and it may have been part of the "Antarctic" faunal elements which later became isolated from other land masses during separation of the continents. Radiation may have been restrained by its own inimical genetic traits and by geoecological isolation.

Phylogenic Inference. Its relationship to other subfamilies is problematical.

\section{Agalliinae Kirkaldy, 1901}

Taxonomy. The agalliines are a relatively large, homogeneous group with widespread distribution. Two tribes are currently recognized, the Agalliini and Nehelini (OMAN et al. 1990). OMAN (1933b, 1934b,c, 1935, 1938b, 1939) provided much of the taxonomic basis for the New World fauna. KRAMER (1964) revised the New World genera. LINNAVUORI (1969a) proposed that the tribe Melicharellini be united with the Agallinae because they share some important features, which they do. However, the former group was later united with the Adelungiinae (see discussion under Adelungiinae). NIELSON \& GODOY (1995a) proposed species groups for the Central American fauna especially in Agallia Curtis, 1833. DAvis (1975) segregated the subfamily into three groups based on female genital features. The Neogeic and Palaearctic fauna of Agallia are in need of revision in which one to several new assemblages may be present that are distinct from the Old World Agallia (OMAN 1933b; DAVIS 1975; NiELSON \& GODOY 1995a).

Habitat and Host Plants. This group is widely adapted to tropical and temperate regions. They feed on a wide range of plant species from herbaceous plants to shrubs and trees.

Distribution and Zoogeographical Origin. The subfamily is cosmopolitan but sparsely distributed in all of the major zoogeographical regions. The Neotropical region has the largest number (14) of endemic genera whereas in the Australian region there are none (Tab. I).

Three genera are shared by more than one zoogeographical region (Tab. XI). The interzoogeographical distribution of Agallia sensu lato, may be temporary, pending the need for new studies of the genus which may exclude the group altogether from the Nearctic and Neotropical regions (Fig. 11). The widespread distribution of Austroagallia Evans, 1935 is most likely due to dispersion and by adventitious means (Fig. 11). It was introduced into Australia according to EvANS $(1966,1971,1977)$, and its presence in the Galapagos Islands (Fig. 6) may be adventitious as well (VIRAKTAMATH 1972). The origin of the genus may be Oriental where most of the known species occur. Agalliopsis Kirkaldy, 1907 is of probable Neotropical origin where radiation to the Nearctic region occurred after the continents were joined during the Miocene. 


\section{AGALLIINAE}

Number of endemic genera

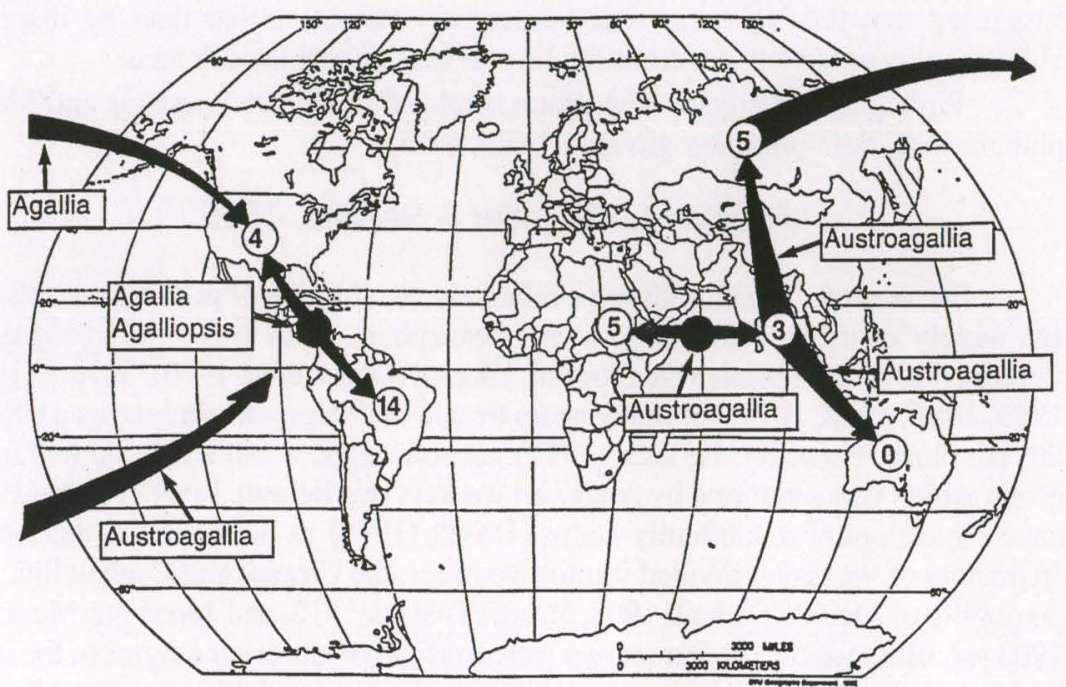

Fig. 11. Distribution of endemic genera of Agalliinae and proposed dispersal pathway of shared genera.

Table XI. Shared genera of the subfamily Agalliinae in three interzoogeographial regions.

\begin{tabular}{ll}
\hline \multicolumn{1}{c}{ Interzoogeographical Region } & \multicolumn{1}{c}{ Genus } \\
\hline Holarctic/Neotropical & Agallia \\
Palaearctic/Ethiopian/Oriental/Australian & Austroagallia \\
Nearctic/Neotropical & Agalliopsis \\
\hline
\end{tabular}

The origin of the Agalliinae is believed to be in the late Jurassic/early Cretaceous period with the center in Gondwanaland. It is possible that the group had "Antarctic" affiliation (exclusive of Australia) given the presence of endemic genera on islands in the Indian and southeastern Pacific oceans. The preponderance of genera in the Neotropical region led EVANS (1971b) to propose that region as the origin of the group, and from there they radiated to Asia via North America. LINNAVOURI \& DELONG (1977) proposed several radiational periods of Agalliinae in South America which led to the subsequent evolution of the subfamily Evansiolinae and the agalliine genera Stenagallia Evans, 1957 and Kuscheliola Evans, 1957 on Juan Ferndandez Islands off the west coast of the continent. Members of Agallia on the island are considered recent immigrants. The absence of endemic forms in Australia is believed to be associated with isolation of the continent from Asia at the time the group had radiated into the Asian area (EvANs 1971b).

We propose that elements of Agalliinae were vicariants, particularly those in the Ethiopian and Oriental regions either by ecological isolation or by movement 
of the Indian subcontinent. The Holarctic fauna share closer affiliation with each other than they do with the Ethiopian or Oriental faunae and the Neotropical fauna share closer affiliation with the Nearctic than with the Palaearctic elements. It is suggested that the Holarctic fauna arose as vicariants rather than by dispersal although this obviously occurred for several species within each area.

Phylogenic Inference. The group is related to the Adelungiinae and Megophthalminae, both primitive groups (DAVIS 1975).

\section{Ulopinae Le Peletier \& Serville, 1825}

Taxonomy. The ulopids are a relatively small group of primitive relicts that are widely distributed in the southern hemisphere. Four tribes are recognized, Cephalelini, Monteithiini, Myerslopiini, Ulopini (OMAN et al. 1990). Evans (1946, $1953,1966,1968,1971)$ for many years treated the Megophthalminae as a tribe of the Ulopinae. However, he later (1977) acknowledged a subfamily status for the group which was supported by nearly all workers (see below). LINNAVUORI (1972) gave Myerslopiini a subfamily status. DAvIS (1975) in his work on the female characters of the group divided it into two tribes, the Ulopini and Cephalelini. The taxonomy of Moonia Distant, 1908, Sitades Distant, 1912, and Mesargus Melichar, 1903 is problematical, the former two were considered junior synomyms of the latter by VILBASTE (1975). LINNAVUORI (1972b) had considered Moonia as a subgenus of Coloborrhis Germar, 1836. The subfamily is under revision by HAMILTON (personal communication).

Habitat and Host Plants. These leafhoppers are cryptic, living in soil and leaf litter where they are presumed to feed on roots of shrubs and trees.

Distribution and Zoogeographical Origin. The ulopids are widespread but somewhat restricted to areas of the Southern Hemisphere (Fig. 12). The Cephalelini are restricted to South Africa, New Zealand and Australia. The range of Myerslopiini is Australian (Australia, New Zealand), Ethiopian (Madagascar) and Neotropical (Chile). The Monteithiini are known only from the high mountains of New Guinea and the Ulopini are widespread in the Old World (Evans 1968, 1971b; LINNAVUORI 1972a; VAN STALLE 1982, 1983).

Most of the endemic genera occur in the Ethiopian (8) and Oriental (6) regions with only a few in the Australian and Palearctic regions (Tab. I). Many are monobasic, particularly in Australia and Africa.

Shared genera among five interzoogeographical regions are given in table XII. Dispersal routes and vicariant pathways of these genera are shown in figure 13. Myerslopia Evans, 1947, until recently, was considered to be endemic to New Zealand where island radiation was extensive (KNIGHT 1973). However, a recent description of a new species in this genus confirms Evans's (1961a [1962]) report of the tribe Myerslopiini in Chile (NIELSON 1996). The range of Megulopa Lindberg, 1925 is narrow, overlapping the north eastern Ethiopian (Sudanian) and western Palearctic (Mediterrean) regions (LINNAVUORI 1972b). Ulopa Fallén, 1814 has been reported from the Mediterranean and European subregions in the Palaearctic region, southern Africa and Madagascar in the Ethiopian region and central India in the 


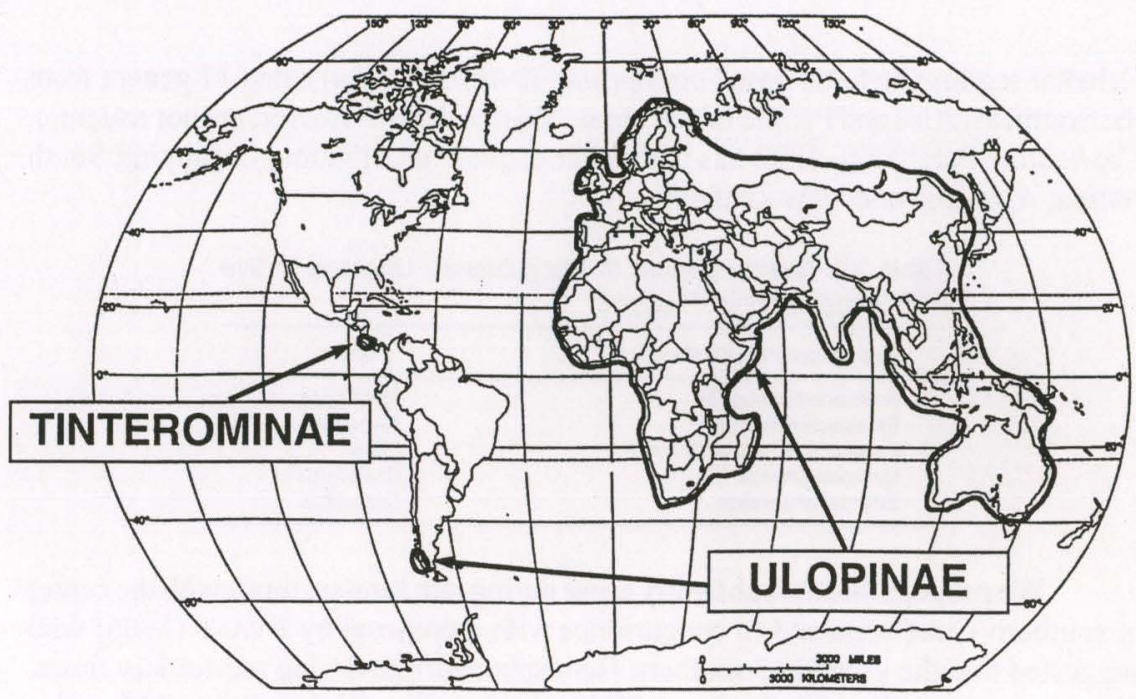

Fig. 12. Distribution of the subfamilies Tinterominae and Ulopinae.

\section{ULOPINAE}

Number of endemic genera

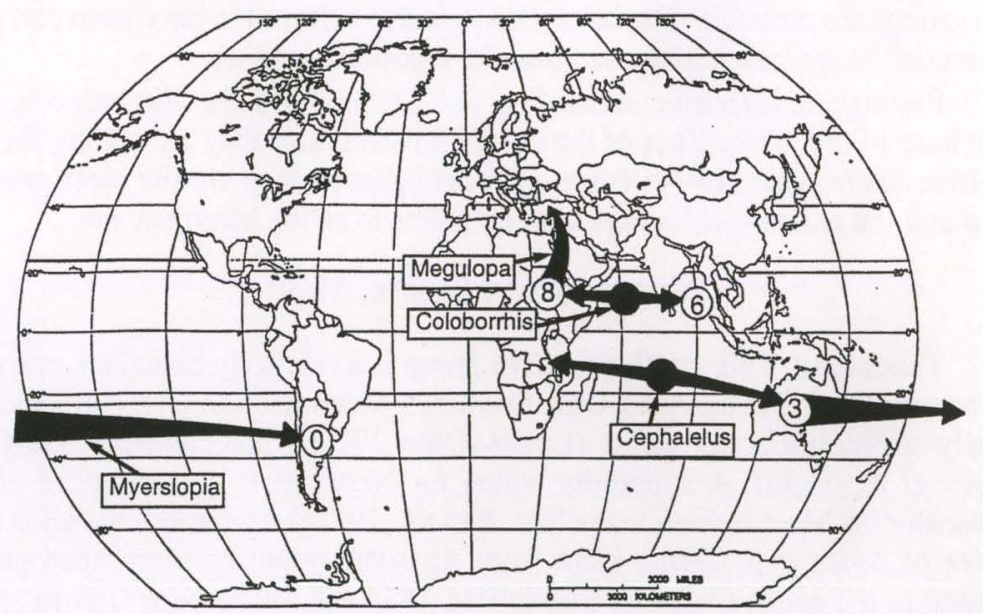

Fig. 13. Distribution of endemic genera of Ulopinae and proposed dispersal pathway of shared genera.

Oriental region (OMAN et al. 1990). However, LINNAVUORI (1972b) cited only the Palaearctic region as the range of the genus and provisionally placed one species from Africa in the group. It is for this reason that the genus is not displayed on the map (Fig. 13). Coloborrhis has the widest distribution ranging from Africa south of the Sahara to Madagascar in the Ethiopian region and India and Sri Lanka in the 
Oriental region, the latter based on Moonia. KNIGHT (1983a) listed 17 genera from the Southeast Asia and Pacific Island areas. Most of them, however, are not endemic. Cephalelus Percheron, 1832 has a peculiar disjunct distribution, occupying South Africa, Australia and New Zealand.

Table XII. Shared genera in the subfamily Ulopinae in five interzoogeographical regions.

\begin{tabular}{ll}
\hline Interzoogeographical Region & Genus \\
\hline Australian/Neotropical & Myerslopia \\
Palaearctic/Ethiopian & Megulopa \\
Palaearctic/Ethiopian/Oriental & Ulopa \\
Ethiopian/Oriental & Coloborrhis \\
Ethiopian/Australian & Cephalelus \\
\hline
\end{tabular}

We propose that the subfamily arose during late Jurassic times with the center in southern Gondwanaland in concurrence with a proposal by EvaNs (1966) who suggested that the group had southern Hemisphere origin during pre-tertiary times. The apparent peculiar distribution exhibited by the tribes Cephalelini and Myerslopiini is supported by the belief that the southern parts of South Africa and South America, New Zealand and Australia were once a large "Antarctic" land mass before the commencement of continental drift. The disjunct range of Cephalelus (South Africa, New Zealand, Australia), Myerslopia (Australia, New Zealand, Chile) and Coloborrhis (Ethiopian and Oriental) supports the "Antarctic" relationship. All of these groups are probable vicariants. Ulopa is also believed to have been part of the "Antarctic" fauna which dispersed into the Palaearctic region.

Phylogenic Inference. According to EVANS (1947), the ulopines originated at the base of one of the lines of the cicadellid stem, thus they are among the most primitive leafhoppers. LINNAVUORI (1972a) believed they are the most primitive group and the extant species appear to be relicts from the Mesozoic era.

\section{Macropsinae Evans, 1935}

Taxonomy. This small, primitive group is a relatively abundant, cosmopolitan assemblage of leafhoppers. Only two tribes, Macropsini and Neopsini, the latter initially given subfamily status (LINNAVUORI 1978c), are presently recognized (OMAN et al. 1990). A subfamily status for Neopsini is problematical and its relationship to Macropsinae is unclear. EvANS (1971a) suggested that all but two species of Macropsis Lewis, 1834 from Australia might be more appropriately assigned to the genus Oncopsis Burmeister, 1838 and all the New Guinea species belong to the genus Macropsis. HAMILTON's (1980b) world wide revision provided new genera for these groups but failed to explain the bizarre disjunct distribution of the genera Ruandopsis Linnavuori, 1978 and Hephathus Ribaut, 1952 (Tab. XII). Futhermore, the two species of Ruandopsis described by LINNAVUORI (1978b) from central Africa that were generically affiliated with four species described by EVANS (197lb) from New Guinea and northern Australia suggest that HAMILTON's taxonomy may be flawed. He evidently had not examined types of the Linnavouri's species which may prove to be quite distinct from Evan's group of species. 
Only two species, Oncopsis cognata Spinola, 1852 and $O$. dorsalis Blanchard, 1852 , the types of which may no longer be extant, have been reported from South America (Chile). HAMILTON (1980b), on the basis of the original descriptions, placed them in the Idiocerinae as probable members of the genus Chileanoscopus Freytag \& Morrison, 1969, a genus described by FREYTAG \& MORRISON (1969).

Habitat and Host Plants. This group is arboreal on trees and shrubs throughout its range on which a number of species are host specific. Some species feed on Nothofagus Blume, 1850 (Cupuliferae) in New Zealand (Evans 1966).

Distribution and Zoogeographical Origin. The Macropsinae are cosmopolitan and have endemic genera in all of the zoogeographical regions, although their numbers are few and not particularly dominant in any region (Tab. I). EvANS (1971b) was puzzled by the nearly complete absence of the subfamily in the Neotropical region, although a possible explanation for that is given below. Although only five genera are endemic to the Australian region, nearly half of the known world faunal species occur in the Southeast Asia and Pacific Island regions (KNIGHT 1983a).

Shared genera in six intergeographical regions are shown in table XIII. The occurrence of Oncopsis in the Oriental region is a presumed single species dispersal from China (HAMILTON 1980b). The widely shared distribution of other genera appears logical, although the origin of the subfamily as proposed by EvANS (1966) suggests the southern hemisphere in general and Australia in particular. He added that the Australian fauna radiated towards India, then to Africa and the Holarctic region in the late Tertiary. Evans (197lb) later suggested that the group is of presumed pre-Tertiary origin and that the center of origin is Australia, based on two endemic Australian genera, Stenoscopus Evans, 1934 and Stenopsoides Evans, 1941.

Table XIII. Shared genera of the subfamily Macropsinae in six interzoogeographical regions.

\begin{tabular}{ll}
\hline \multicolumn{1}{c}{ Interzoogeographical Region } & \multicolumn{1}{c}{ Genus } \\
\hline Cosmopolitan except Neotropical & Macropsis \\
Holarctic & Macropsidius Ribaut, 1952 \\
Holarctic/Oriental & Oncopsis \\
Palaearctic/Australian/Oriental & Pedionis Hamilton, 1980 \\
Palaearctic/Ethiopian/Australian & Hephathus \\
Ethiopian/Australian & Ruandopsis \\
\hline
\end{tabular}

LINNAVUORI (1978b) proposed that the group originated in the Oriental region and was widely distributed at the time when a land bridge connected Australia and Southeast Asia. Radiation into the Holarctic and Ethiopian regions were fairly recent, particularly in certain areas of Africa where all species are derived from Macropsis stock. The inhibition of the group's dispersal into the Neotropical region and tropical Africa may be ecological particularly in view of their previous adaptation to cold climate in the Holarctic region (LINNAVUORI 1978b).

We propose that the group originated during late Jurassic/early Cretaceous times with its likely center in Gondwanaland. They are of probable Mesozoic origin as suggested by EVANS (1971b) and LiNNAVUORI (1978b). The tribe Neopsini is 
considered a relict group (LINNAVUORI 1978b). He also believed that most existing forms of macropsines evolved late and are not true relicts even though the group possess a number of important primitive characters. We propose that the elements of the more primitive groups were isolated in Australia and New Zealand, and in particular South America (Neopsini), as vicariants of the "Antarctic" fauna. Secondary radiation was possible from the Oriental region into the Australian and Palaearctic regions. At the time Macropsis and its relatives arose, South America was already isolated from Africa. The group summarily radiated into the Palaearctic region followed by secondary radiation and dispersal into the Nearctic region via the Bering strait. Absence of the tribe Macropsini in South America may be associated with the direction of the dispersal between these two continents. The majority of other leafhopper groups that originated in the Nearctic region either as endemics or by dispersal from the Palaearctic region failed to occupy the Neotropical region. The southern continent was inacessible during the later half of the Cretaceous and early tertiary periods.

Phylogenic Inference. The macropsines are apparently a primitive group arising close to the base of the cicadellid stem with affinities with the Ulopinae and Biturritidae (Evans 1947, 1948, 1971b). They also have affinities with the Megophthalminae, Agalliinae, Idiocerinae and Iassinae.

\section{Neocoelidiinae Oman, 1943}

Taxonomy. This subfamily is a relatively small group restricted to the New World. Only one tribe, the nominate form, is currently recognized. LINNAVUORI (1959b, 1965b) showed close affiliation of the group with Deltocephalinae but was undecided whether or not to treat it as a tribe of that group. KRAMER (1964d) revised the subfamily and treated 16 genera.

Habitat and Host Plants. The group inhabits savanna and forested areas where they feed on shrubs and trees. Many species are host specific.

Distribution and Zoogeographical Origin. This subfamily is restricted to the New World (Fig. 14). Twelve genera are endemic to the Neotropical region and one, Coelella DeLong, 1953, is believed to be endemic in the Nearctic region (Tab. I). Three genera, Neocoelidia Gillette \& Baker, 1895, Cocoelidia DeLong, 1953 and Neocoelidiana DeLong, 1953 infringe on the Neotropical and Nearctic overlap area (Mexico and Central America).

This rather unique group is believed to have arisen from the Neotropical region well after the African and South American continents separated, possibly during early Cretaceous. The four genera alluded to above are not known to occur in South America. Their origin in the southern Nearctic/northern Neotropical zone appears to be related to the geological history of the panamanian isthmus between middle Cretaceous and early Tertiary. It is probable, however, that they are ancestrally related to Neotropical stock.

Phylogenic Inference. The relationship of this group to other subfamilies is problematical although LINNAVUORI (1959b) considered it as a possible tribe of the subfamily Deltocephalinae. It is conceivable that the group arose from deltocepha- 
line stock. Evans (1947a) alluded to its resemblance to the Coelidiinae and Nirvaninae but its basic features do not show close relationships to either of these subfamilies.

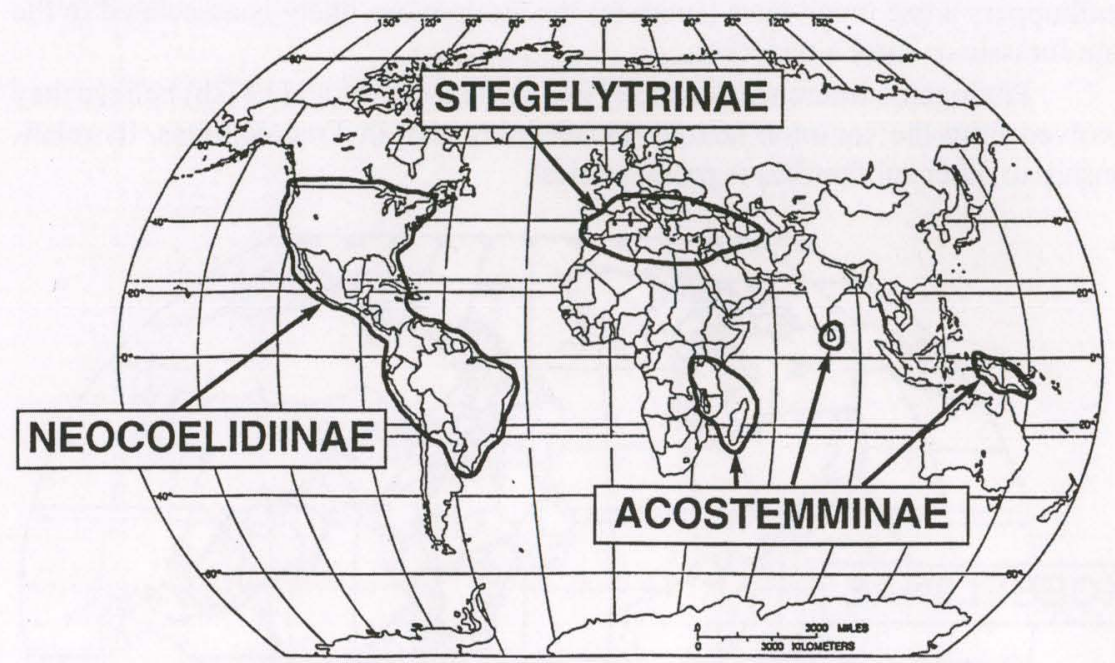

Fig. 14. Distribution of the subfamilies Neocoelidiinae, Stegelytrinae and Acostemminae.

\section{Hylicinae Distant, 1908}

Taxonomy. The hylicines are a small, unique group with some primitive features. Only one tribe, the nominate form, is recognized (OMAN et al. 1990). It formerly had family status (EvANS 1946; METCALF 1962; LINNAVUORI 1969, 1972a) but KRAMER (1964) considered the group as a subfamily and reviewed the Oriental genus Sudra Distant, 1908. LINNAVUORI $(1969,1972 a)$ treated two Ethiopian genera.

Habitat and Host Plants. This group inhabits forest and savanna areas where they feed on shrubs and trees. Some species occur on mixed vegetation of herbaceous and grass species.

Distribution and Zoogeographical Origin. This subfamily is restricted to the Ethiopian and Oriental regions (Fig. 15). None of the genera of this group is known to occupy more than one zoogeographical region. Twelve genera are endemic to the Oriental region and two are endemic in the Ethiopian region (Tab. I). VIRAKTAMATH \& WEBB (1991) recognized 12 genera, eight in the Oriental region and four in the Ethiopian region. They are not well represented in the eastern range of the Oriental region but they do extend to Borneo and Sumatra although none are known in the Australian region (KNIGHT 1983a).

This subfamily may be of early Cretaceous origin with a possible center in Gondwanaland. Radiation was limited and ecological vicariation isolated the African genera, viz., Wolfella Spinola, 1850 from Oriental genera, viz., Traiguma 
Distant, 1908, where radiation apparently has been more successful. EVANs (1948) and LINNAVUORI (1972b) believe this group originated during Triassic times during the Mesozoic era, but in view of more recent evidence that the ancestors of leafhoppers arose much later (Jurassic) the group more likely is associated to the late Jurassic or early Cretaceous.

Phylogenic Inference. EVANS (1948) and LINNAVUORI (1972b) believe they evolved from the common jassoid (cicadelloid) stem in Triassic times. Its relationship to other subfamilies is problematical.

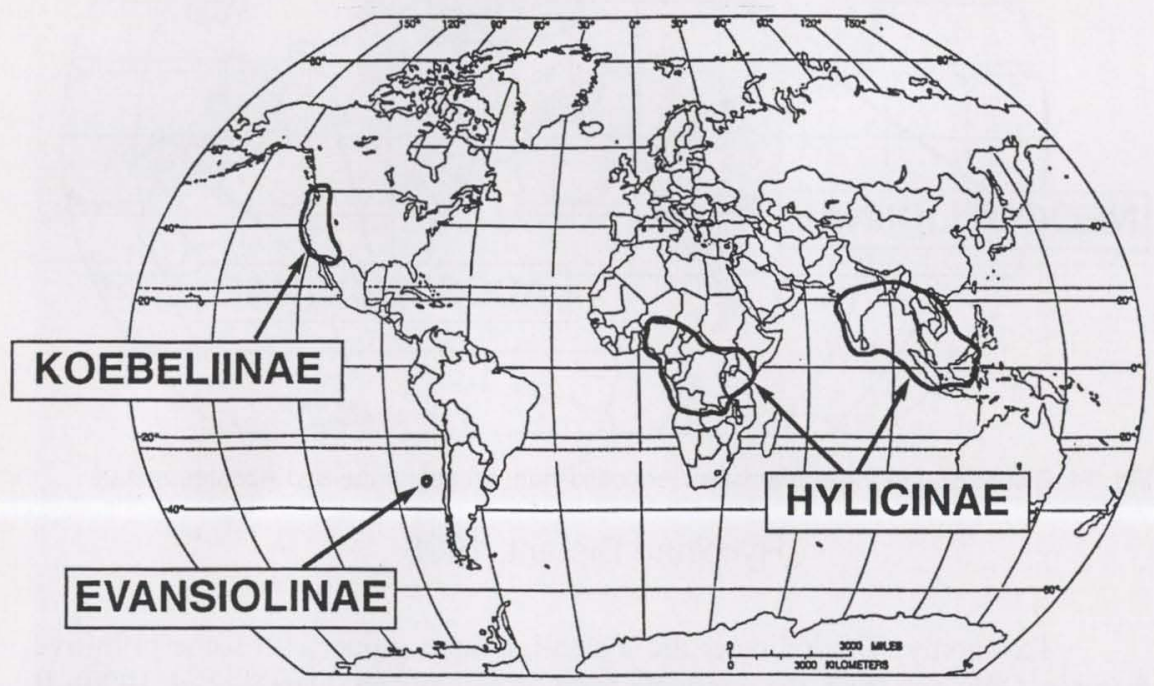

Fig. 15. Distribution of the subfamilies Evansiolinae, Koebeliinae and Hylicinae.

\section{Adelungiinae Baker, 1915}

Taxonomy. Adelungiids are a small Palaearctic group that have similarities to the Agalliinae. Three tribes are recognized, Adelungiini, Achrini and Peyerimhoffiolini (OMAN et al. 1990). DAVIS (1975) divided the group into two tribes, the Adelungiini and Achrini, the former once considered as a tribe of Agalliinae to which it has many affinities (LINNAVUORI 1969a). AL-NE'AMY \& LINNAVUORI (1982a) erected the tribe Peyerimhoffiolini. THERON (1979) described the genus Gannachrus Theron, 1979 from South Africa and placed it in this subfamily but later it was transferred to the subfamily Agalliinae by LINNAVUORI \& AL-NE'AMY (1983).

Habitat and Host Plants. These insects occupy very arid regions of northern Africa and adjacent southwestern Asia where they presumably feed on xerophytic shrubs.

Distribution and Zoogeographical Origin. This group is restricted to the Eremian subregion in the Palaearctic region (Fig. 9). Thirteen endemic genera are recognized (Tab. I). None of the genera have dispersed from its present range having 
been highly adapted to desert conditions (AL-NE'AMY \& LINNAVUORI 1982). We propose that this primitive group are relicts of late Jurassic/early Cretaceous origin.

Phylogenic Inference. This group is allied with the Agalliinae, Megophthalminae, and Evansiolinae (DAVIS 1975; LINNAVUORI \& AL-NE'AMY 1983) but its ancestral relationship to these groups is problematical.

\section{Eupelicinae Sahlberg, 1871}

Taxonomy. This rather small, relict group is widespread in the Old World with a few representatives in the Nearctic region. The group was formerly known as the subfamily Dorycephalinae until recently when use of Eupelicinae was applied in deference to LINNAVUORI's (1979a) proposal. Four tribes are recognized, the Eupelicini, Dorycephalini, Listrophorini and Paradorydiini (OMAN et al. 1990).

EVANS (1947) considered the Dorycephalini, Eupelicini and Paradorydiini as tribes of the subfamily Hecalinae. However, the Hecalinae are now considered a tribe of the Deltocephalinae. LINNAVUORI (1979a) studied the Dorycephalinae (Eupelicinae) of the Ethiopian region and proposed uniting Eupelicini and Listrophorini as one subfamily, the Eupelicinae, and elevating Paradorydiini and Dorycephalini as separate subfamilies.

The genus Dorycephalus Kouchakewitch, 1866 was considered to be Holarctic until EMELYANOV (1966a) segregated the Palearctic forms from the Nearctic ones and established Dorycara Emeljanov, 1966 as the type genus for the latter forms. OMAN (1985a) reviewed the Nearctic fauna under the subfamily Dorycephalinae and concurred with Emelyanov's taxonomic and zoogeographical proposals.

Habitat and Host Plants. This group appears to prefer temperate warm regions. Most if not all species inhabit grass species, often occupying the base of plants where presumably eggs are laid. Some species inhabit the inflorescence of desert plants.

Distribution and Zoogeographical Origin. This subfamily is present in all zoogeographical regions except Neotropical (Fig. 16). Eupelicids are restricted to the Palaearctic region, the paradorydiids are widespread in the Ethiopian, Palaearctic and Australian regions, the listrophorids are chiefly Ethiopian and the dorycephalids are Holarctic. Eleven endemic genera are presently known which are about equally distributed throughout its range except for a single genus in Australia (Tab. I). Only one genus, Paradorydium Kirkaldy, 1901, is shared by more than one zoogeographical region and it occurs in the southern parts of the Palaearctic region, South Africa, India, Australia and New Zealand (Dlabola 1961; Evans 1966; KNIGHT 1973; LINNAVUORI 1979; THERON 1982).

We believe this group had late Jurassic/early Cretaceous origin and that segregates of dorycephalids in the Nearctic and Palaearctic regions radiated slowly along separate lines after the continents separated. The tribe Eupelicini appears to have remained at its place of origin in the Palaearctic region with little evidence of radiation or dispersal. EVANS (1966) presumed that all the members of the tribe Paradorydiini are pre-tertiary relicts. This group appears to have Gondwanaland affiliation with its widespread distribution in Africa, India, Australia and New 
Zealand as part of the "Antarctic" fauna. The listrophorids retained their origin in Africa as part of the Gondwanaland fauna and appear to have radiated very slowly along a separate line.

Phylogenic Inference. EvANS (1947a) believed that the group may be a derivation of the Ulopinae, parallel with the Ledrinae. LINNAVUORI (1979a) shared OMAN's (1949) proposed relationship of Eupelicinae with the Ledrinae, the former being a derivative of the latter.

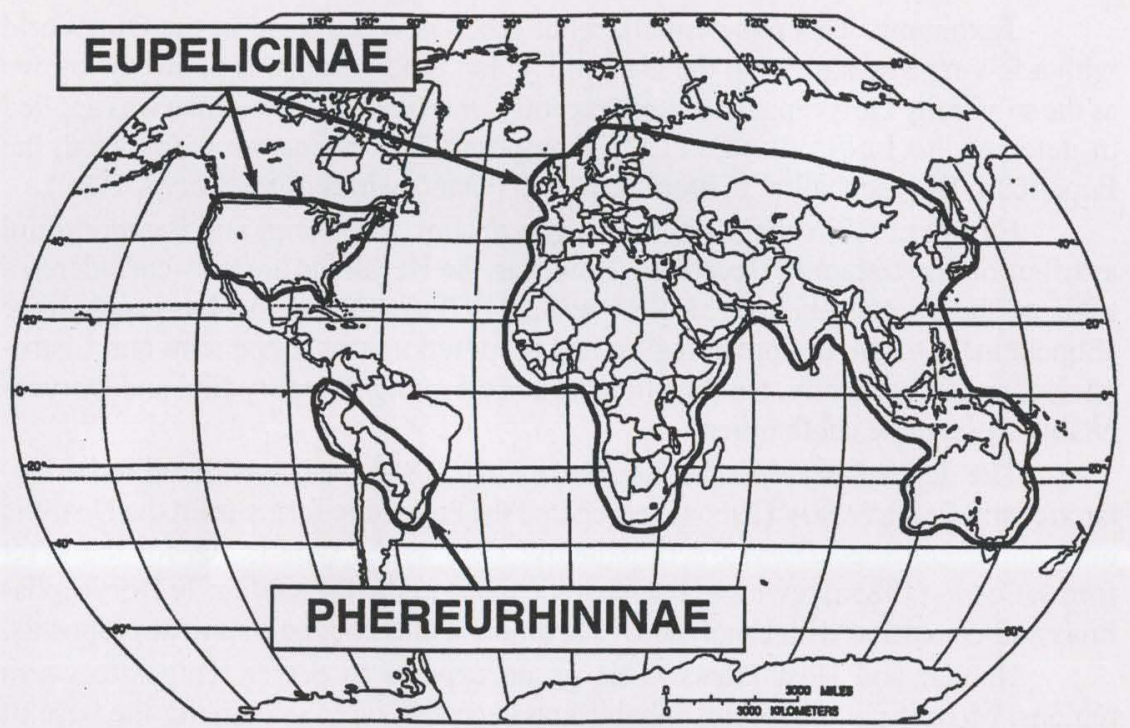

Fig. 16. Distribution of the subfamilies Phereurhininae and Eupelicinae.

\section{Neobalinae Linnavuori, 1959}

Taxonomy. The neobalines are a small group that are not well understood taxonomically and are chiefly restricted to the Neotropical region. The group consists of segregates formerly affiliated with Deltocephalinae and Idiocerinae (LINNAVUORI 1959b). FreYTAG (1988) studied the genus Calliscarta Stål, 1869, adding new species and range of the group. Only one tribe, the nominate form is recognized (OMAN et al. 1990).

Habitat and Host Plants. Neobalines are rare in known habitats and are presumably shrub and tree feeders. They are found in savanna locales in Mexico to tropical forests in Brazil.

Distribution and Zoogeographical Origin. Twelve genera are known thus far and all are endemic to the Neotropical region (Tab. I). Recently, the genus Calliscarta was reported from Mexico (FREYTAG 1988) and the senior writer has collected specimens from northern part of the country, thus its neogeic occupation is marginal in the Nearctic region (Fig. 8). The subfamily appears to have had its origin during 
the Cretaceous well after South America separated from Africa. Dispersion into southern Nearctic region was likely well after stabilization of the Panamanian Isthmus during the Miocene epoch.

Phylogenic Inference. LINNAVUORI (1959b) pointed out affinities of the group with the Cicadellinae, Coelidiinae and Deltocephalinae, indicating that its phylogenetic relationships are problematical.

\section{Paraboloponinae Ishihara, 1953}

Taxonomy. The Paraboloponinae are a very small group with widespread distribution in the Old World (WEBB 1981b). Only one tribe, the nominate form, is recognized (OMAN et al. 1990). LINNAVUORI (1960) treated the group as a tribe of the Deltocephalinae but later he (1978d) referred it back to the nominate subfamily. WEBB (1981b) studied a greater portion of the Old World fauna, adding four new genera.

Habitat and Host Plants. These leafhoppers are arboreal on shrubs and trees in the tropical zones.

Distribution and Zoogeographical Origin. This group is broadly distributed in the Old World (Fig. 3). Seven endemic genera are known and all are nearly equally divided among the four zoogeographical regions (Tab. I). Three genera are interzoogeographical, the Parabolopona Matsumura, 1912 in the Palaearctic/Oriental regions, Parohinka Webb, 1981 in the Oriental/Australian regions and Dryadomorpha Kirkaldy, 1906 in the Palaearctic/Ethiopian/Australian regions. They are widespread in the Southeast Asia/Pacific area, having reached the Cook Island (WEBB 1981b; KNIGHT 1983a).

We propose that these leafhoppers had their origin in southern Asia with the center in the Oriental region. Elements of the group are believed to be ecological vicariants in the Ethiopian and Oriental regions with dominant radiational dispersion in the Australian region. LiNNAVUORI (1978d) proposed that they are of Tertiary origin but in view of their affiliation in the Ethiopian region we believe they arose earlier in late Cretaceous.

Phylogenic Inference. The group has some affinities to the Drabescini (Selenocephalinae) and are believed to be derived from that stock.

\section{Aphrodinae Haupt, 1927}

Taxonomy. This small but widely distributed subfamily, previously known as Acocephalinae and Acucephalinae, has two recognized tribes, the Aphrodini and Paraphrodini (OMAN et al. 1990). Earlier, Evans (1947) included the Errhomenini (treated as Errhomenellini), Evacanthini and Signoretini as tribes of this group. The first two are currently treated in the Cicadellinae and the last has subfamily rank (LINNAVUORI 1979a). LINNAVUORI (1979a) established the Paraphrodini for the Ethiopian genera. Kosmiopelix Kirkaldy, 1906, included in the tribe Aphrodini by Evans (1966), is a synonym of Chiasmus Mulsant \& Rey, 1855 which is a member of the tribe Chiasmusini of the Deltocephalinae (OMAN et al. 1990). However, LINNAVUORI (1979a) had previously placed that group in the tribe Doraturini of the Deltocephalinae. 
Habitat and Host Plants. These species inhabit low vegetational profiles, feeding on a wide variety of herbaceous plant species and are presumed generalists in their Holarctic range.

Distribution and Zoogeographical Origin. These leafhoppers are thinly but widespread in all regions except the Neotropical region and Australia proper (Fig. 17). Only five endemic genera are known, all in the Old World (Tab. I). Only one genus, Aphrodes Curtis, 1829, is Holarctic. The only other genus shared between zoogeographical regions is Stroggylocephalus Flor, 1861 which occurs in the Holarctic and Oriental regions. The subfamily is poorly represented in the Southeast Asia and Pacific areas (KNIGHT 1983a). The African fauna is extremely limited.

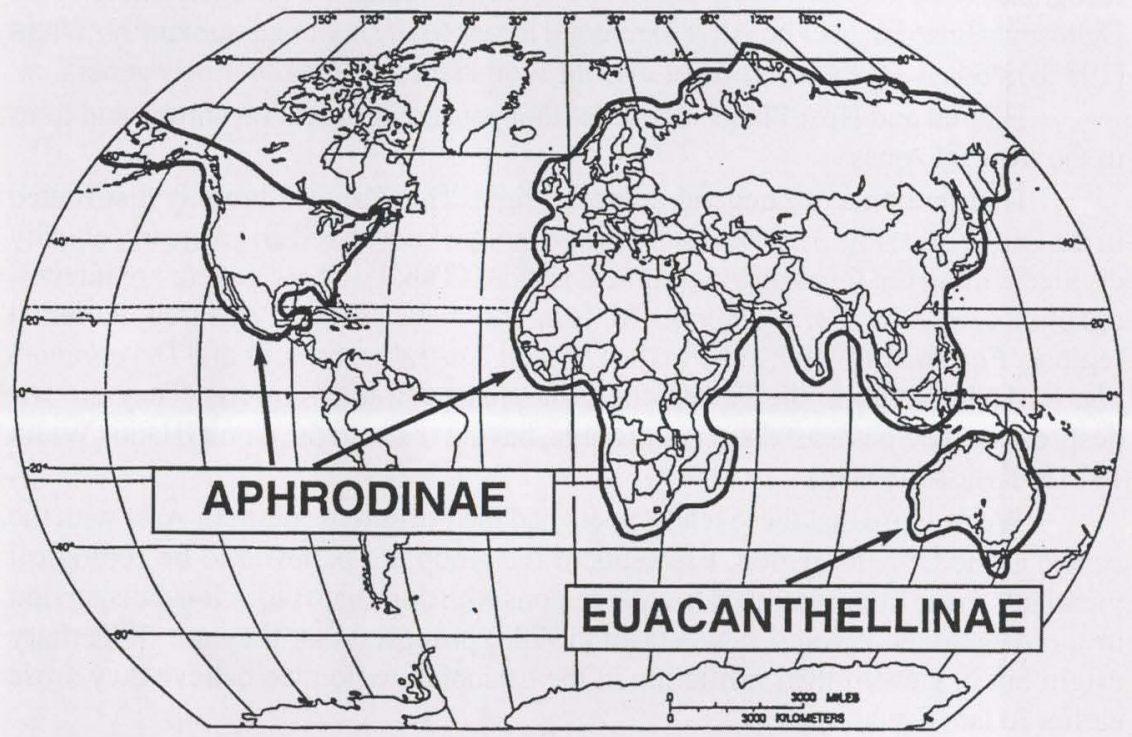

Fig. 17. Distribution of the subfamilies Aphrodinae and Euacanthellinae.

We propose this subfamily possibly arose during the middle Cretaceous after continental drift was well underway. Aphrodes appears to have originated in the Palaearctic region where it dispersed into the Nearctic region via the Bering land bridge and also possibly by adventitious means. According to LINNAVUORI (1979a), the African fauna of this group, which is extremely limited, arose from the Palaearctic region during southward radiation of Aphrodes when the climate in Africa was cooler and more humid. The two species of Aphrodes in Africa are known only from females which may prove to be elements of an undescribed genus of the tribe Paraphrodini when males become known, thus the genus may not be present in the Ethiopian region at all. Stroggylocephalus is believed to have been introduced in the Nearctic region from its apparent origin in the Palaearctic region.

Phylogenic Inference. The relationship of this group to other subfamilies is problematical. 


\section{Acostemminae Evans, 1972}

Taxonomy. The Acostemminae are a small, Old World group that are primarily Ethiopian. Only one tribe, the nominate form, is currently recognized (OMAN et al. 1990). EvANS (1972) established the subfamily and added the genus Telopetulcus Evans, 1972, described from a single species from New Guinea. In the same paper, he elevated the tribe Krisnini to subfamily status and included 4 genera which have since been transferred to Acostemminae. The Krisninae were later given tribal status under the Iassinae. The Ethiopian fauna was treated in the subfamily Acroponinae (LINNAVUORI \& QUARTAU 1975) which was later suppressed as a junior synonym of Acostemminae (LINNAVUORI \& AL-NE'AMY 1983).

Habitat and Host Plants. The species are tropical, presumably feeding on shrubs and trees.

Distribution and Zoogeographical Origin. This group is known only in the Old World (Fig. 14). Seven endemic genera are recognized, six in the Ethiopian region and one in the Australian region (not Australia proper) (Tab. I). The record of Telopetulcus in the Oriental region (New Guinea) cited by OMAN et al. (1990) is actually in the Australian region (KNIGHT 1983a). The widely disjunctive distribution between Telopetulcus in New Guinea and its Ethiopian relatives raises some question on the validity of their taxonomic relationships.

This rare and unique group may have Cretaceous origin in association with Selenocephalinae and Penthimiinae. LINNAVUORI \& QUARTAU (1975) and LINNAVUORI \& AL-NE'AMY (1983) believe the group originated in the Malagasian subregion and radiated into Africa.

Phylogenic Inference. LINNAVUORI \& QUARTAU (1983) believe the group is a derivative of the same stock as the Selenocephalinae, Drabescinae and Penthiiminae.

\section{Megophthalminae Kirkaldy, 1906}

Taxonomy. This small, flightless, relict group is found in the Palaearctic, Ethiopian and Nearctic regions. Only one tribe, Megophthalmini, is currently recognized (OMAN et al. 1990). The subfamily was formerly known as Paropiinae until the type genus, Paropia Germar, 1833, was declared a junior synonym of Megophthalmus Curtis, 1833. Evans (1947a, 1951a, 1957a) treated the group as a tribe of Ulopinae, and pointed out several characters shared by Ulopini and Megophthalmini in defense of those proposed by OMAN (1949) and WAGNER (1951). LINNAVUORI's (1972a) treatment of the Ethiopian fauna recognised Megophthalminae and Ulopinae as distinct subfamilies. DAVIS (1975) studied the group's female genital features and concluded that it was comprised of a single tribe in the subfamily.

OMAN (1941) treated the Nearctic elements of the subfamily in which he segregated them from the Palaearctic genus, Paropulopa Fieber, 1866, and described two new genera (Brenda Oman, 1941, Tiaja Oman, 1941) for the seven known Nearctic species. This action is one of many changes by systematists that not only

Revta bras. Zool. 17 (1): 81 - 156, 2000 
clarifies the taxonomy of holarctic groups (and others as well) but also reveal clues to their endemicity and zoogeographical relationships. New species in the Nearctic region were added by OMAN (1972); SAWBRIDGE (1975b, 1977) and GILL \& OMAN (1982).

Habitat and Host Plants. These leafhoppers appear to be confined to soil debris, leaf litter and root inhabiting habitats. OMAN (1972) studied Tiaja in Oregon where he found species feeding on Arctostaphylos root region (rhizosphere) and was able to rear nymphs to adult stage on excised stems and leaf petioles of Arctostaphylos. Similar litter and root feeding habitats were reported for the Palaearctic species (CURTIS 1833; EDWARDS 1894).

Distribution and Zoogeographical Origin. This relict group is known only in the Ethiopian and Holarctic regions (Fig. 18). Seven endemic genera are presently known in the group (Tab. I). Although few in number the genera are nearly equally distributed among the three known zoogeographical regions. There are no known interzoogeographical genera. In the Nearctic region, OMAN (1972) postulated that the North American elements were at earlier times more widely distributed than the present range from Mexico to Oregon. SAWBRIDGE (1975) and Gill \& OMAN (1982) extended the range to British Columbia and the California Channel Islands.

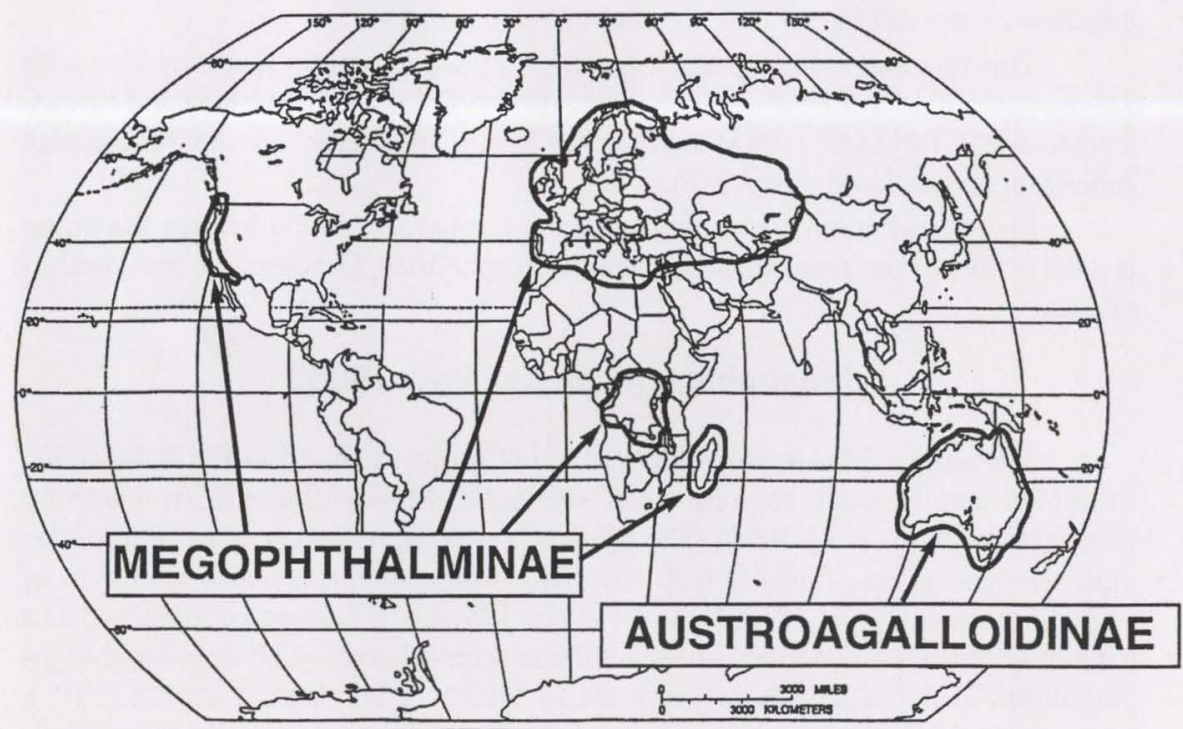

Fig. 18. Distribution of the subfamilies Megophthalminae and Austroagalloidinae.

LINNAVUORI (1972a) presented the range of the Ethiopian fauna for two known genera, Odomas Jacobi, 1912 and Dananea Linnavuori, 1972, the former more common and restricted to isolated mountain areas and adjacent parts of Congo where effective radiation occurred. VAN STALLE (1983a,b) added additional taxa from East Africa (Zaire). The Palaearctic group are restricted to the European area. 
We believe this primitive group had late Jurassic/early Cretaceous origin and the elements in North America are vicariants that radiated in recent times from a former broadly distributed fauna. Each endemic group appeared to have evolved along separate lines, viz., the Megophthalmus in Europe, Brenda and Tiaja in North America and Odomas and Dananea in Africa.

Phylogenic Inference. The relationship of this group to other subfamilies of leafhoppers is obscure (OMAN 1972). OMAN (1949) and LINNAVUORI (1971) have associated the group with the Agalliinae but it is uncertain how or if they are derived from the Ulopinae. Evans (1947) believed they are related to the latter group.

\section{Xestocephalinae Baker, 1915}

Taxonomy. This small, but widespread subfamily is dominated by the cosmopolitan genus, Xestocephalus Van Duzee, 1892. Two tribes, Xestocephalini and Portanini, are recognized (OMAN et al. 1990). The group was previously allied with the Deltocephalinae by OMAN (1943), EVANS (1949a, 1951a) and LINNAVUORI (1956a). Later, OMAN (1949) recognized it as a separate subfamily. LINNAVUORI (1979b) concurred, pointing out, however, that certain similarities between the two groups were quite artificial.

The genus Portanus Ball, 1932, which formed the basis for the Neotropical tribe Portanini, was earlier placed in the tribe Platymetopiini by EvaNS (1947). OMAN (1949a) transferred it to Xestocephalinae, then later LINNAVUORI (1959a) erected a new tribe, Portanini, for the group in the subfamily. DAVIS (1975a) reviewed the taxonomy in his reclassification of the group based on female characters. He removed the genus Portanus from the group, citing specific characters that separate it from Xestocephalus. However, he did not assign the genus to a higher category.

Habitat and Host Plants. Many species occur in a wide variety of habitats. Some species are believed to be myrmecophilous whereas others feed primarily at the base of the plants where they are difficult to collect by sweeping.

Distribution and Zoogeographical Origin. This group is nearly cosmopolitan yet is virtually absent from most of the Palaearctic region. Six endemic genera are known and no more than two occupy each of four zoogeographical regions (Tab. I). There are no known endemic groups in the Northern Hemisphere. The cosmopolitan genus Xestocephalus has radiated into all of the zoogeographical regions but is not present in Europe and most of Asia. It occupies much of the Southeast Asia and Pacific Islands where nearly a third of the world faunal species occur (KNIGHT 1983a). Speciation has proliferated in Africa (LinNAVUORI 1979b), Australia (EVANS 1966, 1973a), Neotropical region (LinNAVUORI 1959b) and North and Central America (CWIKLA 1985).

LINNAVUORI (1978b) believed the group arose during the Tertiary period but we believe it had its origin much earlier during late Jurassic/early Cretaceous times in Gondwanaland to account for its near cosmopolitan distribution. The center of origin of the near cosmopolitan genus, Xestocephalus, is problematical but it appears that elements of the group in the Neotropical, Ethiopian, Oriental and Australia 
proper are vicariants. Radiation into the Nearctic region doubtlessly occurred from southern elements in the Neotropical region. The tribe Portanini originated in the Neotropical region.

Phylogenic Inference. LiNNAVUORI (1978b) believed the group arose from the Aphrodinae stock. Its relationship to other subfamilies is problematical.

\section{Mileewinae Evans, 1947}

Taxonomy. This small group is treated as a subfamily following studies by LINNAVUORI \& DELONG (1977) and LINNAVUORI (1979b) on the Neotropical and Ethiopian fauna, and YouNG's (1986) suggestion that the group may merit a subfamily ranking. It was treated as a tribe of the Typhlocybinae by YouNG (1965) and as a tribe of the Cicadellinae by OMAN et al. (1990). The spelling of the subfamily name was corrected from Mileewaninae to Mileewinae by Dr. L. L. Deitz in a paper published posthumously by him for Young (1993). The genus Archeguina Young, 1993 from New Guinea, provisionally placed in the tribe Mileewini by YouNG (1993), belongs to an unnamed tribe as it is neither closely allied to Cicadellini nor to Mileewini (sensu lato) in the Old World. Only one tribe, Mileewini, is presently recognized.

Habitat and Host Plants. Many forms are found in moist habitats in understory of shrubs and small trees in montane tropical and subtropical forest regions (LINNAVUORI 1979b; NIELSON \& GODOY 1995).

Distribution and Zoogeographical Origin. This group is limited to pantropical areas (Fig. 10). Only five (?) endemic genera are presently known and these are nearly equally distributed within the Ethiopian, Oriental and Neotropical regions (Tab. I). They are completely absent in Australia although one species has been reported from New Guinea (Evans 1966). Ujna Distant, 1908 has been reported from the Oriental region and in the Malagasian subregion which is part of the Ethiopian region. The genus Mileewa Distant, 1908, which occupies more than one zoogeographical region, is especially rich in the Ethiopian and Oriental regions (LINNAVUORI 1979b). Numerous species of the genus Amahuaka Melichar, 1926 have been described from the Neotropical region, from Peru north into Mexico (YoUNG 1965; LiNNAVUORI \& DELONG 1977; NiELSON \& GodOY 1995).

We postulate that the group originated during the late Jurassic/early Cretaceous with its center in Gondwanaland. The Ethiopian and Neotropical elements are vicariants, each lineage having radiated separately within its respective geographical realm. LINNAVUORI \& DELONG (1977b), however, postulated that the Neotropical lineage, Amahuaka, was introduced from Africa by adventitious means by a derivative of the Mileewa stock. This of course would have taken place post Columbian time which is clearly not plausible in view of the extensive radiation that has already occurred during the Miocene in Middle America. The Oriental and Ethiopian fauna of Mileewa and Ujna are possibly ecological vicariants from an original widespread population, the Oriental elements of Mileewa radiated into eastern Palaearctic region. There is a possibility that either or both genera were carried into the Oriental region via drift of the Indian subcontinent. 
Phylogenic Inference. The phylogenetic relationships of this group is highly problematical given its proposed affiliation with Typhlocybinae or Cicadellinae.

\section{Mukariinae Distant, 1908}

Taxonomy. This very small group and former tribe of Nirvaninae achieved subfamily status after LINNAVUORI (1979b) compared major features of the African and Oriental fauna with typical members of Nirvaninae and Penthimiinae, its closest relatives. Only one tribe, Mukariini, is recognized (OMAN et al.1990).

Habitat and Host Plants. These rather rarely collected leafhoppers are believed to be shrub and tree feeders in tropical regions. Several forms of this group are believed to live under bark of trees and sometimes exhibit thigmotropic behaviour (LINNAVUORI 1979b). Some evidence suggest that females of African species are brachypterous which greatly limited dispersal and speciation in their present range.

Distribution and Zoogeographical Origin. The range of this group is restricted to the Ethiopian and Oriental regions with infringement into the Australian and Palaearctic regions (Fig. 19). Three endemic genera are presently known, two in the Guinean subregion of Africa and one in the Oriental region (Tab. I). One genus, Mukaria Distant, 1908, of probably Oriental origin is shared marginally by the Australian (New Guinea) and Palaearctic (Japan) regions. EvANs' (1972a) record in New Guinea is considered Australian rather than Oriental but of probable Oriental origin.

The origin of the subfamily may be in late Cretaceous resulting in present day survival in two isolated areas of Africa (LINNAVUORI 1979b), and to account for its disjunct distribution between West Africa and the Oriental region that developed when populations were ecologically vicariated.

Phylogenic Inference. LINNAVUORI (1979b) postulated that mukariines are an early derivative of the Penthimiinae stock. Oriental members have retained many of the Penthimiine-like characters while the African species have become flattened as an adaptation for living under bark of trees.

\section{Nioniinae Oman, 1943}

Taxonomy. This small subfamily is composed of two tribes, Nioniini and Magnentiini (OMAN et al. 1990). OMAN (1943) erected the subfamily after having previously considered the group as a member of the Tartessinae. The group was formerly assigned as a tribe in the Macropsinae by EVANS (1947). Later, EvANS (1971a) concurred with Oman's establishment of the subfamily for Nionia Ball, 1915 but believed the genus Magnentius Singh-Pruthi, 1930 belonged in the Penthimiinae. LINNAVUORI (1978a) disputed placement of the genus in Penthimiinae and established the tribe Magnentiini for it and placed the group in Nioniinae.

Habitat and Host Plants. Numerous specimens of adults and nymphs were collected by the senior author in mountainous regions on woody shrubs in Costa Rica. They are presumably shrub feeders in the Old World. 


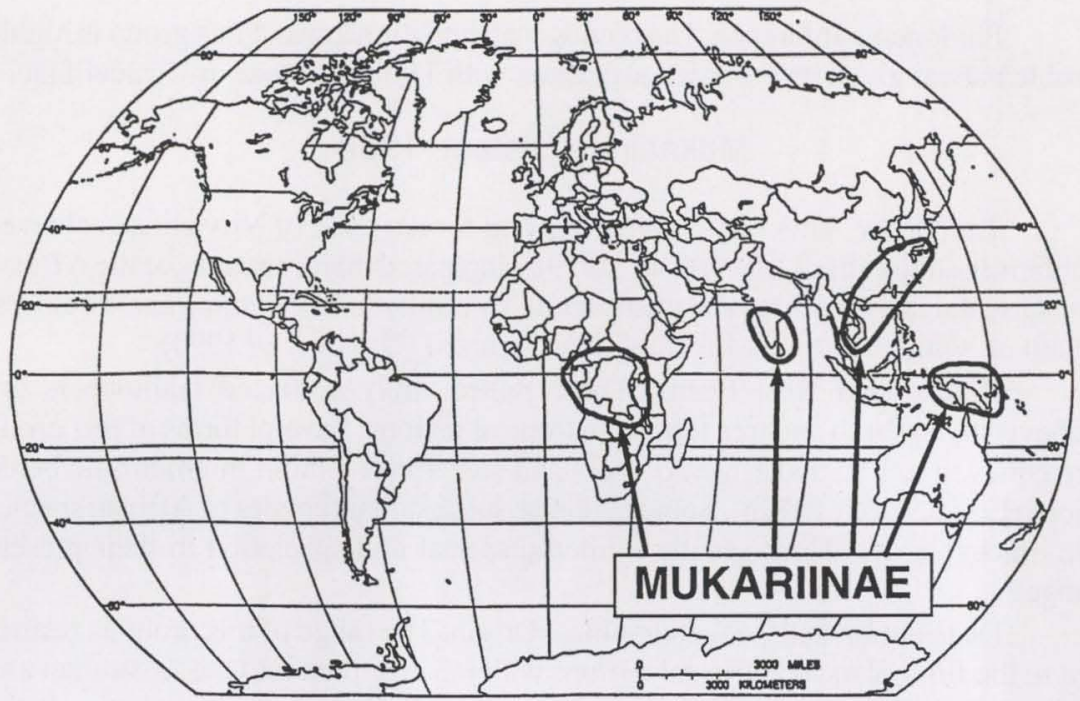

Fig. 19. Distribution of the subfamily Mukariinae.

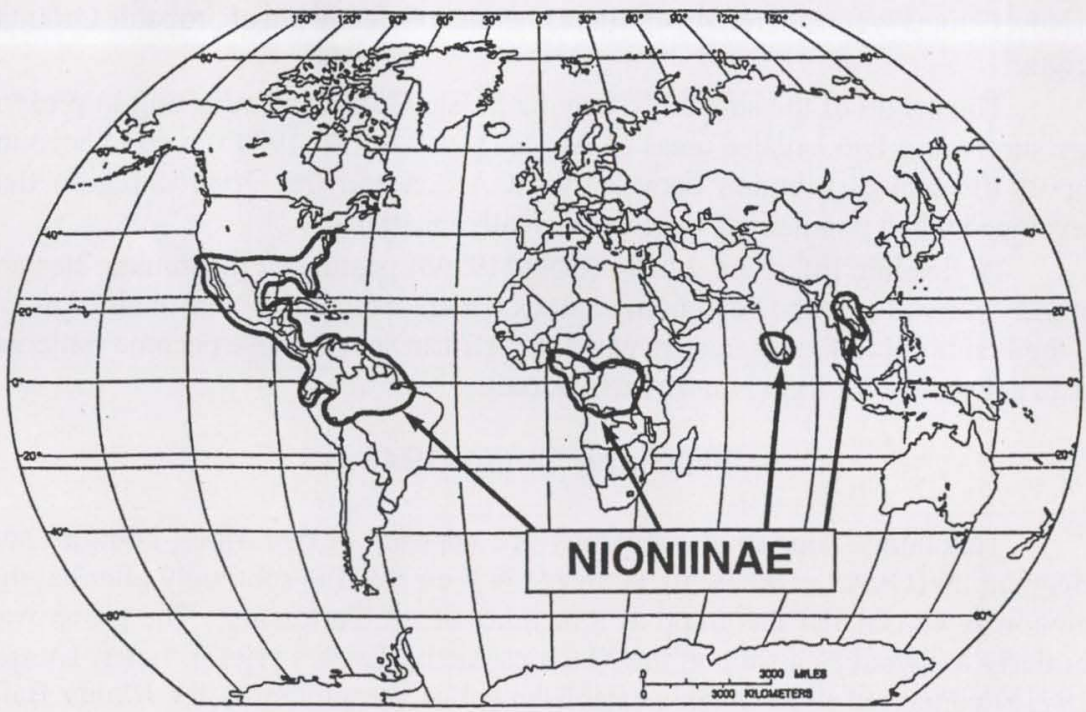

Fig. 20. Distribution of the subfamily Nioniinae.

Distribution and Zoogeographical Origin. This small, relict group has wide distribution in the Neotropical, Nearctic, Ethiopian and Oriental regions (Fig. 20). Three genera comprise the Nioniinae. Only two endemic genera are presently known, one each in the Neotropical and Ethiopian regions (Tab. I). Nionia is 
restricted chiefly to the Neotropical region but has gained access to the southern Nearctic realm. Ndua Linnavuori, 1978 is confined to Guinea and Zaire in the Ethiopian region. One genus, Magnentius, has an interzoogeographical range and occupies central Africa in the Ethiopian region and southern India in the Oriental region. Recently, specimens of the subfamily were found in southeast Asia and probably represent a new genus (FREYTAG, personal communication).

LINNAVUORI (1978a) considered the subfamily as a relict group of presumed pre-tertiary origin. We propose that the Nioniinae arose in late Jurassic/early Cretaceous times with its center in Gondwanaland. Extant genera are remnants of a widespread fauna that was vicariated when South America broke away from Africa. Each group evolved along separate lines. The Oriental fauna that is restricted to India and southeast Asia are also believed to be vicariants either via movement of the subcontinent to its present position or by ecological isolation.

Phylogenic Inference. The phylogenetic relationships of this subfamily to other groups is problematical.

\section{Phereurhininae Kramer, 1976}

Taxonomy. This very small group was split off the Cicadellinae by KRAMER (1976a) to accommodate three genera of neotropical leafhoppers after YoUNG (1968) excluded them from the former group. MEJDALANI (personal communication) in his studies is of the opinion that the group belongs in the tribe Proconiini based on the hind knee character which does not reach the proepimeron. Only one tribe, the nominate form, is recognized (OMAN et al. 1990).

Habitat and Host Plants. The habitat is in South American tropical forests where little is known about their host plants.

Distribution and Zoogeographical Origin. The group is widely distributed across a broad band in central South America (Fig. 16). The genus Clydacha Melichar, 1926 is thus far restricted to Peru, Phereurhinus Jacobi, 1905 is known from Peru, Bolivia and Brazil and Dayoungia Kramer, 1976 occupies Argentina and Brazil. It is proposed that this subfamily arose during the early Cretaceous after South America separated from the African continent.

Phylogenic Inference. We propose the subfamily is derived from Cicadellinae stock, having several features allied to that group, i.e., frontal sutures reaching the discally situated ocelli and the swollen clypeus. It is probably more closely related to the tribe Proconiini (and may have arisen from that stock) than to Cicadellini by virtue of the posterior knees not reaching the posterior proepimeral margins.

\section{Stegelytrinae Baker, 1915}

Taxonomy. This small and most likely a primitive group was formerly regarded as a tribe of the Coelidiinae (METCALF 1964b; HAMILTON 1983c, and other workers). Nielson (1975) proposed retention of the Stegelytrinae, a group not even remotely related to Coelidiinae. Only a single tribe, its nominate form, is recognized (OMAN et al. 1990). 
Habitat and Host Plants. These leafhoppers are presumed shrub feeders in xerophytic habitats. They appear to be ecologically well adapted to hot, dry climates.

Distribution and Zoogeographical Origin. This group is restricted to the Palaearctic region in the Mediterranean subregion (Fig. 14). Three known genera, Stegelytra Mulsant \& Rey, 1855, Iberia Kirkaldy, 1907, and Wadkufia Linnavuori, 1965 , occur in close proximity to one another, from southern Europe to North Africa and east to Iran. They may be relicts of late Jurassic/early Cretaceous origin that had wide distribution in the Palaearctic region and have since become adapted to their present range.

Phylogenic Inference. The group has several primitive characters which suggest its relationship to Coelidiinae is distant if not problematical. Its relationship to other subfamilies is likewise problematical.

\section{Makilingiinae Evans, 1947}

Taxonomy. Evans (1947) originally established the subfamily for the genus Makilingia Baker, 1914, the only representative of the group. It was later regarded as member of the Cicadellinae but was returned to Makilingiinae by YounG (1968). LINNAVUORI (1979a) referred it to the nominate tribe in the subfamily Cicadellinae. Only one tribe, the nominate form, is recognized (OMAN et al. 1990).

Habitat and Host Plants. These insects inhabit tropical forests in the Philippines and Sulawesi. Host plants are unknown.

Distribution and Zoogeographical Origin. The group is known in the Philippine Islands and more recently in Sulawesi (WEBB, personal communication) where only one endemic genus is known (Tab. I, Fig. 9). Several species are recognized. Its affinities to the Cicadellinae suggest that this group evolved from that stock from the Indo-Malayan region and evolved along a separate line after becoming insularly isolated during the Cretaceous when the Philippine Islands were formed.

Phylogenic Inference. Evans (1947) associated the group with the Cicadellinae and thus they are believed to be its closest relatives.

\section{Phlogisinae Linnavuori, 1979}

Taxonomy. This group is considered a relict and was recently established by LINNAVUORI (1979a) for the genus Phlogis Linnavuori, 1979. Only one tribe is recognized from its nominate genus (OMAN et al. 1990).

Habitat and Host Plants. The habitat is in tropical forests but their host plants are unknown.

Distribution and Zoogeographical Origin. This subfamily, until recently, was known only from Cameroon in the Ethiopian region where only one endemic genus is recognized. WEBB (personal communication) has found members of the group in India, China and the Far East which extend the range into the Oriental and Palaearctic regions (Tab. I, Fig. 21). As a relict group, it may have arisen during the late Jurassic/early Cretaceous in Gondwanaland where it was widespread primarily 
in the southern Old World region. Ecological vicariation also likely occurred as with other subfamilies of similar distribution.

Phylogenic Inference. According to LINNAVUORI (1979a) the subfamily is not closely related to any other known group. Although it has some characters (coarse pitting) of the Nioniinae and its general habitus resembles the Cicadellinae, it has several features that clearly distinguishes it from these groups. The relict group has a combination of primitive and highly specialized characters.

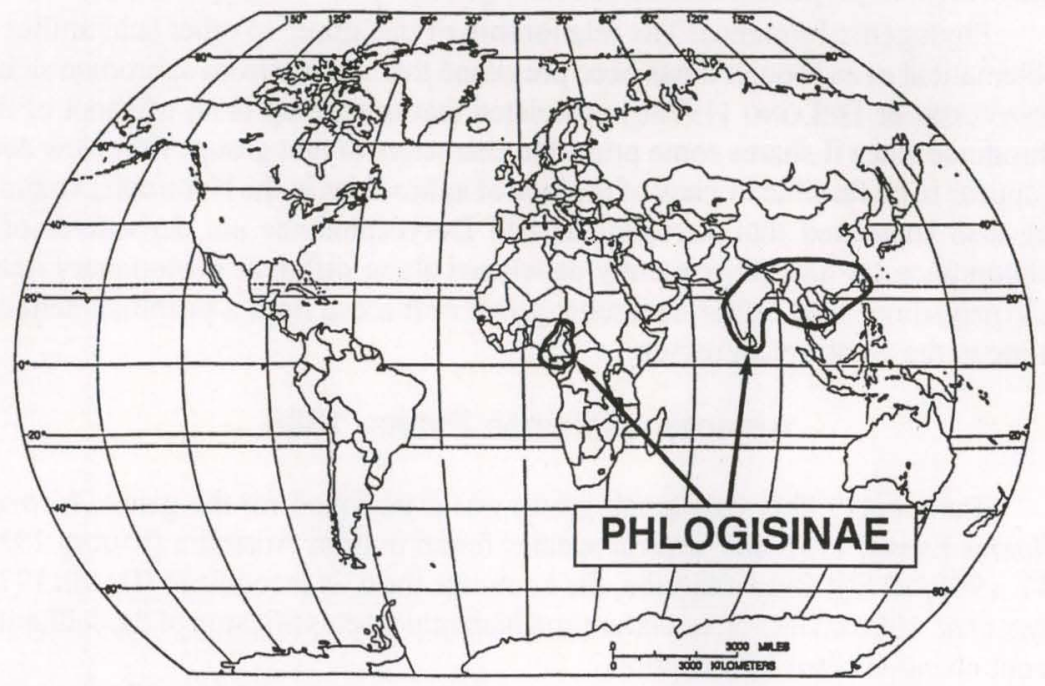

Fig. 21. Distribution of the subfamily Phlogisinae.

\section{Arrugadinae Linnavuori, 1965}

Taxonomy. This unique group is represented by a single genus, Arrugada Oman, 1938, in the Neotropical region. Only one tribe, its nominal form, is presently recognized (OMAN et al. 1990). OMAN (1936) regarded it as a relative of Huleria Ball, 1902, a Nearctic genus that was placed in the tribe Cochlorhini within Deltocephalinae. Evans (1947) considered it as a representative of Aphrodinae. LINNAVUORI (1965b) established the subfamily Arrugadiinae [sic!] and pointed out several key features that it possessed which distinguished it from Deltocephalinae and Aphrodinae.

Habitat and Host Plants. The group inhabits the high mountain areas of Peru and Bolivia. The host plants are unknown.

Distribution and Zoogeographical Origin. The subfamily is known only by a single genus in a restricted area of the Neotropical region (Bolivia, Peru) (Tab. I, Fig. 9). Only three species are presently recognized. This subfamily may have arisen during the late Cretaceous period well after South America separated from Africa. LINNAVUORI \& DELONG (1978b) proposed that two early dispersals of the aphro- 
dine stock took place into the New World, one into South America which led to Arrugadinae and one into North America which gave rise to Eupelicinae.

We differ from the latter view in that even if separate dispersals took place from the Palaearctic to the Nearctic region it is highly unlikely that Aphrodinae radiated from the Nearctic to the Neotropical region. There is considerable evidence that radiation of many leafhopper groups in the New World actually took place in the opposite direction, from their origin in the Neotropical region to the Nearctic realm, based on preponderance of endemic genera in the Neotropical region.

Phylogenic Inference. The relationship of this group to other subfamilies is problematical even though it has been presumed that it arose from aphrodine stock. LINNAVUORI \& DELONG (1978b) postulated that this group is an offshoot of the Aphrodinae since it shares some primitive characters of that group. This view does not appear to be feasible in view of the lack of aphrodines in the Neotropical region. They also suggested that Arrugadinae and Dorycephalinae are derivatives of a common ancestor and subsequently developed along different evolutionary lines. The Arrugadinae may either be a relict group or it arose from a primitive deltocephaline in the Neotropical region.

\section{Austroagalloidinae Evans, 1938}

Taxonomy. This very small group was established for the genus Austroagalloides Evans, 1935 and several species found only in Australia (EvANs 1938, 1947, 1966, 1977). Only one tribe, the nominate form, is recognized (DAVIS 1975; OMAN et al. 1990). The nomenclature and hierarchical classificaton of the subfamily has not changed since its inception.

Habitat and Host Plants. Members of this group live in xerophytic habitats and feed exclusively on eucalypts (Evans 1947).

Distribution and Zoogeographical Origin. The subfamily is endemic to Australia and has 8 known species that are widespread from western to southeastern Australia, one of which also occurs in Tasmania (Tab. I, Fig. 18). This group may have had its origin in Southern Gondwanaland during late Jurassic times and became isolated in Australia where it slowly radiated on the continent. EvANS (1947) suggested a late Tertiary origin as part of the autochthonous fauna of Australia.

Phylogenic Inference. Evans (1947) suggested that inasmuch as this group shared certain features with the Melicharellinae (Adelungiinae) that they possibly had a common origin. This proposal appears unlikely as the Adelungiinae are far removed zoogeographically (Eremian subregion of the Palaearctic region ) from Australia. DAVIS (1975) allied the group with Eurymelinae. It appears, therefore, that its relationship to other subfamilies is problematical.

\section{Bythoniinae Linnavuori, 1959}

Taxonomy. Bythoniinae was established for the nominate genus, Bythonia Oman, 1938, by LinNAVUORI (1959b). Only two species were known at that time. The genus was previously referred to the Iassinae by Evans (1947). More recently, 
BLOCKER \& WeBB (1990) and FELIX \& MEJDALANI (1998) returned the group to the Iassinae, each adding one new species. We are following Linnavuori as a provisional decision until the study of the phylogeny of the family Cicadellidae is completed. Only one tribe, the nominate form, is recognized (OMAN et al. 1990).

Habitat and Host Plants. This subfamily occurs in tropical habitats. The host plants are unknown.

Distribution and Zoogeographical Origin. The group is known only from the Neotropical region (Tab. I, Fig. 22). Three species occur in Brazil and the other one has been reported from Bolivia and Peru (LINNAVUORI 1959b; BLOCKER \& WEBB 1990; FELIX \& MEJDALANI 1998). The subfamily is believed to have originated during late Cretaceous period in South America after the continent separated from Africa. Radiation was limited and confined to the Neotropical region.

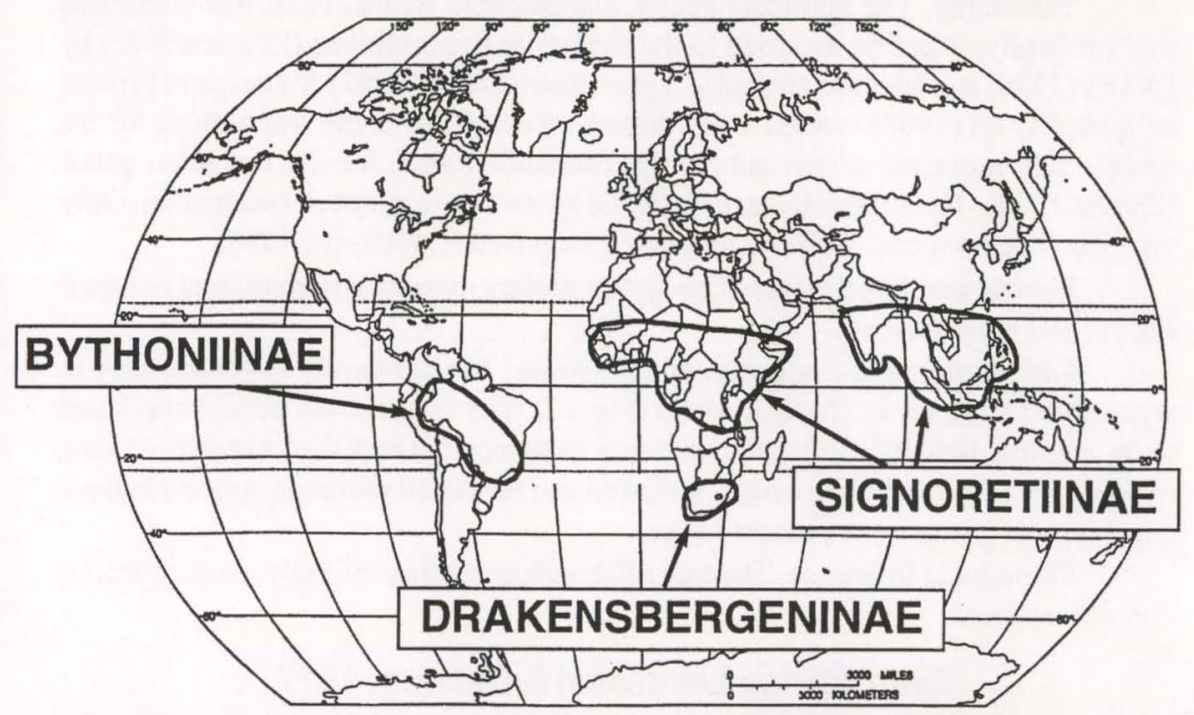

Fig. 22. Distribution of the subfamilies Bythoniinae, Drakensbergeninae and Signoretiinae.

Phylogenic Inference. LINNAVUORI (1959b) found some resemblance of certain external features of Bythonia to the Iassinae. He pointed out that although certain external features relate the group to Nioniinae and Tartessinae it differs from them in other essential characters. The male genitalia are somewhat similar to those in Neobalinae and Coelidiinae but because of external features it could be allied with either of them. The true relationship of the group remains problematical.

\section{Drakensbergeninae Linnavuori, 1979}

Taxonony. This small recently established group is comprised of a single tribe, the nominate form, for Drakensbergena Linnavuori, 1961 which is thus far comprised of two species (LINNAVUORI 1979a; OMAN et al. 1990). 
Habitat and Host Plants. Members of this group live in very dry habitats, presumably on shrubs or trees.

Distribution and Zoogeographical Origin. The subfamily is currently restricted to South Africa (Fig. 22). Only two species are known. The origin of this subfamily is in southern Africa where they are part of the original Cape fauna and have become specialized in their living habits (LINNAVUORI 1979a). They may have arisen in the Cretaceous after Africa separated from Antarctica.

Phylogenic Inference. The group is believed to have been derived from Dorycephalinae (Eupelicinae) stock and superficially resemble Eupelicini in general habitus and in male genital features (LINNAVUORI 1979a).

\section{Euacanthellinae Evans, 1966}

Taxonomy. The nominate genus, Euacanthella Evans, 1938, that comprises this subfamily, was first assigned to the subfamily Euacanthinae (Evacanthinae) by EVANS (1938) and later transferred to Aphrodinae (EvANs 1947). Subsequent to these actions, Evans (1966) erected a new tribe Euacanthellini in the Aphrodinae for the group, then proposed a new subfamily, Euacanthellinae, for the nominate genus (EvANS 1974). The subfamily is represented by the single genus of two species. Only one tribe, the nominate form, is currently recognized (OMAN et al. 1990).

Habitat and Host Plants. This group prefers marshy environments but their host plants are unknown.

Distribution and Zoogeographical Origin. The subfamily is known only in Australia, Tasmania and New Zealand (Fig. 17). The origin of the genus is believed to be late Jurassic/early Cretaceous and may be associated with the "Antarctic" fauna of southern Gondwanaland origin. Isolation and restricted radiation appears to have confined the group to its present range.

Phylogenic Inference. The true relationship of this subfamily to other groups is problematical.

\section{Evansiolinae Linnavuori \& DeLong, 1977}

Taxonomy. This primitive, relict group was established to accommodate the monobasic genus Evansiola China, 1957 and three attendant species. Only one tribe, the nominate form, is recognized (OMAN et al. 1990).

Habitat and Host Plants. All species live in leaf litter and soil debris and are presumably root feeders on their host plants.

Distribution and Zoogeographical Origin. The group is thus far confined to the Juan Fernandez Islands off the coast of Chile (Fig. 15). We believe the group may have arisen during late Jurassic/early Cretaceous times and was part of the "Antarctic" fauna of southern Gondwanaland origin and has become insularly isolated.

Phylogenic Inference. LinNAVUORI \& DELONG (1979a) believe this group arose from Agalliinae stem even though they have megophthalmine-like appearance. The lack of ocelli, reduced flying wings, chaetotaxy and other features laid the basis for a separate subfamily distinct from the Agalliinae and Megophthalminae. 


\section{Koebeliinae Baker, 1897}

Taxonomy. This primitive, relict subfamily that was erected for the nominate genus Koebelia Baker, 1897 had been considered previously as a tribe of Ledrinae by Evans (1947, 1966, 1969a) and METCALF (1962). KRAMER's (1966) study of the Ledrinae characterized the genus. He concurred with the removal of Koebelia from Ledrinae by OMAN's (1949) earlier establishment of the group as a distinct subfamily, the Koebeliinae. Later, OMAN (1971b) made a careful study of all known species and found them more closely related to the Ulopinae than to Ledrinae. Only one genus and one tribe, the nominate form, is recognized (OMAN et al. 1990).

Habitat and Host Plants. This group is a specialist on Pinus Linnaeus, 1735 (Coniferae) in the coastal and arid zones in western North America.

Distribution and Zoogeographical Origin. This group is confined to five western states (U.S.) and one western province (Canada) in North America (Fig. 15). It likely occurs in northern Mexico since specimens have been found along the southern borders of California and Arizona (OMAN 1971b).

The nominate genus may be an allochthonous endemic that arose during late Jurassic/early Cretaceous and was isolated from an original parent population that previously had widespread distribution in western Pangaea. Elements of this population became extinct after continental drift occurred, especially during the epochal ice age. Radiation has been limited in recent times by its dependency on pine as well as other ecological barriers.

Phylogenic Inference. OMAN's (1971b) study showed that Koebeliinae are closely related to the Ulopinae. Its relationship to other subfamilies remains problematical.

\section{Signoretiinae Baker, 1915}

Taxonony. The Signoretiinae are an unique group that was previously placed as a tribe in the Aphrodinae by EVANS (1947) after BAKER (1915) had created the subfamily to separate the group from the Cicadellinae. LINNAVUORI (1978a) and ANUFRIEV (1971f) described and keyed the Ethiopian fauna. Only one tribe, the nominate form, is currently recognized (OMAN et al. 1990). Only one genus, Signoretia Stål, 1859, is presently known.

Habitat and Host Plants. These insects are found in moist, swampy meadows and may be specialists on grasses (EVANS 1947; LINNAVUORI 1978a).

Distribution and Zoogeographical Origin. The subfamily is confined to the Ethiopian (Africa) and Oriental (India) regions (Fig. 22). This group is believed to have Cretaceous origin and may have been vicariated by an ecological barrier (arid) between Africa and India. The center of its origin may be the Ethiopian region. Radiation has been slow and limited in its present range. Processes of extinction probably took place as well, that reduced size of its range.

Phylogenic Inference. The group is related to the Evacanthini (Cicadellinae) in some essential characters and is believed to be derived from Cicadellinae stock (LINNAVUORI 1978a). 


\section{Tinterominae Godoy \& Webb, 1994}

Taxonomy. This very small, peculiar group was recently established to accommodate a new genus Tinteromus Godoy \& Webb, 1994 and two new species (GODOY \& WEBB 1994).

Habitat and Host Plants. The group is found in cool, moist habitats in rain forests at high elevations. They presumably feed on shrubs and trees.

Distribution and Zoogeographical Origin. Members of Tinterominae are presently known only in the central mountainous regions of Costa Rica at elevation of 1100-2000 m. (Fig. 12). A third, undescribed species (female) has been recognized from a site near the type locality of the known species (Zurqui de Moravia) (GoDOY \& WEBB 1994) and a new record for Tinteromus omani Godoy \& Webb, 1994 is reported here from Monteverde Reserve. We believe it is an autochthonous endemic, having originated in situ.

We propose that this subfamily originated in the Neotropical region during the late Tertiary after the Panamanian Isthmus was finally established during the Miocene. It appears to be one of the latest lineages that developed among leafhopper subfamilies.

Phylogenic Inference. GoDOY \& WEBB (1994) presented degrees of phenetic similarities or dissimilarities of 34 characters between the new subfamily and several other groups (Xestocephalinae, Mileewinae, Cicadellinae, Nirvaninae, Neoceolidiinae, Coelidiinae and Makiligiinae). On the whole, Tinterominae had the lowest percentage of similarity of shared characters among all groups with which it was compared. Its closest relatives, phenetically, were Cicadellinae and Nirvaninae. The very long antennae with five basal segments before the flagellum (three in all other subfamilies) including a very long scape is unique and is believed to be a specialized feature, the function of which is not understood. The group stands alone and its phylogenetic relationship to other groups is problematic.

\section{DISCUSSION AND CONCLUSIONS}

In the nearly 50 years that have ensued since METCALF (1949) first proposed that leafhoppers are excellent indicators of zoogeographical regions, numerous studies on systematics with concomitant distributional data have since verified his statement. These data have also greatly enhanced leafhoppers as biological, ecological, altitudinal, latitudinal and insular indicators of zoogeographical regions and subregions. Their phytodependency, high host specificity and low vagility also have contributed to a significant endemic zoogeographical profile.

Leafhoppers are one of the largest families of insects, initially arose from primitive stock possibly during the late Jurassic/early Cretaceous period prior to continental drift and eventually gave rise to over 40 recognized extant subfamilies (OMAN et al. 1990). The phylogenetic relationships among these subfamilies, however, are still poorly understood. The systematics of the family still remain a formidable task. It is likely that the unknown world fauna, particularly in the tropical regions of the world, far outnumber the estimated over 2,000 genera and 12,000+ species that are now on record. 
In spite of the lacunae in our knowledge of leafhopper systematics and phylogeny, we have attempted a distributional analysis of the various taxal groups, which hopefully may provide a broader understanding of the origin of subfamilies, tribes and genera and be useful as an important adjunct in phylogenetic systematics. The historical pathway of zoogeographical distribution via vicariance, dispersal and adventitious events has been evident from subfamilies to species. No single event has been responsible for distribution of all taxa and not all events can be applied to individual major taxa except perhaps the cosmopolitan groups.

The zoogeographical distribution and proposed origin of 42 subfamilies of leafhoppers are summarized in table XIV. Details on distribution and origin are already given under the respective treatment of the subfamilies. The majority (23) of the subfamilies as presently constituted appear to have had their ancestral origin during Gondwanaland times (late Jurassic/early Cretaceous) prior to or during the onset of continental drift because there is no feasible explanation to account for those that have cosmopolitan or disjunct distribution. Eighteen subfamilies may have originated during the Cretaceous, most of them in the Old World, and one (Tinterominae) arose during the Tertiary in the New World.

Table XIV. Summary of the zoogeographical distribution and proposed origin of 42 subfamilies of the Cicadellidae (1).

\begin{tabular}{|c|c|c|}
\hline Distribution & Origin & Subfamily \\
\hline Cosmopolitan (2) or near & Late Jurassic/Early Cretaceous & $\begin{array}{l}\text { Deltocephalinae, Typhlocybinae, } \\
\text { Cicadellinae, Idiocerinae, lassinae, } \\
\text { Ledrinae, Agalliinae, Macropsinae, } \\
\text { Nirvaninae, Coelidiinae, Nioniinae, } \\
\text { Ulopinae, Eupelicinae, } \\
\text { Xestocephalinae }\end{array}$ \\
\hline Cosmopolitan or near & Cretaceous & Penthimiinae, Aphrodinae \\
\hline Old World only & Cretaceous & $\begin{array}{l}\text { Selenocephalinae, Acostemminae, } \\
\text { Paraboloponinae, Mukariinae }\end{array}$ \\
\hline Old World only & Late Jurassic/Early Cretaceous & Hylicinae \\
\hline Ethiopian/Oriental & Cretaceous & Signoretinae \\
\hline Ethiopian/Neotropical & Late Jurassic/Early Cretaceous & Mileewinae \\
\hline Oriental/Australian & Cretaceous & Tartessinae \\
\hline Neogeic & Cretaceous & Neocoelidinae, Gyponinae \\
\hline Holarctic & Late Jurassic/Early Cretaceous & Megophthalminae \\
\hline Palaearctic only & Late Jurassic/Early Cretaceous & Adelungiinae, Stegelytrinae \\
\hline Neotropical only & Cretaceous & $\begin{array}{c}\text { Neobalinae, Phereurhininae, } \\
\text { Arrugadinae, Bythoniinae }\end{array}$ \\
\hline Neotropical only & Late Jurassic/Early Cretaceous & Evansolinae \\
\hline Neotropical only & Tertiary & Tinterominae \\
\hline Ethiopian only & Cretaceous & Phlogisinae, Drakensbergeninae \\
\hline Australia only & Late Jurassic/Early Cretaceous & Austroagalloidinae, Euacanthellinae \\
\hline Australia only & Cretaceous & Eurymelinae \\
\hline Nearctic only & Late Jurassic/Early Cretaceous & Koebeliinae \\
\hline Oriental only & Cretaceous & Makilingiinae \\
\hline
\end{tabular}

(1) Distribution includes occupation by endemics, dispersal and adventitious means. For distribution based on endemic genera only, see table I; (2) cosmopolitan or near cosmopolitan includes taxa that occupy at least marginally 4-6 zoogeographical regions.

As indicated above, $90 \%$ of all known genera $(2,123)$ are endemics; $7 \%$ are bigeographical and $3 \%$ are multigeographical, suggesting a very strong zoogeographical bonding. About $76 \%$ of all extant genera are pantropical in origin, representing a broad band of faunal distribution between the northern ( 20 degrees) and southern (20 degrees) latitude of the equator. 
The Neotropical region has the richest and most diverse leafhopper fauna, doubtlessly influenced by the richest and most diverse flora in the world and by the conducive climate. The Nearctic region is poorest faunistically, and without contributions in the Deltocephalinae from the Neotropical and Palaearctic regions, the region would be relatively depauperate. Australia has the highest representation of endemic "primitive" subfamilies, confirming that the region was closely affiliated with "Antarctica" fauna of Gondwanaland which also included Tasmania, New Zealand, southern South Africa, Madagascar and perhaps New Caledonia.

Although the Ethiopian and Neotropical regions are represented by the highest number of subfamilies, their taxal affinities are poorest, indicating that isolation of and distance between the continents had a significant impact on radiation and phylogeny of the fauna. The closest taxal affinities were evident between the Ethiopian/Oriental, Palaearctic/Nearctic, Oriental/Australian and Neotropical/Nearctic regions, all of which, during one or more geological events, allowed for dispersal or introduction of faunal elements. The Oriental/Australian (excluding Australia) fauna are taxically closer than the Oriental/Ethiopian fauna. Of particular interest is the relatively close faunal relationship between the Ethiopian and Oriental regions which are ecologically separated by a broad arid region between them. We propose that the entire area was once a faunal continuum, later ecologically vicariated by arid conditions during pre-modern times (Tertiary) which isolated the fauna, each radiating along related but separate lines. However, it is believed that certain elements of the leafhopper fauna were vicariated when India drifted to its present location, carrying some ancestral stock of a few subfamilies (Ledrinae, Ulopinae, Hylicinae) to the Oriental region.

The role of geographical and ecological vicariations had a significant impact on origin, distribution and phylogeny of the group. However, some workers (ESKOV \& GolOVATCH 1986) believe that vicariance had little to do with distribution, that the land mass during pangaeaic times was flooded with fauna and much of the extant fauna are remnants that survived the extinction process. Our view is that the cosmopolitan subfamilies, chiefly, Deltocephalinae, Typhlocybinae, Cicadellinae, Coelidiinae, Idiocerinae, Ledrinae, Iassinae, Agalliinae and disjunct groups such as the Ulopinae, as they are presently taxonomically constituted, are vicariants.

We recognize that cosmopolitanism does not necessarily imply earliest phylogenetic origin, and furthermore, the strictly zoogeographical origin of most of the cosmopolitants is currently quite problematical. Two subfamilies, Deltocephalinae and Typhlocybinae, considered among the most derived groups are the most diverse and cosmopolitan.

Dispersal also played a significant role. Pathways generally were most evident from south to north (Neotropical/Nearctic, Oriental/Palaearctic) and from west to east (Palaearctic/Nearctic, Oriental/Australian) based on taxal affinities among various taxal groups. There are, of course, exceptions in which dispersals have occurred in the opposite direction but these have not been deep intrusions for the most part.

Adventitious events played a very minor role in the overall distribution of leafhoppers. In all cases these obviously occurred within the last 500 years and formed the basis for economic leafhopper pest problems in modern agriculture. 
Important insular events are recognized among several groups that prove to be endemic to their respective insular regions. Several genera among the Cicadellinae, Coelidiinae and Agalliinae are endemic to the West Indies which was formed by an early tectonic movement (Caribbean plate) of Central America. The fauna was carried to their present location where they radiated under isolated conditions.

The number of shared genera was greater in the Nearctic/Neotropical regions than in the Palaearctic/Nearctic regions, indicating a closer geographical affiliation between the former two than the latter two regions. The relationhip is believed to be reflected in the closing of the seaway between North and South America during the Miocene which allowed for dispersal of the fauna. Shared taxa in the Palaearctic/Oriental regions were about equal to shared taxa in the Palaearctic/Nearctic regions, but significantly higher than shared taxa in the Palaearctic/Ethiopian regions. In the latter regions, the arid zone between them apparently reduced the rate of faunal dispersal.

ACKNOWLEDGMENTS. We thank the following for their constructive and useful comments which immeasurably improved the content of the paper: Christopher H. Dietrich (Illinois Natural History Survey, Urbana, USA), Gabriel Mejdalani (Universidade Federal do Rio de Janeiro, Rio de Janeiro, Brazil) and two anonymous reviewers. We express also our appreciatiom to Randal Baker, Graphics Designer (Monte L. Bean Museum, Brigham Young University) for his computer-generated faunal distribution and taxal pathway maps. This study was facilitated by the Monte L. Bean Life Science Museum, Brigham Young University.

\section{REFERENCES}

All leafhopper references cited before 1956 are found in:

Metcalf, Z.P. 1964. General Catalogue of the Homoptera. Fascicle VI. Cicadelloidea. Bibliography of the Cicadelloidea (Homoptera: Auchenorrhyncha). U.S. Department of Agriculture, Agricultural Research Service, 349p.

Those cited between 1956-1985 are found in:

OMAN, P.W.; W.J. KNIGHT \& M.W. Nielson. 1990. Leafhoppers (Cicadellidae): A bibliography, generic check-list and index to the world literature 1956-1985. Wallingford, Oxon, C.A.B. International Institute of Entomology, 368p.

All other references including non-leafhopper papers are cited below.

ABDUL-NouR, H. 1988. Deux nouveaux genres et especes de Cicadellidae due Liban (Homoptera). Nouv. Rev. Entomol. 5 (1): 35-41.

ARZone, A.; E. VIDANo \& A. Alma. 1987. Auchenorrhyncha introduced into Europe from the Nearctic region: Taxonomic and phytopathological problems, p.3-17. In: M.R. WILSON \& L.R. NAULT. (Eds). Proceedings of the $2^{\text {nd }}$ International Workshop on Leafhoppers \& Planthoppers of Economic Importance. Provo, UT, C.A.B. International Institute of Entomology.

Bekker-Migdisova, E.E. 1949. Mesozoic Homoptera of middle Asia. Proc. Paleontol. Inst. USSR Acad. Sci. 22: 1-68.

BLOCKER, H.D.; Q. FANG \& W.C. BLACK. 1995. Review of Nearctic deltocephaline-like leafhoppers. Ann. Entomol. Soc. Amer. 88 (3): 294-315.

BLOCKER, H.D. \& K.J. LARSEN. 1991. A new leafhopper genus, Cocrassana (Homoptera:Cicadellidae) from Mexican Tripsacinae and a synopsis of related genera. Jour. Kans. Entomol. Soc. 64 (2): 
123-126.

Blocker, H.D. \& M.D. WebB. 1990. The leafhopper genus Bythonia (Homoptera: Cicadellidae). Entomol. News 101 (5): 297-300.

BRIGGS, J.C. 1989. The historic biogeography of India: Isolation or Contact? Syst. Zool. 38 (4): 322-332. Brown, J.H. \& A.C. GiBson. 1983. Biogeography. St. Louis, The C.V. Mosby Company, 643 pp.

BRUNDIN, L. 1967. Insects and the problem of austral disjunctive distribution. Ann. Rev. Entomol. 12: 149-168.

Crisci, J.V.; M.M. Cigliano; J.J. Morrone \& S. Roig-Junent. 1991. Historical biogeography of southern South America. Syst. Zool. 40 (2): 152-171.

DARLINGTON, P.J. 1957. Zoogeography: the geographical distribution of animals. New York, John Wiley \& Sons Inc.

DE BOER, A.J. \& J.P. Duffels. 1996a. Historical biogeography of the cicadas of Wallacea, New Guinea and the West Pacific: a geotectonic explanation. Palaeo 124: 153-177.

-1996b. Biogeography of Indo-Pacific cicadas east of Wallace's line, p. 297-330. In: A. KEAST \& S.E. MilLER (Eds). The origin and evolution of Pacific Island biotas, New Guinea to Eastern Polynesia: patterns and processes. Amsterdam, SPB Academic Publishing.

DiETRICH, C.H. 1993. Phylogenetic analysis of leafhoppers (Homoptera: Cicadellidae) family-groups: Problems and prospects, p.27-28. In: S. Drosopoulos; P.V. PetraKis; M.F. CLARIDGE \& P.W. DE FrIJER (Eds). Proc. $8^{\text {th }}$ Auchenorrhyncha Congress, Delphi, Greece.

DiETRICH, C.H. 1994. Systematics of the leafhopper genus Draeculacephala Ball (Homoptera: CicadeIlidae). Trans. Amer. Entomol. Soc. 120 (2): 87-112.

Dietrich, C.H. \& F.E. VegA. 1995. Leafhoppers (Homoptera: Cicadellidae) from Dominican amber. Ann. Entomol. Soc. Amer. 88 (3): 263-270.

DlabolA, J. 1987. Neue Zikadenarten von Saudi Arabien (Homoptera: Auchenorrhyncha). Annot. Zoolog. et Bot. 177: 1-11.

DWorakowsKa, I. 1972. Revision of the genus Aguriahana Dist. (Auchenorrhyncha, Cicadellidae, Typhlocybinae). Polskie Pismo Entomologiczne 42 (2): 273-312.

EsKov, K.Y. \& S.I. Golovatch. 1986. On the origin of trans-Pacific disjunctions. Zool. Jahrb. Syst. 113: $265-285$.

FANG, Q.; H.D. BLOCKER \& W. C. BLACK. 1995. Cladistical analyses of Nearctic deltocephaline-like leafhoppers (Homoptera: Cicadellidae) using morphological and molecular data. Ann. Entomol. Soc. Amer. 88 (3): 316-323.

Felix, M. \& G. Mejdalani. 1998. A new species of the Neotropical genus Bythonia (Hemiptera: Cicadellidae) and the female of $B$. consensa. Entomol. News 109: 307-314.

FREYTAG, P.H. 1987. Two new genera, Brevicisana and Minimana and four new species of Gyponinae (Homoptera: Cicadellidae). Ohio Jour. Sci. 87 (1): 33-35.

FREYTAG, P.H. 1989. Three new genera and six new species of South American gyponine leafhoppers (Homoptera: Cicadellidae). Trans. Kentucky Acad. Sci. 50 (1-2): 1-8.

. 1990. Two new genera, Mediocerus and Mexicanocerus, and five new species of Idiocerinae (Homoptera: Cicadellidae). Trans. Kentucky Acad. Sci. 51 (1-2): 32-35.

Godoy, C. \& M.D. WEBB. 1994. Recognition of a new subfamily of Cicadellidae from Costa Rica based on phenetic analysis with similar taxa (Hemiptera: Homoptera: Auchenorrhyncha). Trop. Zool. 7: 131-144.

GooD, R. 1974. The geography of flowering plants. New York, John Wiley \& Sons Inc., $4^{\text {th }}$ ed., $557 \mathrm{p}$.

HamiLton, K.G.A. 1985. Review of Draeculacephala Ball (Homoptera, Auchenorrhyncha, Cicadellidae). Entomol. Abhand. Mus. Tierk. Dresden 49 (5): 83-103.

-1990. Insects from the Santana formation, lower Cretaceous, of Brazil. Homoptera. Bul. Amer. Mus. Nat. Hist. 195: 82-122.

Hayashi, M. \& K. Aral. 1990. Five new species of Pagaronia Ball (Homoptera, Cicadellidae Cicadellinae) from Central Honshu. Esakia 1: 5-13.

HAYASHI, M. \& K. YoshidA. 1995. New species of the genus Pagaronia (Homoptera, Cicadellidae, 
Cicadellinae) from Japan. Japan Jour. Syst. Entomol. 1 (1): 73-93.

HenniG, W. 1965. Phylogenetic systematics. Ann. Rev. Entomol. 10: 97-116.

KellogG, J.N. \& V. VeGA. 1995. Tectonic development of Panama, Costa Rica, and the Colombian

Andes: Constraints from global positioning system geodetic studies and gravity, p.75-87, In: P.

MANN (Ed.). Geological and tectonic development of the Caribbean plate boundary in southern

Central America. Boulder, CO. Geological Society of America Special Paper 295.

KNIGHT, W.J. \& M.W. NIELSON. 1986. The higher classification of the Cicadellidae. Tymbal 8: 10-14. KNIGHT, W.J. \& M.D. WEBB. 1988. Evidence for an Indo-Pacific origin of Hawaiian endemics in Balclutha and related genera (Cicadellidae: Homoptera: Macrostellini). Great Basin Nat. Mem. 12: $86-102$.

.1993. The phylogenetic relationships between virus vector and other genera of macrosteline leafhoppers, including descriptions of new taxa (Homoptera: Cicadellidae: Deltocephalinae). Syst. Entomol. 18: 11-55.

MetCalf, Z.P. 1949. Zoogeography of the Homoptera. XIII Intern. Congr. Zool. 1948, p. 539-544.

Nielson, M.W. 1996. A new species of Myerslopia from Chile (Homoptera: Cicadellidae). Entomol. News 107 (5): 322-326.

Nielson, M.W. \& C. Godoy. 1992 (1995). New species of Colladonus (Homoptera: Cicadellidae) from Costa Rica, with key to species. Brenesia 38: 37-44.

OMAN, P.W.; W.J. KNight \& M.W. Nielson. 1990. Leafhoppers (Cicadellidae): A bibliography, generic check-list and index to the world literature, 1956-1985. C.A.B. Internat. Inst. Entomol., $368 \mathrm{p}$.

SHCHERBAKOV, D.E. 1991. Diagnostics of the families of Auchenorrhyncha (Homoptera) as based on wings. I. Fore wing. Entomol. Oboz. 60: 828-843.

- 1992. The earliest leafhoppers (Hemiptera: Karajassidae, n. fam.) from Jurassic of Karatau. Neue Jahrb. Geol. Paleontol. Monatsh. (1): 39-51.

- 1993. Geological history of Auchenorrhyncha, p.3-4. In: S. Drosopoulos; P.V. PETRAKIS; M.F. ClARIDGe \& P.W. DE VRIJER (Eds). Proc. $8^{\text {th }}$ Auchenorrhyncha Congr.. Delphi, Greece, 112 p.

SMILEY, C.J. 1979. Pre-tertiary phytogeographical and continental drift - some apparent discrepancies, p.311-319. In: J. GRAY \& A.J. BOUCOT (Eds). Historical biogeography, plate tectonics and the changing environment. Corvallis, Oregon State University Press.

THAPA, V.K. 1989. Some higher Himalayan typhlocybine leafhoppers (Homoptera: Cicadellidae) of Nepal. Insecta Matsumurana 42: 93-110.

THERON, J.G. 1986. New genera and species of southern African Coelidiinae (Homoptera: Ciadellidae), with description of the new tribe Equeefini. Phytophyl. 18: 153-163.

THORNE, R.F. 1973. Floristic relationships between tropical Africa and tropical America, p.27-47. In: B.J. MegGers; E.S. Ayensu \& W.D. DuCKwORTH (Eds.). Tropical forest ecosystems in Africa and South America: a comparative review. Washington, D.C., Smithsonian Institute Press.

Thulborn, R.A. 1986. Early Triassic tetrapod faunas of southeastern Gondwana. Alcheringa 10: 297-313.

Viraktamath, C.A. \& C.W. Wesley. 1988. Revision of the Nirvaninae (Homoptera: Cicadellidae) of the Indian subcontinent. Great Basin Nat. Mem. 12: 182-223.

WALLACE, A.R. 1876. The geographical distribution of animals. London, Macmillan, Vol. 2.

WeBB, M.D. 1987. The endemic Macrostelini of the island of St. Helen (Homoptera, Cicadellidae). Rev. Zool. Afric. 100: 453-464.

Wegner, A. 1924. Die Entstehung der Kontinente und Ozeane. Braunschweig, Vieweg.

WeiJermars, R. 1989. Global tectonics since the breakup of Pangea 180 million years ago: Evolution maps and lithospheric budget. Earth-Science Rev. 26: 113-162.

WhiтсомB, R.F. \& A.L. Hicks. 1988. Genus Flexamia: New species, phylogeny, and ecology. Great Basin Nat. Mem. 12: 224-318.

YounG, D.A. 1986. Taxonomic study of the Cicadellinae (Homoptera: Cicadellidae). Part 3. Old World 
Cicadellini. North Carolina State Univ. Tech. Bul. 281: 1-639p. 1993. New genus and five new species of mileewine leafhoppers from New Guinea (Homoptera: Cicadellidae). Proc. Entomol. Soc. Wash. 95 (2): 228-240.

ZHANG, Y. 1990. A taxonomic study of Chinese Cicadellidae (Homoptera). Tianze Eldonejo, Yangling, Shaanxi, China, 218p.

. 1994. A taxonomic study of Chinese Coelidiinae (Homoptera, Cicadellidae). Henan Sci. \& Techn. Press, 151p.

ZHANG, Y. \& M.D. WeBB. 1993. A generic revision of the Austro-Oriental Selenocephalinae (Homoptera: Cicadellidae): Work in progress., p.35. In: S. Drosopoulos; P.V. PETRAKIS; M.F. Claridge \& P.W.F. DE VRIJER (Eds). Proc. $8^{\text {th }}$ Internat. Auchenorrhyncha Congr., Delphi, Greece, 112p.

Recebido em 23.VII.1998; aceito em 03.II.2000 